\title{
THE USE OF MICROBUBBLES AS CONTRAST AGENTS IN THE OPTICAL IMAGING OF TISSUE
}

\author{
by \\ Homa Assadi \\ M.Sc. Azad University, Tehran, Iran, 2006 \\ B.Sc. Esfahan University, Esfahan, Iran, 1998
}

\author{
A dissertation \\ presented to Ryerson University \\ in partial fulfillment of the \\ requirements for the degree of \\ Doctor of Philosophy \\ in the Program of \\ Biomedical Physics
}

Toronto, Ontario, Canada, 2018

(C) Homa Assadi, 2018 


\section{Author's Declaration}

I hereby declare that I am the sole author of this dissertation. This is a true copy of the dissertation, including any required final revisions, as accepted by my examiners.

I authorize Ryerson University to lend this dissertation to other institutions or individuals for the purpose of scholarly research.

I further authorize Ryerson University to reproduce this dissertation by photocopying or by other means, in total or in part, at the request of other institutions or individuals for the purpose of scholarly research.

I understand that my dissertation may be made electronically available to the public.

Homa Assadi 


\title{
Abstract
}

\section{THE USE OF MICROBUBBLES AS CONTRAST AGENTS IN THE OPTICAL IMAGING OF TISSUE}

\author{
Homa Assadi \\ Doctor of Philosophy, Biomedical Physics \\ Ryerson University, 2018
}

In this study, micrometer-sized $(<5 \mu \mathrm{m})$ microbubbles (MBs) were investigated as optical contrast agents. Exogenous contrast agents in optical imaging can enhance the detection of cancerous tissue, however they are limited by their potential side effects such as organ accumulation and toxicity with repeated administration. In ultrasound imaging, microbubbles are FDA approved and used clinically as contrast agents. Microbubbles can also produce a refractive index mismatch between the gas-filled core and surrounding water media, potentially modifying optical properties of tissue when injected intravenously into tissue.

Cancer detection can potentially be achieved by imaging microvasculature functionality through the blood volume fraction measurements with diffuse optical imaging (DOI). In order to study the potential application of using MBs for DOI, the effect of MBs on the bulk optical properties of a skin tissue phantom solution at various volume fractions 
of human blood was assessed at various injection doses of Definity ${ }^{\circledR}$ microbubble. The absorption and reduced scattering coefficients were computed and compared in the absence and presence of microbubbles. The presence of microbubbles in the blood caused a statistically significant enhancement in the reduced scattering contrast ( 1.3 times) at 660 $\mathrm{nm}$ wavelength which increases with the dose of Definity ${ }^{\circledR}$ MBs $(166 \mu \mathrm{L} / \mathrm{kg})$ at $6 \%$ blood volume fraction. However, the absorption contrast enhancement remained relatively constant as microbubble dose increased. The scattering contrast enhancement confirmed the feasibility of using MBs as DOI contrast agents to improve the detection of tissue with high blood concentration conditions.

Microbubbles were also investigated as optical coherence tomography (OCT) contrast agents. OCT structural and speckle variance (sv) images, as well as the speckle decorrelation times, were evaluated under no-flow and flow conditions from a skin tissue phantom with two embedded microtubes. Faster decorrelation times and greater structural and svOCT image contrasts were detected with the presence of MBs. The effects of the presence of MBs on the image contrast were maximal (2 times) at no flow in the svOCT imaging mode and reduced with blood average flow velocity from zero to $12 \mathrm{~mm} / \mathrm{s}$. This result confirmed the feasibility of using MBs to enhance svOCT visualization of microvasculature morphology. 


\section{Acknowledgements}

I would like to express my special appreciation and thanks to my supervisors Dr. Alexandre Douplik and Dr. Raffi Karshafian for their guidance. I thank them for encouraging my research and for allowing me to grow as a research scientist. I would also like to thank Dr. Michael Kolios and Dr. Carl Kumaradas, for serving as my committee members and giving brilliant comments and suggestions. I would especially like to thank Dr. Kumaradas for all his contributions of time and ideas to make my $\mathrm{Ph} . \mathrm{D}$. experience productive and stimulating. I appreciate and treasure everything he has taught me. I would like to thank Dr. Ana Milic for her support, words of encouragement and guidance on the right path.

My time at Ryerson was made enjoyable in large part due to the many friends that became a part of my life. Thanks to my friends, Aditya Pandya, Dena Monjazebi, Reyhaneh Nosrati, Pooya SobheBidari and Arthur Worthington for always being supportive.

I owe thanks to a special person, my husband, Arash for his continued and unfailing love, support and understanding during my pursuit of a Ph.D. degree that made the completion of this thesis possible. I greatly value his contribution and deeply appreciate his belief in me. I appreciate my little boy Arsha for abiding my ignorance and the patience he showed during my Ph.D. Lastly, I would like to thank my parents and my parents in-law for all their love and encouragement in my pursuits. 


\section{Table of Contents}

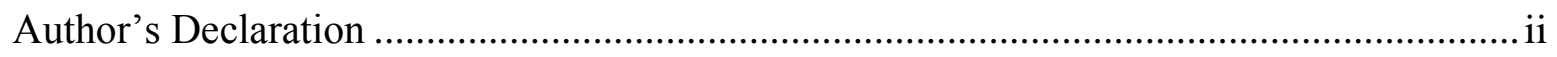

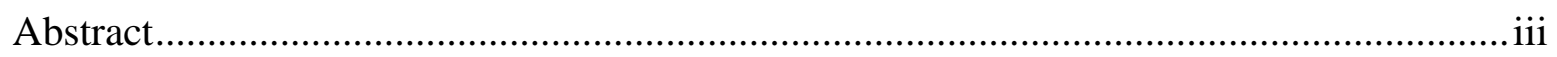

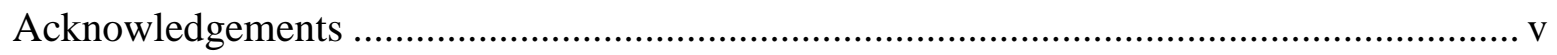

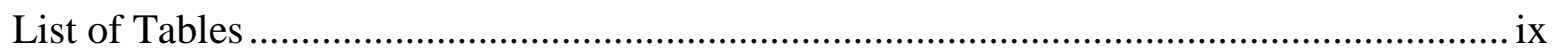

List of Figures............................................................................................................ Xiv

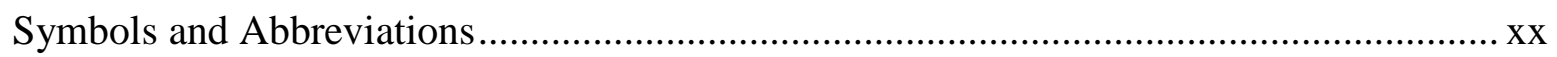

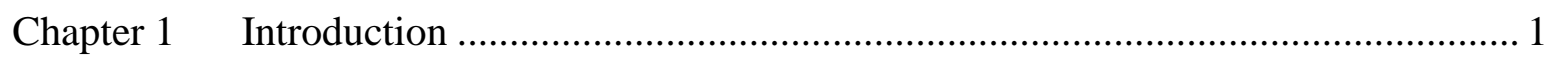

1.1 Optical imaging of tissue and cancer detection ................................................. 1

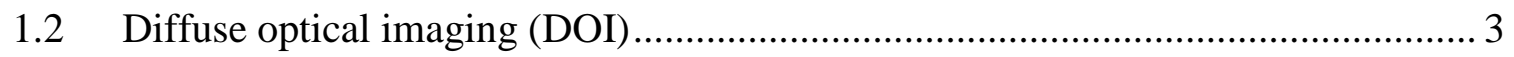

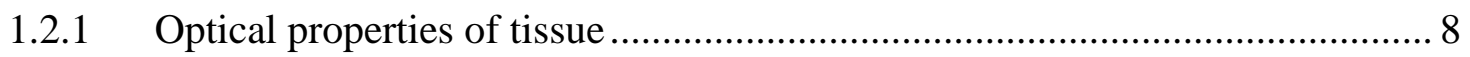

1.2.2 Calculating optical properties by inverse adding doubling (IAD) ................. 11

1.3 Optical coherence tomography ………………………................................... 12

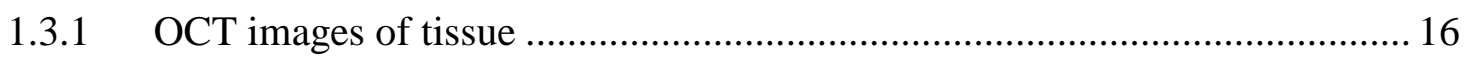

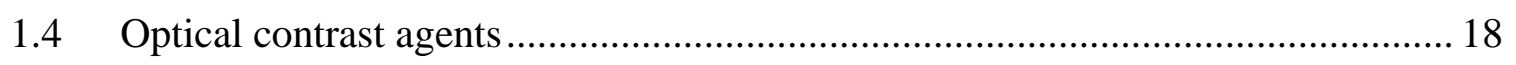

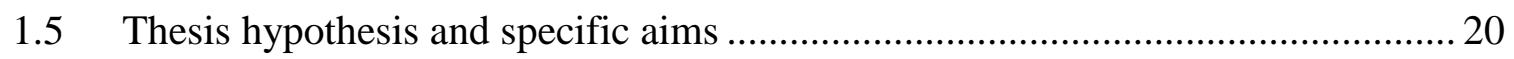

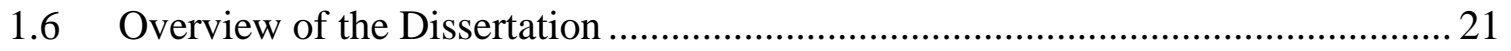

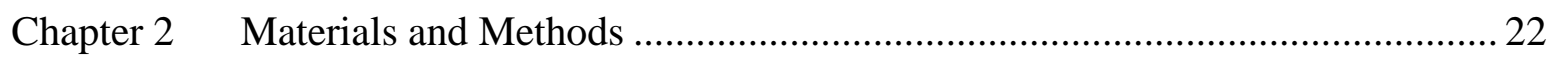




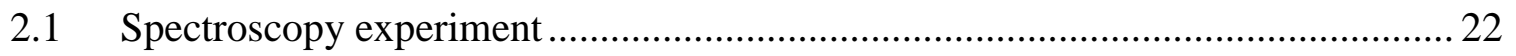

2.1.1 Inverse adding doubling and optical properties........................................24

2.1.2 Bulk tissue phantom solution (Intralipid, Human Blood, PBS) …………..... 27

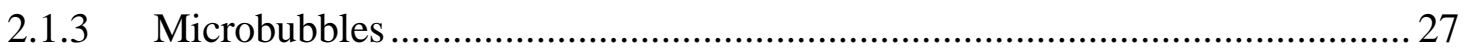

2.1.4 Optical stability of MBs solution................................................................ 32

2.1.5 Ethic approval for use of human blood ........................................................ 33

2.1.6 Optimal wavelength selection ................................................................ 33

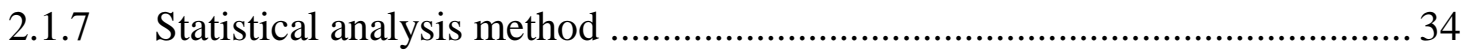

2.2 Optical coherence tomography method …………….......................................... 34

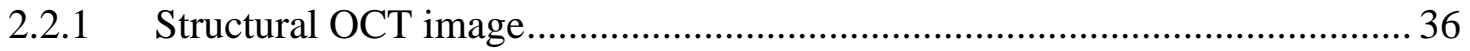

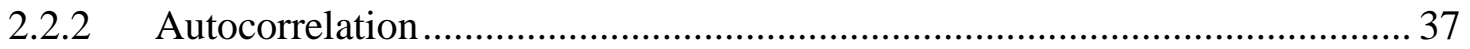

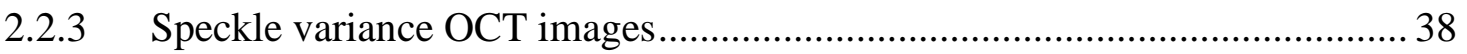

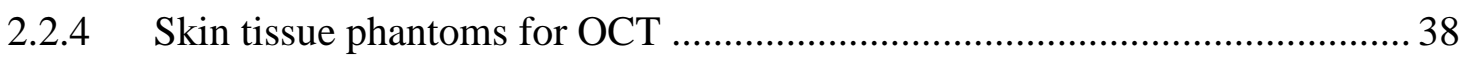

2.2.5 Microbubbles in OCT experiments ........................................................... 40

Chapter 3 Tissue optical properties in presence of microbubbles.................................... 42

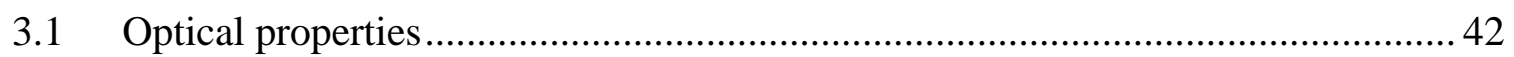

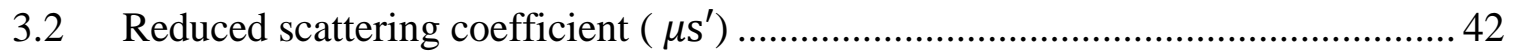

3.2.1 The effect of microbubbles on $\mu \mathrm{s}^{\prime}$ at wavelengths $660 \mathrm{~nm}$ and $1310 \mathrm{~nm} \ldots \ldots . .47$

3.2.2 Reduced scattering contrast and reduced scattering contrast enhancement ...50

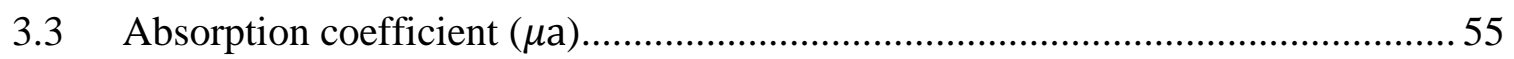

3.3.1 The effect of microbubbles on $\mu$ a at wavelengths $660 \mathrm{~nm}$ and $1310 \mathrm{~nm} \ldots \ldots . .58$

3.3.2 Absorption contrast and absorption contrast enhancement .............................. 61 
Chapter 4 Microvascular contrast enhancement in optical coherence tomography using

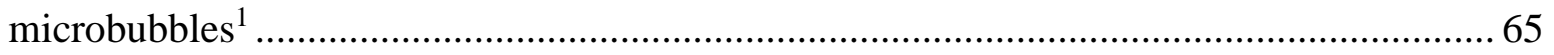

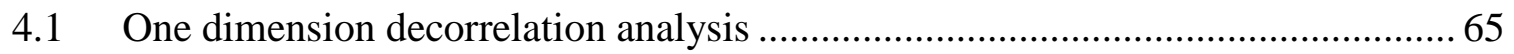

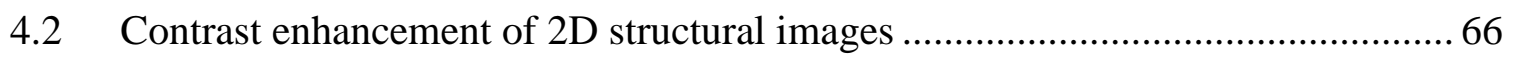

4.3 Contrast enhancement of 2D speckle variance (sv OCT) images .......................69

Chapter 5 Summary and Conclusions ................................................................. 73

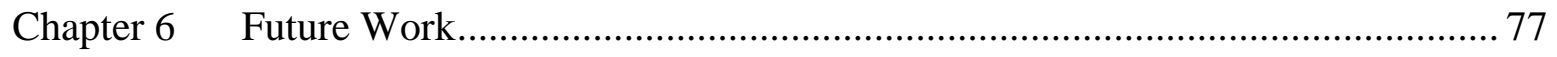

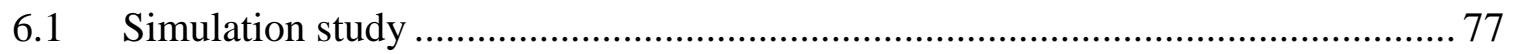

6.1.1 Calculating optical properties by Mie theory ....................................... 77

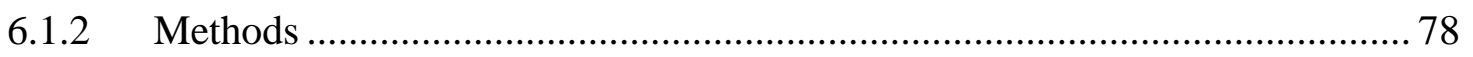

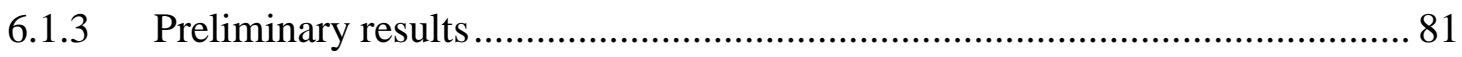

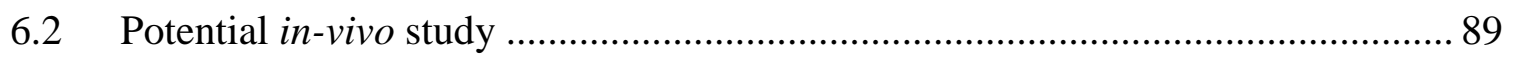

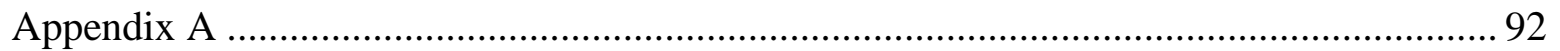

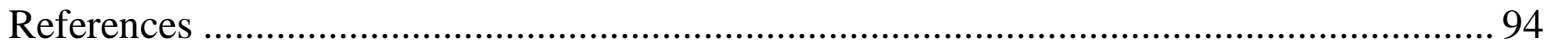




\section{List of Tables}

Table 2-1: Volume calculations in phantom 1 with $0.2 \% \mathrm{v} / \mathrm{v}$ human blood. The first column of the table shows the Definity® microbubble injection doses $(D \mathrm{I})$. The second column represents the Definity® volume fractions in tissue ( $\rho$ Def). The third column shows the Definity® volume in the phantom solution. The fourth, fifth and seventh columns state the volume of intralipid (VIL), $0.2 \%$ Blood $(V 0.2 \%-B)$, and total phantom for the relevant $D I$. The sixth column represents the effective volume of PBS (VPBSeff) in phantom 1..........30 Table 2-2: Volume calculations in phantom 2 with $1.5 \% \mathrm{v} / \mathrm{v}$ human blood. The first column of the table shows the Definity® microbubble injection doses (DI). The second column represents the Definity® volume fractions in tissue $(\rho$ Def). The third column shows the Definity® volume in the phantom solution. The fourth, fifth and seventh columns state the volume of intralipid (VIL), $1.5 \%$ Blood $(V 1.5 \%-B)$, and total phantom for the relevant $D I$. The sixth column represents the effective volume of PBS (VPBSeff) in phantom 2. 30 Table 2-3: Volume calculations in phantom 3 with 3\% v/v human blood. The first column of the table shows the Definity ${ }^{\circledR}$ injection doses $(D I)$. The second column represents the Definity® volume fractions in tissue ( $\rho$ Def). The third column shows the Definity® volume in the phantom solution. The fourth, fifth and seventh columns state the volume of intralipid (VIL), 3\% Blood $(V 3 \%-\mathrm{B})$, and total phantom for the relevant $D \mathrm{I}$. The sixth column represents the effective volume of PBS (VPBSeff) in phantom 3. 
Table 2-4: Volume calculations in phantom 4 with $6 \% \mathrm{v} / \mathrm{v}$ human blood. The first column of the table shows the Definity® microbubble injection doses (DI). The second column represents the Definity® volume fractions in tissue $(\rho$ Def). The third column shows the Definity® volume in the phantom solution. The fourth, fifth and seventh columns state the volume of intralipid (VIL), $6 \%$ Blood $(V 6 \%-\mathrm{B})$, and total phantom for the relevant $D \mathrm{I}$. The sixth column represents the effective volume of PBS (VPBSeff) in phantom 4. ............... 31

Table 6-1: Mie calculator input parameters............................................................ 80

Table 6-2: Number of scatterers per unit volume. The first column of the table shows the Definity® microbubble injection doses. The second column represents the number of IL per unit volume calculated for a $5 \% \mathrm{v} / \mathrm{v}$ concentration. The third and fourth column represent the number of RBC per unit volume calculated for a high blood concentration $(6 \% \mathrm{v} / \mathrm{v})$ and low blood concentration $(0.2 \% \mathrm{v} / \mathrm{v})$. The fifth and sixth column represent the number of MB per unit volume calculated for a high blood concentration $(6 \% \mathrm{v} / \mathrm{v})$ and low blood concentration $(0.2 \% \mathrm{v} / \mathrm{v})$

Table 6-3: Mie calculation of anisotropy factor and scattering cross section at $660 \mathrm{~nm}$.....82 Table 6-4: Calculation of reduced scattering coefficient for IL scatterers and RBCs at 660 nm. The first column of the table represents the number of IL scatterers per unit volume calculated for a $5 \% \mathrm{v} / \mathrm{v}$ concentration. The second column represents the reduced scattering coefficient of IL. The third column represents the number of RBCs per unit volume calculated for a high blood concentration $(6 \% \mathrm{v} / \mathrm{v})$. The fourth column represents the reduced scattering coefficient of RBCs calculated for a high blood concentration. The fifth column represents 
the number of RBCs per unit volume calculated for a low blood concentration $(0.2 \% \mathrm{v} / \mathrm{v})$. The sixth column represents the reduced scattering coefficient of RBCs calculated for a low blood concentration. 82 Table 6-5: Calculation of reduced scattering coefficient for MB scatterers at $660 \mathrm{~nm}$. The first column of the table shows the Definity® microbubble injection doses. The second column represents the number of $\mathrm{MBs}$ per unit volume calculated for a high $\mathrm{MB}$ concentration. The third column represents the reduced scattering coefficient of MBs calculated for a high MB concentration. The fourth column represents the number of MBs per unit volume calculated for a low MB concentration. The fifth column represents the reduced scattering coefficient of MBs calculated for a low MB concentration. 83 Table 6-6: Calculation of the total reduced scattering coefficient for each bulk phantom at $660 \mathrm{~nm}$. The first column of the table shows the Definity® microbubble injection doses. The second column represents the total reduced scattering coefficient of the bulk phantom without MBs for a high blood concentration $(6 \% \mathrm{v} / \mathrm{v})$. The third column represents the total reduced scattering coefficient of the bulk phantom with MBs for a high blood concentration $(6 \% \mathrm{v} / \mathrm{v})$. The fourth column represents the total reduced scattering coefficient of the bulk phantom without MBs for a low blood concentration $(0.2 \% \mathrm{v} / \mathrm{v})$. The fifth column represents the total reduced scattering coefficient of the bulk phantom with MBs for a low blood concentration $(0.2 \% \mathrm{v} / \mathrm{v})$. The sixth column represents the reduced scattering contrast of the bulk phantom without MBs. The seventh column represents the reduced scattering contrast of the bulk phantom with MBs. The eighth column represents the reduced scattering contrast enhancement of the bulk phantom. 84 
Table 6-7: Mie calculation of anisotropy factor and scattering cross section at $1310 \mathrm{~nm} . .85$ Table 6-8: Calculation of reduced scattering coefficient for IL scatterers and RBCs at 1310 $\mathrm{nm}$. The first column of the table represents the number of IL scatterers per unit volume calculated for a $5 \% \mathrm{v} / \mathrm{v}$ concentration. The second column represents the reduced scattering coefficient of IL. The third column represents the number of RBCs per unit volume calculated for a high blood concentration $(6 \% \mathrm{v} / \mathrm{v})$. The fourth column represents the reduced scattering coefficient of RBCs calculated for a high blood concentration. The fifth column represents the number of RBCs per unit volume calculated for a low blood concentration $(0.2 \% \mathrm{v} / \mathrm{v})$. The sixth column represents the reduced scattering coefficient of RBCs calculated for a low blood concentration. 85 Table 6-9: Calculation of reduced scattering coefficient for MBs at $1310 \mathrm{~nm}$. The first column of the table represents the Definity® microbubble injection doses. The second column represents the number of MBs per unit volume calculated for a high MB concentration. The third column represents the reduced scattering coefficient of MBs calculated for a high MB concentration. The fourth column represents the number of MBs per unit volume calculated for a low MB concentration. The fifth column represents the reduced scattering coefficient of MBs calculated for a low MB concentration. 86

Table 6-10: Calculation of the total reduced scattering coefficient for each bulk phantom at $1310 \mathrm{~nm}$. The first column of the table represents the Definity® microbubble injection doses. The second column represents the total reduced scattering coefficient of the bulk phantom without MBs for a high blood concentration $(6 \% \mathrm{v} / \mathrm{v})$. The third column represents the total reduced scattering coefficient of the bulk phantom with MBs for a high blood concentration 
$(6 \% \mathrm{v} / \mathrm{v})$. The fourth column represents the total reduced scattering coefficient of the bulk phantom without MBs for a low blood concentration $(0.2 \% \mathrm{v} / \mathrm{v})$. The fifth column represents the total reduced scattering coefficient of the bulk phantom with MBs for a low blood concentration $(0.2 \% \mathrm{v} / \mathrm{v})$. The sixth column represents the reduced scattering contrast of the bulk phantom without MBs. The seventh column represents the reduced scattering contrast of the bulk phantom with MBs. The eighth column represents the reduced scattering contrast

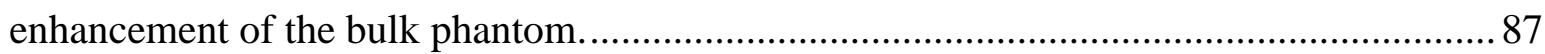




\section{List of Figures}

Figure 1-1: (a) The orientation of the three-dimensional (3D) reconstructed DOT image of a right breast with ductal carcinoma. Slices along the y axis are arranged from left to right, from the source plane to the detector plane, respectively. Each slice represents a $16 \times 11 \mathrm{~cm}$ image in $\mathrm{x}-\mathrm{z}$ plane with slice thickness, $\Delta \mathrm{y}=1 \mathrm{~cm}$. Slices at selected spatial positions are presented. The cross sectional images of (b) total hemoglobin concentration (THC) and (c) reduced scattering coefficient of breast tissue were obtained at 786nm. Adapted from [26].5 Figure 1-2: Total hemoglobin concentration cross sectional images. Image slices from source to detection plane are presented at $1 \mathrm{~cm}$ intervals in caudal-cranial view. DOI images corresponding to post 4th, 5th and 7th chemotherapy are arranged from top to bottom. THC color bar scales are not fixed and are adjust to maximize the THC color contrast between tumor and normal region. $\Delta y$ is slice thickness. Adapted from [26].................................. 6 Figure 1-3: Cross sectional images of $\mu \mathrm{s}^{\prime}$ at $786 \mathrm{~nm}$. Image slices from source to detection plane are presented at $1 \mathrm{~cm}$ intervals in a caudal-cranial view. DOI images corresponding to post 4th, 5th and 7th cycle of chemotherapy are arranged from top to bottom. Adapted from [26].

Figure 1-4: (a) OCT system. (b) The interference pattern. Adapted from [46].... 13 
Figure 1-5: Fluorescence and svOCT imaging of response to radiation in tumor and vascular compartments in vivo. Functional changes in perfusion in the tumor microvasculature were

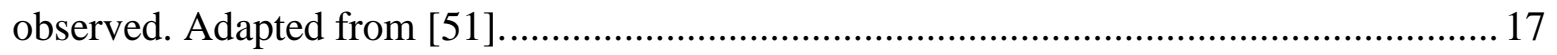
Figure 1-6: Schematic illustration of the microbubble agent particle. ............................. 19 Figure 2-1: Integrating sphere system (ISS). (a) Total transmittance measurement setup. (b) Diffuse reflectance measurement setup. Baffles are placed in the sphere to block the direct path of light from a source port to a detector port. The light source is to the left as shown by the arrows. 24 Figure 2-2: Time course graph to investigate MBs stability diluted in water. Total transmittance change in first 5 minutes is less than $0.1 \%$ at wavelength $550 \mathrm{~nm} \ldots \ldots \ldots \ldots . . . . .32$

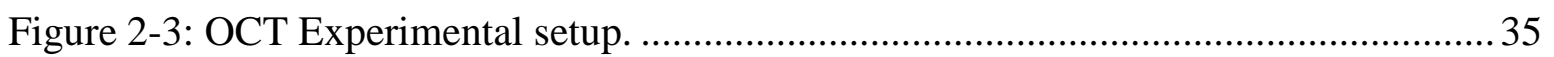
Figure 2-4: Typical structural B-scan of the phantom. The left microtube was filled with blood, and the right with blood+MBs $(2.5 \%$ volume fraction of a stock suspension were injected into the blood microtube). ROIs of blood and blood+MB mixture are labeled with half-circles at the top circular section of microtube lumens. Background ROI was chosen at the same depth as shown. The vertical dashed line indicates the location of the acquired Ascans. 37

Figure 2-5: Schematic of two embedded blood vessel skin phantom fabricated for OCT experiment.

Figure 3-1: Reduced scattering coefficient spectra measured in this thesis for the tissue phantom with low blood concentration $(0.2 \% \mathrm{v} / \mathrm{v})$ in color (Asterisk) compared with reduced scattering coefficient spectra of human skin in vitro from the literature review in black 
adapted from [27]. Reduced scattering coefficient results in this thesis are in general agreement with published values

Figure 3-2: The reduced scattering coefficient for the 20 phantom conditions (four blood concentrations at five Definity® microbubble injection doses $(0,25,50,83.3,166 \mu \mathrm{L} / \mathrm{kg}))$ (a) $0.2 \%$ blood, (b) $1.5 \%$ blood, (c) $3 \%$ blood, (d) $6 \%$ blood. The error bars correspond to the values of standard deviation (SD) of three samples. .46

Figure 3-3: The reduced scattering coefficient vs blood concentrations $(0.2 \%, 1.5 \%, 3 \%$ and $6 \%)$ at five Definity® microbubble injection doses $(0,25,50,83.3,166 \mu \mathrm{L} / \mathrm{kg})$ at wavelengths of (a) $660 \mathrm{~nm}$ and (b) $1310 \mathrm{~nm}$. The error bars correspond to the standard deviation (SD). Solid lines are used to guide the eye. 48

Figure 3-4: The reduced scattering signal enhancement, $S$ s, is plotted for four Definity® injection doses of microbubbles $(25,50,83.3$, and $166 \mu \mathrm{L} / \mathrm{kg}$ ) at wavelengths of (a) $660 \mathrm{~nm}$ and (b) $1310 \mathrm{~nm}$. The error bars correspond to the values of standard deviation (SD)..... 49 Figure 3-5: The reduced scattering contrast between low blood concentration $(0.2 \% \mathrm{v} / \mathrm{v})$ and high blood concentrations $(1.5 \%, 3 \%$ and $6 \% \mathrm{v} / \mathrm{v})$ tissue phantom at various Definity® microbubble injection doses $(0,25,50,83.3$ and 166) is plotted at wavelengths of (a) $660 \mathrm{~nm}$ and (b) $1310 \mathrm{~nm}$. The error bars correspond to the values of standard deviation (SD)......53 Figure 3-6: The reduced scattering contrast enhancement vs various Definity® microbubble injection doses $(25,50,83.3$ and $166 \mu \mathrm{L} / \mathrm{kg}$ ) is plotted at wavelengths of (a) $660 \mathrm{~nm}$ and (b) 1310nm. The error bars correspond to the values of standard deviation (SD). Solid lines are used to guide the eye. 54 
Figure 3-7: (a) Absorption coefficient spectra measured in this thesis for the tissue phantom with low blood concentration $(0.2 \% \mathrm{v} / \mathrm{v})$, (b) Published absorption coefficient spectra of human skin [27]. Absorption coefficient results in this thesis are in general agreement with published values. 56

Figure 3-8: The absorption coefficient for the 20 phantom conditions (four blood concentrations at five Definity® microbubble injection doses $(0,25,50,83.3,166 \mu \mathrm{L} / \mathrm{kg}))$ (a) $0.2 \%$ blood, (b) $1.5 \%$ blood, (c) $3 \%$ blood, (d) $6 \%$ blood. The error bars correspond to the values of standard deviation (SD) 57 Figure 3-9: The absorption coefficient vs blood concentrations $(0.2 \%, 1.5 \%, 3 \%$ and $6 \%)$ at five Definity ${ }^{\circledR}$ microbubble injection doses $(0,25,50,83.3,166 \mu \mathrm{L} / \mathrm{kg})$ at wavelengths of (a) $660 \mathrm{~nm}$ and (b) $1310 \mathrm{~nm}$. The error bars correspond to the values of standard deviation (SD). Solid lines are used to guide the eye are a guide to the eye........................................59

Figure 3-10: The absorption signal enhancement, $S$ a , is plotted for four Definity $®$ injection doses of microbubbles $(25,50,83.3,166 \mu \mathrm{L} / \mathrm{kg}$ ) at wavelengths of (a) $660 \mathrm{~nm}$ and (b) 1310 $\mathrm{nm}$. The error bars correspond to the values of standard deviation (SD). .60 Figure 3-11: The absorption contrast between low blood concentration $(0.2 \% \mathrm{v} / \mathrm{v})$ and high blood concentrations $\left(1.5 \%, 3 \%\right.$ and $6 \%$ v/v) tissue phantom at various Definity ${ }^{\circledR}$ microbubble injection doses $(0,25,50,83.3$ and 166) is plotted at wavelengths of (a) $660 \mathrm{~nm}$ and (b) $1310 \mathrm{~nm}$. The error bars correspond to the values of standard deviation (SD). ......63 Figure 3-12: The absorption contrast enhancement vs various Definity® microbubble injection doses $(25,50,83.3$ and 166) is plotted at wavelengths of (a) $660 \mathrm{~nm}$ and (b) $1310 \mathrm{~nm}$. 
The error bars correspond to the values of standard deviation (SD). Solid lines are used to guide the eye 64

Figure 4-1: Decorrelation time plots for blood and blood+MB mixture under eight flow conditions in $300 \mu \mathrm{m}$ tube. The error bars correspond to the values of standard deviation (SD). 66

Figure 4-2: Structural images, corresponding contrast of blood and blood+MB mixture and ratios of blood $+\mathrm{MB}$ to blood contrasts under eight flow conditions (a) structural image of the phantom with $600 \mu \mathrm{m}$ microtubes at $0.5 \mathrm{~mm} / \mathrm{s}$ average blood flow velocity; (b) structural image contrast for $600 \mu \mathrm{m}$ microtube phantom at various average blood flow velocities $(0$, $0.5,1,2,3,5,8,12 \mathrm{~mm} / \mathrm{s}$ ); (c) standard deviation image calculated from eight sequential structural images at $0.5 \mathrm{~mm} / \mathrm{s}$ blood flow velocity; (d) structural image of the phantom with $300 \mu \mathrm{m}$ microtubes at $0.5 \mathrm{~mm} / \mathrm{s}$ average blood flow velocity; (e) structural image contrast for $300 \mu \mathrm{m}$ microtube phantom at various average blood flow velocities $(0,0.5,1,2,3,5,8,12$ $\mathrm{mm} / \mathrm{s}$ ); (f) Ratio of blood+MB / blood structural contrasts for both microtube diameters. . 68 Figure 4-3: (a) svOCT image of the phantom with $600 \mu \mathrm{m}$ microtubes calculated from 8 subsequent structural images at $0.5 \mathrm{~mm} / \mathrm{s}$ average blood flow velocity; (b) svOCT image contrast for $600 \mu \mathrm{m}$ microtubes plotted as a function of average blood flow velocity; (c) svOCT image of the phantom with $300 \mu \mathrm{m}$ microtubes calculated from 8 subsequent structural images at $0.5 \mathrm{~mm} / \mathrm{s}$ average blood flow velocity; (d) svOCT image contrast for 300 $\mu \mathrm{m}$ microtubes plotted as a function of average blood flow velocity; (e) Ratio of blood+MB / blood sv contrasts for both microtube diameters plotted as a function of average blood flow velocity. 70 
Figure 4-4: En-face (x-y lateral dimensions) svOCT average intensity projections of volumetric phantom scans. Color bar is normalized value to the maximum intensity. Eight projections corresponding to eight flow conditions in $600 \mu \mathrm{m}$ diameter microtubes with blood (left microtube) and blood+MB mixture (right microtube). Image intensities are normalized to the maximum value. The flow direction is labeled with black arrows. The OCT slow scanning axis is anti-parallel to the flow direction. 72 Figure 6-1: Bright field microscopy (Zeiss AxioObserver, objective 40X(0.6), Zeiss Live Cell,) of phantom 4, microbubbles are observed as black spheres, RBC are observed as bright spheres and IL presents at background. The average distance between MBs and RBCs

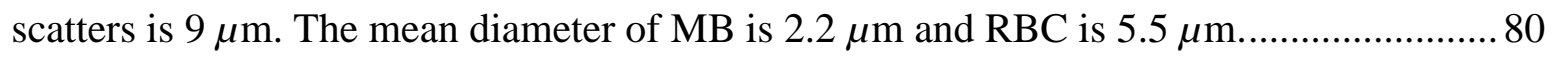
Figure 6-2: The Reduced scattering contrast enhancement vs Definity ${ }^{\circledR}$ microbubble injection doses $(25,50,83.3$ and $166 \mu \mathrm{L} / \mathrm{kg}$ ) depicted at (a) 660nm and (b) 1310nm. Red lines represent experimental results from spectroscopy and blue squares are simulation results from Mie calculation. Solid lines are used to guide the eye. 88 


\section{Symbols and Abbreviations}

\begin{tabular}{|c|c|}
\hline $\mathrm{ACF}$ & Auto correlation function \\
\hline DOI & Diffuse optical imaging \\
\hline DR & Diffuse reflectance \\
\hline NIR & Near infra-red \\
\hline ISS & Integrating sphere spectrophotometer \\
\hline IL & Intralipid \\
\hline MBs & Microbubbles \\
\hline $\mathrm{NA}_{\mathrm{obj}}$ & Numerical aperture \\
\hline OCT & Optical coherence tomography \\
\hline $\mathrm{RBC}$ & Red blood cells \\
\hline TT & Total transmittance \\
\hline$X$ & Size parameter \\
\hline$\varepsilon$ & Particle concentration \\
\hline$\rho$ & Particle volume fraction \\
\hline$I_{0}$ & Incident intensity \\
\hline$P\left(s, s^{\prime}\right)$ & Phase function \\
\hline$\mu_{\mathrm{t}}$ & Attenuation coefficient \\
\hline$a$ & Albedo \\
\hline
\end{tabular}


$\tau$

$g$

$n_{\mathrm{p}}$

$n_{\text {med }}$

$l_{\mathrm{c}}$

$\Delta \lambda$

$\lambda 0$

$\mu_{\mathrm{S}}^{\prime \mathrm{H}}$

$\mu_{\mathrm{s}}^{\prime \mathrm{H}, \mathrm{MB}}$

$\mu_{\mathrm{S}}^{\mathrm{L}}$

$\mu_{\mathrm{s}}^{\prime \mathrm{L}, \mathrm{MB}}$

$\mu_{\mathrm{a}}^{\mathrm{H}}$

$\mu_{\mathrm{a}}^{\mathrm{H}, \mathrm{MB}}$

$\mu_{\mathrm{a}}^{\mathrm{L}}$

$\mu_{\mathrm{a}}^{\mathrm{L}, \mathrm{MB}}$

$S_{\mathrm{S}}^{\mathrm{L}}$

$S_{\mathrm{S}}^{\mathrm{H}}$
Optical depth

Anisotropy factor

Particle refractive index

Medium refractive index

Coherence length

Wavelength bandwidth

Center wavelength

Reduced scattering coefficient of high blood concentration phantom tissue

Reduced scattering coefficient of high blood concentration phantom tissue with MB

Reduced scattering coefficient of low blood concentration phantom tissue

Reduced scattering coefficient of low blood concentration phantom tissue with MB

Absorption coefficient of high blood concentration phantom tissue

Absorption coefficient of high blood concentration phantom tissue with MB

Absorption coefficient of low blood concentration phantom tissue

Absorption coefficient of low blood concentration phantom tissue with MB

Reduced scattering signal enhancement of low blood concentration phantom tissue

Reduced scattering signal enhancement of high blood concentration phantom tissue 


$\begin{array}{ll}S_{\mathrm{a}}^{\mathrm{L}} & \begin{array}{l}\text { Absorption signal enhancement of low blood concentration phantom } \\ \text { tissue }\end{array} \\ S_{\mathrm{a}}^{\mathrm{H}} & \begin{array}{l}\text { Absorption signal enhancement of high blood concentration phantom } \\ \text { tissue }\end{array} \\ C_{\mathrm{a}} & \text { Absorption contrast } \\ C_{\mathrm{a}}^{\mathrm{MB}} & \text { Absorption contrast with MB } \\ \frac{C_{\mathrm{a}}^{\mathrm{MB}}}{C_{\mathrm{a}}} & \text { Absorption contrast enhancement } \\ C_{\mathrm{s}} & \text { Reduced scattering contrast } \\ C_{\mathrm{s}}^{\mathrm{MB}} & \text { Reduced scattering contrast with MB } \\ \frac{C_{\mathrm{s}}^{\mathrm{MB}}}{C_{\mathrm{s}}} & \text { Reduced scattering contrast enhancement } \\ C_{\mathrm{W}} & \end{array}$




\section{Chapter 1 Introduction}

\subsection{Optical imaging of tissue and cancer detection}

The motivation of the thesis was to determine if microbubble contrast agents can be used to enhance the detection of cancerous tissue with optical imaging techniques. Cancer detection can be enhanced by imaging microvasculature morphology and functionality. The microvasculature is composed of capillaries, arterioles, and venules that are between $5 \mu \mathrm{m}$ and $300 \mu \mathrm{m}$ in diameter [1] and provides the major portion of nutrient supply in the tissue [2], [3]. The morphology of the microvasculature is important for cancer detection because cancerous tissue typically has new vessel formation with a higher vessel density than healthy surrounding tissue [4]. The microvasculature functionality is of great significance for cancer detection since blood flow [5], [6] and blood volume fraction [4], [7] are generally higher because of new vessel formation in cancerous tissue than surrounding healthy tissue.

Imaging modalities such as magnetic resonance imaging (MRI), computed tomography (CT), x-ray and ultrasound (US) are unable to detect a cancerous tumor at an early stage or to visualize vessels smaller than $300 \mu \mathrm{m}$ in routine clinical practice [8]. Optical imaging offers potential for imaging both microvasculature morphology and functionality at relatively low cost [9]. In optical imaging, light undergoes absorption and scattering in the blood which has different optical properties compared to surrounding tissue. The higher blood volume fraction in cancerous tissue results in larger scattering and absorption values 
compared to healthy tissue. For instance diffuse optical imaging (DOI) and optical coherence tomography (OCT) are well-established optical modalities that use visible and near infrared (NIR) light. The microvasculature functionality can be imaged with DOI through the blood optical properties and blood volume fraction measurements [10], [11]. Microvasculature morphology and functionality can also be imaged with (OCT) through visualization of vessel density and measurements of blood flow, respectively [12]. Modification of the blood optical properties such as scattering and absorption would allow image contrast enhancement of the microvasculature [13]. Exogenous contrast agents can be used to improve optical imaging with the ability to enhance the optical contrast between the microvasculature and surrounding tissues [14].

A solution termed microbubble (MB) enhanced imaging is presented in this study, which is based on adding microbubble solution (Definity®) to the blood, thus improving the detection of tissue microvasculature with DOI and OCT. Definity® MBs are USA Food \& Drug Administration (FDA) approved intravascular contrast agents used in diagnostic ultrasound [15], [16]. MBs are made from non-toxic gas such as perfluorocarbon, which introduce a refractive index mismatch that cause scattering to differentiate between blood and surrounding tissues. Their use as potential optical contrast agents for DOI and OCT was investigated in this study. To the best of our knowledge, this is the first study of the effect of MBs on the DOI image contrast. This is also the first study of the effect of MBs on speckle variance (sv) OCT image contrast of blood flow in vessels. 


\subsection{Diffuse optical imaging (DOI)}

Diffuse optical imaging is a tomographic technique that uses light $(650 \mathrm{~nm}<\lambda<$ $1400 \mathrm{~nm}$ ) to present quantitative spectral information regarding the optical properties of tissue. DOI can be used to diagnose a cancerous tumor and monitor treatment response [17][19]. DOI measures light intensity attenuation integrated over the depth of the bulk tissue, and the source of the contrast comes from optical properties of tissue, such as reduced scattering coefficient $\left(\mu_{s}^{\prime}\right)$, and absorption coefficients $\left(\mu_{a}\right)$. Spatial maps of these tissue optical properties are then generated [10]. This method separates the effects of absorption and scattering to generate images of the whole tissue volume with potential to monitor microvasculature functionality. In DOI the region of interest is partially light-transmitting and an example is that of the breast. By analyzing the transmitted and reflected light, optical properties $\left(\mu_{s}^{\prime}\right.$ and $\left.\mu_{a}\right)$ of the tissue are estimated with a penetration depth of a few millimetres [10]. Spatial variations in the light scattering and absorption properties of tissue can be imaged with the advantage of being non-invasive, fast and without the risk of ionizing radiation [10]. DOI has been used in various applications such as breast cancer imaging, brain functional imaging, stroke detection, photodynamic therapy monitoring and radiation therapy monitoring [11], [20]-[22]. DOI has a low spatial resolution in the range of 6-10 $\mathrm{mm}$ which makes it difficult to use as a screening tool for early stage cancer, so interest has shifted to its use in monitoring treatment response [10]. Although, DOI cannot resolve microvasculature due to its low spatial resolution, it can still provide valuable information for cancer margin evaluation [10]. DOI can provide information on the blood volume fraction 
in tissue [10], and such an increase of tissue blood volume can be linked with angiogenesis [23]. Histopathological studies have also demonstrated a correlation between increased blood volume fraction, vascular density and cancer grades [23], [24]. For example, a study on breast cancer with DOI showed potential in differentiating between normal and malignant breast tissue [19] and monitoring progression of neoadjuvant chemotherapy [25]. Spatial maps of breast tissue optical properties such as total hemoglobin concentration (THC) and reduced scattering coefficient were obtained at $786 \mathrm{~nm}$ in reference [26]. Patients with ductal carcinoma of a breast had a higher THC and $\mu_{s}^{\prime}$ values in the tumor region which gives a higher contrast ratio between tumor and normal tissue shown in Figure 1-1 [26]. 


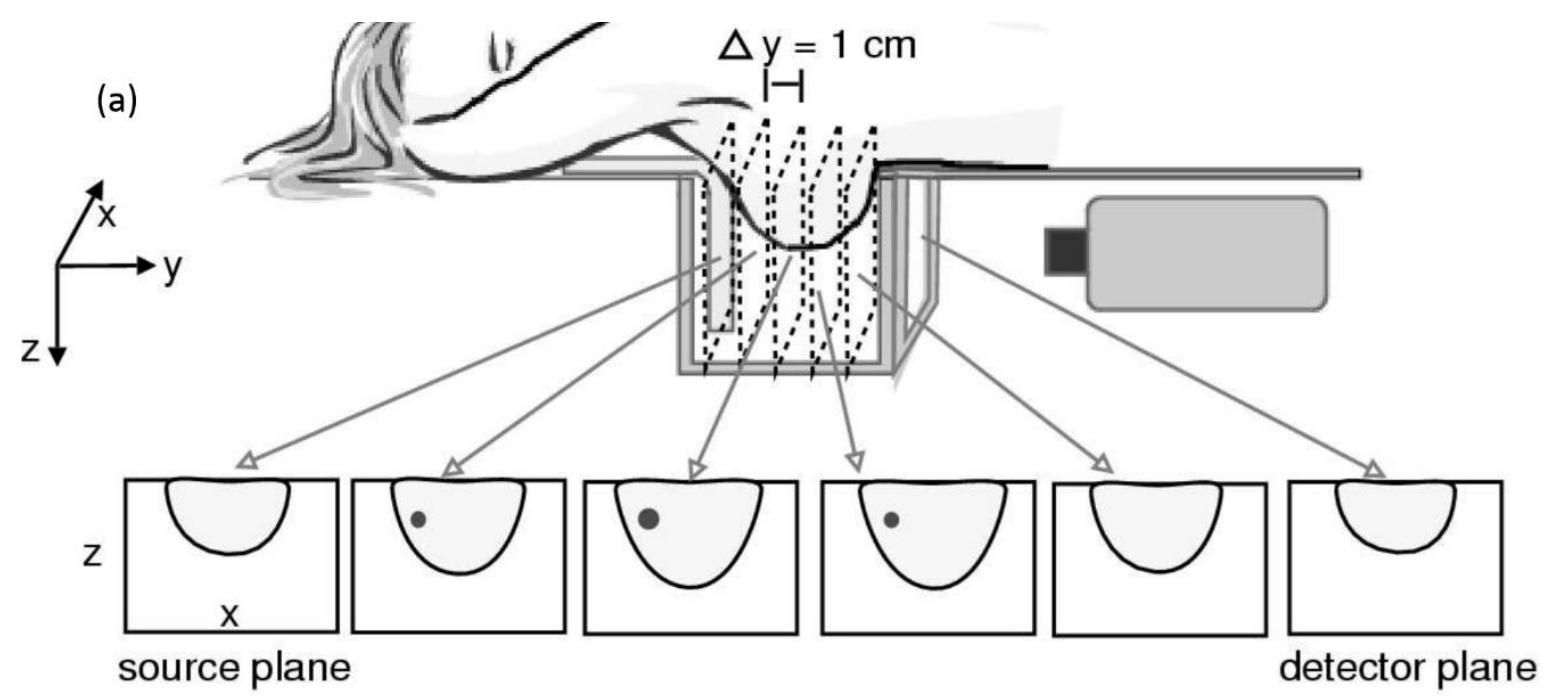

(b)

Total hemoglobin concentration ( $\mathrm{uM}$ )

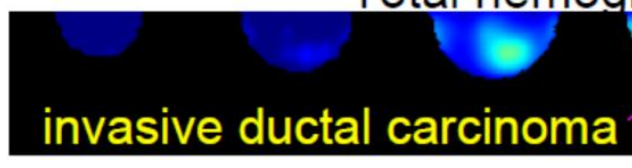

(c)

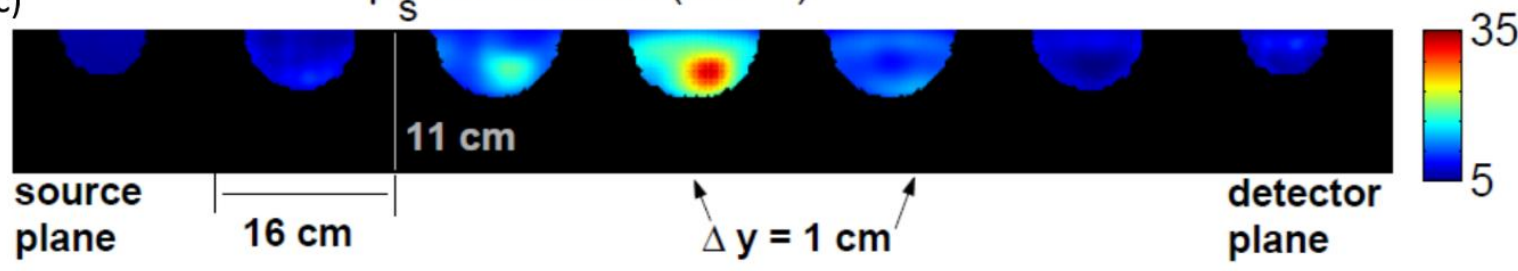

Figure 1-1: (a) The orientation of the three-dimensional (3D) reconstructed DOT image of a right breast with ductal carcinoma. Slices along the y axis are arranged from left to right, from the source plane to the detector plane, respectively. Each slice represents a $16 \times 11 \mathrm{~cm}$ image in $\mathrm{x}$-z plane with slice thickness, $\Delta y=1 \mathrm{~cm}$. Slices at selected spatial positions are presented. The cross sectional images of (b) total hemoglobin concentration (THC) and (c) reduced scattering coefficient of breast tissue were obtained at 786nm. Adapted from [26].

For monitoring treatment response, DOI images of total hemoglobin concentration and reduced scattering coefficient at $786 \mathrm{~nm}$ (commonly available laser diode) at different time points within the chemotherapy cycle were also shown in Figure 1-2 and Figure 1-3, 
respectively [26]. In the THC images after the 7th chemotherapy cycle, the contrasted region appears smaller than that of the corresponding 4th chemotherapy cycle [26]. The $\mu_{\mathrm{s}}^{\prime}$ exhibits a similar trend to THC, the tumor is shrinking over the course of the treatment as reflected in reduced scattering values. However, the optical contrast between normal and the tumor region is not significant at the 7 th chemotherapy cycle because of tumor neo-vasculature regression over the course of therapy. Microbubbles may be used to enhance the DOI optical contrast between normal and the tumor tissues MB uptake in the tumor region therefore may help to improve the treatment monitoring.

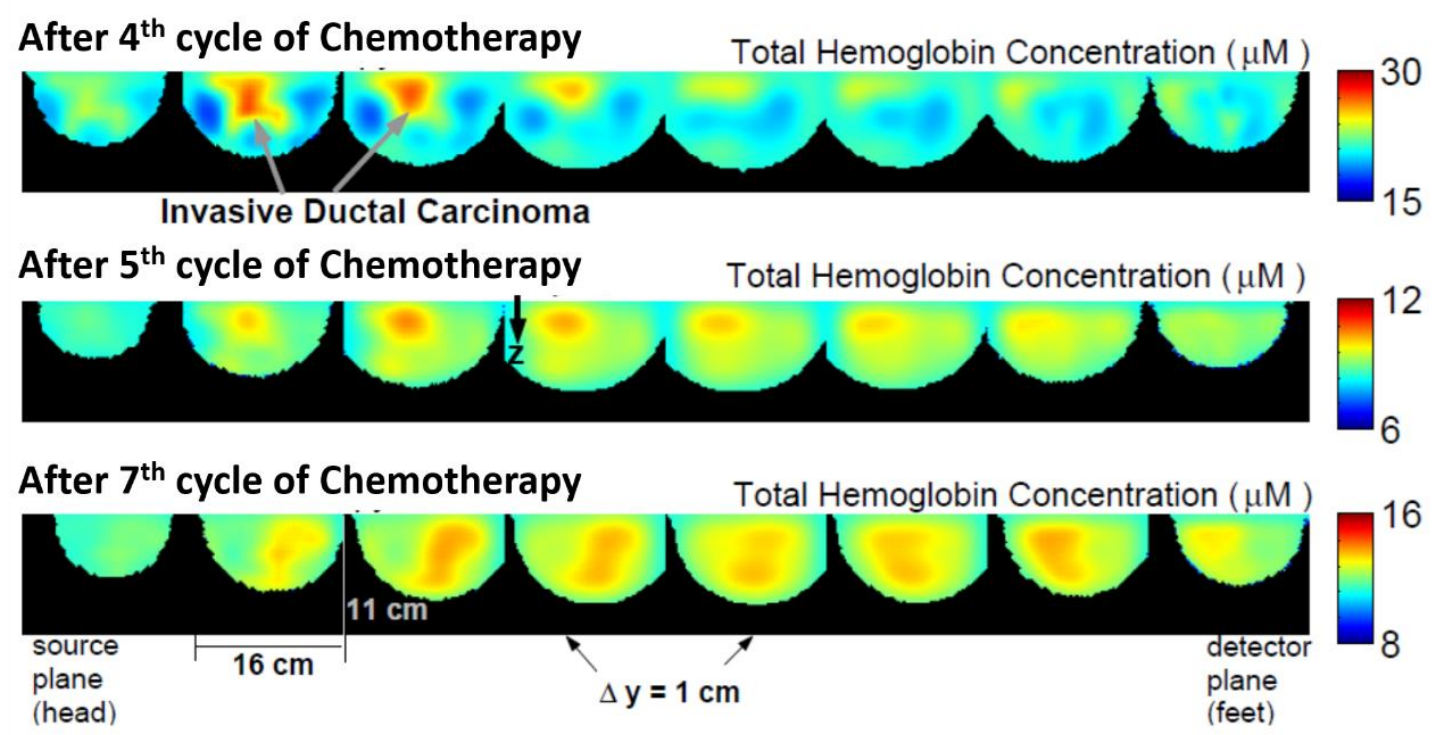

Figure 1-2: Total hemoglobin concentration cross sectional images. Image slices from source to detection plane are presented at $1 \mathrm{~cm}$ intervals in caudal-cranial view. DOI images corresponding to post 4 th, 5 th and 7 th chemotherapy are arranged from top to bottom. THC color bar scales are not fixed and are adjust to maximize the THC color contrast between tumor and normal region. $\Delta y$ is slice thickness. Adapted from [26]. 

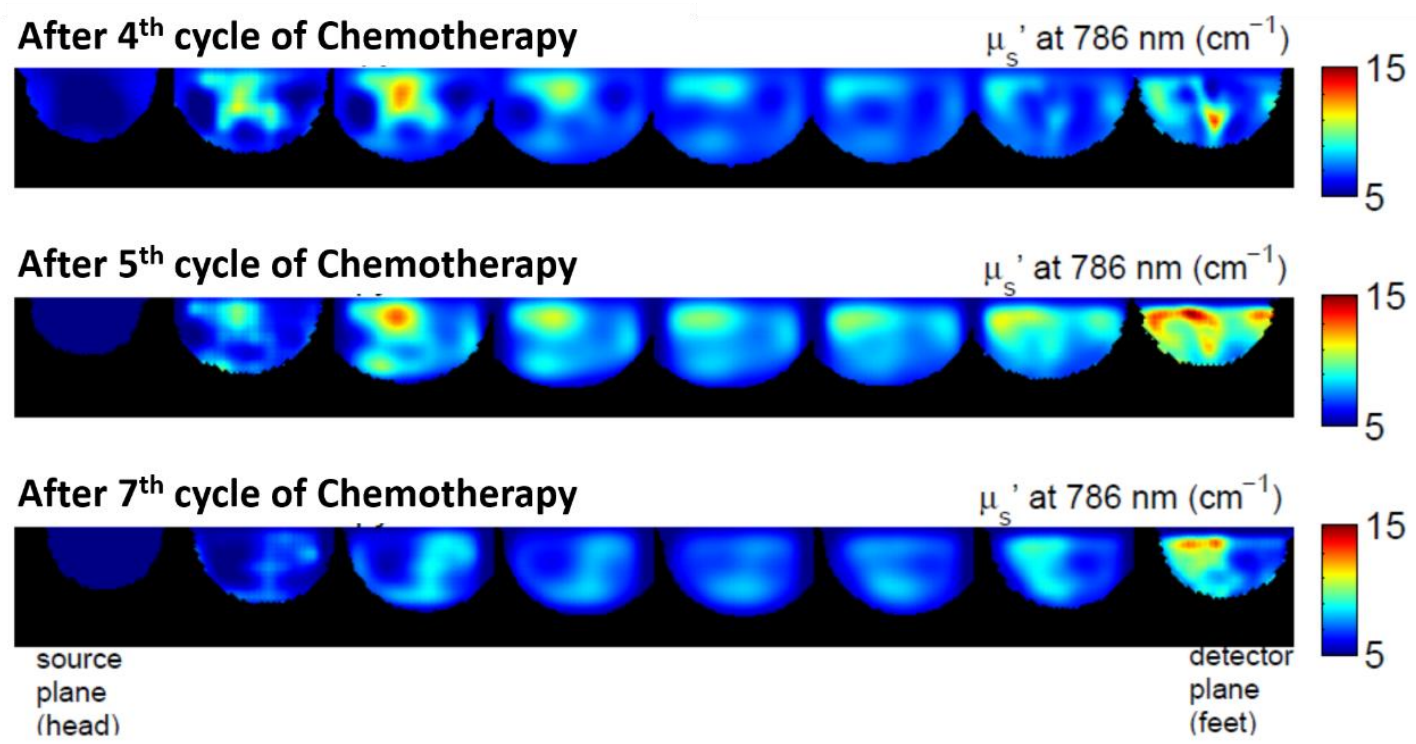

Figure 1-3: Cross sectional images of $\mu_{\mathrm{s}}^{\prime}$ at $786 \mathrm{~nm}$. Image slices from source to detection plane are presented at $1 \mathrm{~cm}$ intervals in a caudal-cranial view. DOI images corresponding to post 4th, 5th and 7 th cycle of chemotherapy are arranged from top to bottom. Adapted from [26].

Microbubbles administered intravascularly can modify the blood optical properties and enhance the contrast between tissues with higher and lower concentrations of blood. In this thesis, microbubbles were considered as DOI optical contrast agents to investigate the alteration of optical properties of tissue phantoms using spectroscopy. A spectroscopy method was used to measure total transmitted (TT) and diffuse reflected (DR) of light after interaction with a bulk tissue phantom in order to calculate the absorption and reduced scattering coefficients. Contrast enhancement was studied for tissue phantoms with low blood concentration and high blood concentration, mimicking normal [27], [28] and cancerous tissues [29]-[32], respectively. 


\subsubsection{Optical properties of tissue}

DOI relies on the optical properties of tissue as the source of contrast; hence any change in tissue optical properties due to microbubble agents may enhance the image contrast. The scattering coefficient represents the probability of photon scattering in tissue per unit path length, $\mathrm{mm}^{-1}$.

Independent approximation is defined as the distances between particles are large compared to the particle dimensions and scattering can be considered individually. For concentrations of particles for which the independent scattering approximation is applicable, the scattering coefficient $\mu_{\mathrm{s}}$ is proportional to the particle concentration [33], [34]; thus $\mu_{\mathrm{s}}$ increases proportionally to the concentration of the particles as

$$
\mu_{\mathrm{s}}=\varepsilon \sigma_{\mathrm{s}}
$$

where $\varepsilon$ is the number of particles per unit volume, $\mathrm{mm}^{-3}$, and $\sigma_{\mathrm{s}}$ is the scattering cross section of the particle, $\mathrm{mm}^{-3}$. It is defined as

$$
\sigma_{\mathrm{s}}=\frac{P_{\mathrm{s}}}{I_{0}}
$$

where the $P_{\mathrm{s}}$ is the total scattered power, watt, and $I_{0}$ is the incident intensity, watt. $\mathrm{mm}^{-3}$. The efficiency of a particle to scatter light can be expressed by its scattering

efficiency, $Q_{\mathrm{s}}=\frac{\sigma_{\mathrm{s}}}{\sigma_{\mathrm{g}}}$, where $\sigma_{\mathrm{g}}$ is the geometric cross section of the particle: $\sigma_{\mathrm{g}}=\pi r^{2}[33]$, [34], $\mathrm{r}$ is radious of the particle.

The absorption coefficient represents the probability of photon absorption in tissue per unit path length, $\mathrm{mm}^{-1}$. For concentrations of particles in which the independent 
scattering approximation is applicable, the absorption coefficient $\mu_{\mathrm{a}}$ is proportional to the particle concentration [33]; thus $\mu_{\mathrm{a}}$ increases proportionally to the concentration of the particles as:

$$
\mu_{\mathrm{a}}=\varepsilon \sigma_{\mathrm{a}},
$$

where $\sigma_{\mathrm{a}}$ is the absorption cross section of the particle. It is given by,

$$
\sigma_{\mathrm{a}}=\frac{P_{\mathrm{a}}}{I_{0}}
$$

where the $P_{\mathrm{a}}$ is the absorbed power and $I_{0}$ is the incident intensity. The efficiency of a particle absorbing light can be expressed by the absorption efficiency, $Q_{\mathrm{a}}=\frac{\sigma_{\mathrm{a}}}{\sigma_{\mathrm{g}}}$, where $\sigma_{\mathrm{g}}$ is the geometric cross section of the particle, $\sigma_{\mathrm{g}}=\pi r^{2}$ [33], [34].

The reciprocal of the scattering coefficient, $l_{\mathrm{s}}$, or the reciprocal of the absorption coefficient, $l_{\mathrm{a}}$, is the average distance that light will travel before being scattered or absorbed, respectively. That is called the absorption or scattering mean free path. The attenuation coefficient is the sum of the scattering and absorption coefficient, $\mu_{\mathrm{t}}=\mu_{\mathrm{a}}+\mu_{\mathrm{s}}$, and the total mean free path is the reciprocal of the attenuation coefficient $l_{\mathrm{t}}=\frac{1}{\mu_{\mathrm{t}}}[33],[35]$.

Light propagation is also dependent upon three dimensionless parameters: the albedo, $a$, the optical depth, $\tau$, and the phase function, $p\left(s \cdot s^{\prime}\right)$. The albedo defined as the ratio of scattering coefficient to the attenuation coefficient, $a=\frac{\mu_{\mathrm{s}}}{\mu_{\mathrm{s}}+\mu_{\mathrm{a}}}$. The albedo varies between zero and one: a value of zero indicates the absence of scattering and a value of one means that the tissue does not absorb light. The optical depth, $\tau$, is the product of the depth, $d$, and the attenuation coefficient: 


$$
\tau=\left(\mu_{s}+\mu_{a}\right) d=\mu_{\mathrm{t}} d
$$

The phase function is the fraction of light scattered into the direction of the unit vector $s^{\prime}$ relative to light incident from the direction of the unit vector $s$. The phase function is normalized so that its integral over all directions is one,

$$
\int_{4 \pi} p\left(s, s^{\prime}\right) d w^{\prime}=1
$$

where $d w^{\prime}$ is a differential solid angle in the $s^{\prime}$ direction. The phase function of a volume is independent of the particle concentration [33]. Therefore, for a collection of identical particles (monodisperse) the phase function for the volume element is identical to the phase function for the single particle. The average cosine of the phase function, commonly known as the anisotropy factor, $\mathrm{g}$, is another property of interest in light scattering. It is a measure of the scatter retained in the forward direction from a scattering event [33]. It can be obtained from the phase function by,

$$
g=\int_{4 \pi} p\left(s, s^{\prime}\right)\left(s \cdot s^{\prime}\right) d w .
$$

The anisotropy factor can be any value between -1 and 1 . If $g=-1$, then scattering is completely in the backwards direction; if $g=1$, then scattering is totally in the forwards direction; and if $g=0$, then scattering is independent of the direction of the incident light.

The reduced scattering coefficient, $\mu_{\mathrm{s}}^{\prime}$, is defined combining the scattering coefficient and the anisotropy factor [36],

$$
\mu_{\mathrm{s}}^{\prime}=\mu_{\mathrm{s}}(1-g)
$$


If there are many more scattering events than absorption events, $\mu_{\mathrm{a}} \ll \mu_{\mathrm{s}}$, this is called the diffusion regime [37]. The $\mu_{\mathrm{s}}^{\prime}$ describe the diffusion of photons in a random walk of step size of $\frac{1}{\mu_{\mathrm{s}}^{\prime}} \mathrm{mm}$ (reduced scattering mean free path) where each step involves isotropic scattering [37].

In particular the scattering properties of the medium depend on the relative refractive index of particles, $n$, with respect to the background medium, $n_{\text {med }}$, on the size and shape of the particles, and on the wavelength of the light, $\lambda$ [34]. The scattering dependence on size and wavelength for spherical particles is defined by the size parameter, $k a$, given by:

$$
k a=\frac{2 \pi r}{\lambda}
$$

Rayleigh scatters, $(k a \ll 1)$, have a small scattering efficiency and the phase function does not depend on $\lambda$ [34]. In the intermediate size-to-wavelength range, defined as the Mie scattering, $(k a \cong 1)$.

\subsubsection{Calculating optical properties by inverse adding doubling (IAD)}

Inverse adding doubling (IAD) is a method for computing the intrinsic optical properties of tissue such as $\mu_{\mathrm{s}}{ }^{\prime}$ and $\mu_{\mathrm{a}}$ based on the measured diffuse reflectance and total transmittance [38], [39]. Diffuse Reflectance is the light being reflected by the sample normalized by the incoming light intensity. Total Transmittance is the light being transmitted by the sample normalized by the incoming light. 
The adding-doubling is an accurate solution of the radiative transport equation that can be applied to a medium with any scattering and absorption values [35]. It has a number of advantages [39] such as (a) a variety of optical properties can be determined; and (b) it has an acceptable accuracy and speed. IAD starts with an initial guess of $a, \tau$, and $g$ obtained at fixed intermediate values of the tissue optical properties $(a=0.5, \tau=1$, and $g=0.9)$ for one wavelength [35]. The IAD algorithm calculates for a series of different wavelengths, the optical properties of the previous wavelength would be considered as the initial guess for the next wavelength [35]. The method starts calculating the reflection and transmission for fixed optical properties values. The calculated values are compared with the measured reflection and transmission from spectroscopy experiments; if they match, then these values would be recorded and used for the next wavelength. If they do not match, then another guess is made and this process repeated until the calculated and measured values match [35]. The IAD method has been used to compute optical properties of whole blood [40], human dermis and human skin tissue [27] for a wide range of wavelengths. In this study, the IAD was applied to extract the optical spectra $\left(\mu_{\mathrm{s}}^{\prime}\right.$ and $\left.\mu_{\mathrm{a}}\right)$ of the skin tissue phantoms.

\subsection{Optical coherence tomography}

Optical coherence tomography (OCT) is a noninvasive, depth resolved method to produce cross-sectional images in ophthalmology [41], cardiovascular diagnosis, and dermatology [42] with a typical resolution of micron. OCT is based on light backscattering [43], [44] using wavelengths in the region $650 \mathrm{~nm}<\lambda<1400 \mathrm{~nm}$ [12], and the source of contrast is the refractive index mismatches between structures in the tissue [45]. The use of 
infrared light (such as $1310 \mathrm{~nm}$ in this study) allows more penetration into the highly scattering media such as skin tissue. OCT is an interferometric technique, light is split into and recombined from reference and sample arms, respectively. A typical time domain OCT is based on a Michelson interferometer, as shown in Figure 1-4. Part of the split light travels in a reference path and the other part of the split light travels in a sample path, reflecting from a reference mirror and layers within a sample, respectively [46]. Constructive interference only occurs if the optical path length of the reference and sample arm are matched to within the coherence length of the light [12]. The coherence length is the propagation distance over which coherent light wave maintains a coherence light. In conventional time domain OCT, the interference pattern can be produced by moving the reference mirror to change the reference light path length and to match various optical paths due to structures within the sample. The speed of OCT is limited due to mechanical scanning of the reference mirror. The reflectivity profile of structures, called an A-scan, that provides information about the spatial distribution of structures within the sample [12]. A cross-sectional image, called a B-scan, can be produced by laterally combining multiple A-scans.

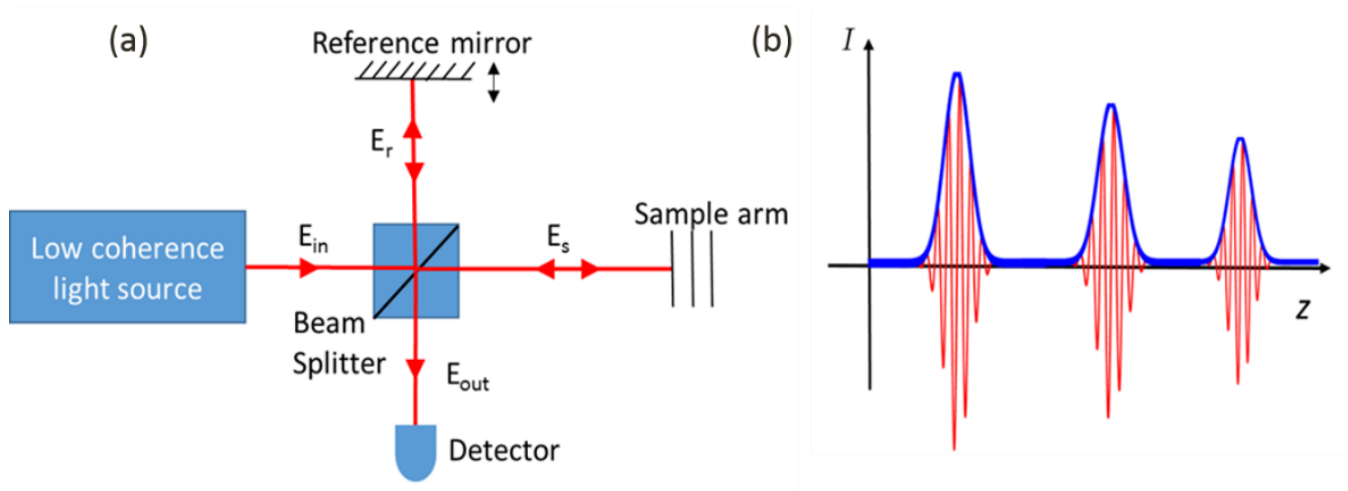

Figure 1-4: (a) OCT system. (b) The interference pattern. Adapted from [46]. 
The essential parameters are the center wavelength and the numerical aperture that determine the OCT imaging capabilities such as the maximum imaging depth, axial resolution and lateral resolution. In any highly scattering medium such as a biological tissue, the depth scan is limited by scattering and absorption. The center wavelength determines the imaging depth and spatial resolution of the system. Typical OCT systems operate with a center wavelength of either short wavelength (300 nm - $455 \mathrm{~nm})$ or longer wavelength (900 $\mathrm{nm}-1300 \mathrm{~nm}$ ). Short wavelength light source is popular for ophthalmic diagnostic since it provides higher resolution [12]. The longer wavelength systems provide deeper penetration suitable for highly scattering media such as skin tissue [12].

The axial resolution of an OCT system can be determined by the central wavelength and wavelength bandwidth of the light source. The coherence length of a broadband light source is defined by $l_{\mathrm{c}} \approx 0.44 \frac{\lambda_{0}^{2}}{\Delta \lambda}[12]$, where $\lambda_{0}$ is the central wavelength and $\Delta \lambda$ is the bandwidth of the light source. The axial resolution of an OCT system is defined by $R_{\mathrm{a}}=$ $\frac{l_{c}}{2}=0.22 \frac{\lambda_{0}^{2}}{\Delta \lambda}$ [47]. Shorter central wavelength and larger bandwidth OCT systems result in a higher axial resolution imaging. The lateral resolution of an OCT system defined by $R_{l}=$ $1.22 \frac{\lambda_{0}}{2 N A_{\mathrm{Obj}}}$, where $\mathrm{NA}_{\mathrm{obj}}$ is the numerical aperture of the objective lens used in the sample arm. Shorter central wavelength and larger numerical aperture OCT systems result in a higher lateral resolution imaging. Therefore, the axial resolution and lateral resolution may be independently controlled. 
Autocorrelation method used to provide information regarding the dynamic properties of particles such as blood flow. An autocorrelation method is capable of mapping transverse particles-flow velocity with an OCT system [48]. The autocorrelation function $\left(A C F_{i}\right)$ is the correlation between intensity values $I_{i}$ of a pixel at times $t_{i}$ and $t_{i+\tau}$ with increasing time delay $\tau[48]$, given by

$$
A C F_{\tau}=\frac{\sum_{i=1}^{N-\tau}\left(I_{i}-\bar{I}\right)\left(I_{i+\tau}-\bar{I}\right)}{\sum_{i=1}^{N}\left(I_{i}-\bar{I}\right)^{2}}
$$

Where $N$ is number of time intervals, $\bar{I}$ is the mean intensity of that pixel over $N$ time interval. An autocorrelation method uses the statistical nature of the fluctuation of the backscattered light intensity modulated by the scatterers' displacement. In the absence of noise, the backscattered light intensity pattern remains stationary as long as the particles do not change their position. Particle motion leads to a temporal change in the scattered intensity since one interference pattern is continuously replaced by another [48]. Thus, the intensity fluctuations are linked to the movement of scatterers and therefore the temporal correlation function depends on the scatterers' displacement. The measurable correlation properties of light can be linked to the dynamic properties of particles. In this thesis, an autocorrelation function was used to assess the flow of a blood stream in the presence of microbubble contrast agents. In flowing blood, scatterers follow the flow and produce a fluctuation in OCT intensity. In stationary blood, MBs motion is Brownian in nature, which also produces OCT intensity fluctuations. OCT autocorrelation analysis were used for flowing and stationary blood conditions in the result section. 
One of the OCT imaging techniques used to visualize microvasculature is speckle variance OCT [49]. The speckle variance OCT calculates the inter-frame intensity variance of structural images. The speckle variance OCT contrast is based on the difference in timevarying properties. Speckle variance OCT can be calculated from the number of B-scans acquired from the same $i$-location by the following equation [50]:

$$
S V_{j k}=\frac{1}{N} \sum_{i=1}^{N}\left(I_{i j k}-\overline{I_{J k}}\right)^{2}
$$

where $N=8$ is the number of B-scans acquired from the same $j k$-location, $I_{i j k}$ is the intensity of the pixel of the $i$-th B-scan, $j$ is the axial pixel, $k$ is the lateral pixel, and $\overline{I_{j k}}$ is the mean intensity of that pixel over $N$ sequential B-scans [50].

\subsubsection{OCT images of tissue}

One of the most promising applications of functional OCT has been the imaging of blood vessels by the speckle variance OCT that uses the blood motion as the source of contrast to visualize microvasculature [50]. A challenge in the clinical applications of svOCT is the development of a contrast mechanism that generates physiological information in addition to morphological structure [51]. Optical contrast agents may be used to overcome this limitation. In a recent in-vivo study, fluorescence imaging was used to compliment svOCT imaging as shown in Figure 1-5 in order to visualize the response of vasculature functionality within tumors over time [51]. FITC Dextran (green) was used as a contrast agent for fluorescence imaging and combined with svOCT imaging to extract the 
microvasculature functional changes during therapy due to blood perfusion of the fluorescent Dextran contrast agent. Figure 1-5 shows the response of a small region-of-interest within the tumor area to therapy with a significant decrease in vascular perfusion.

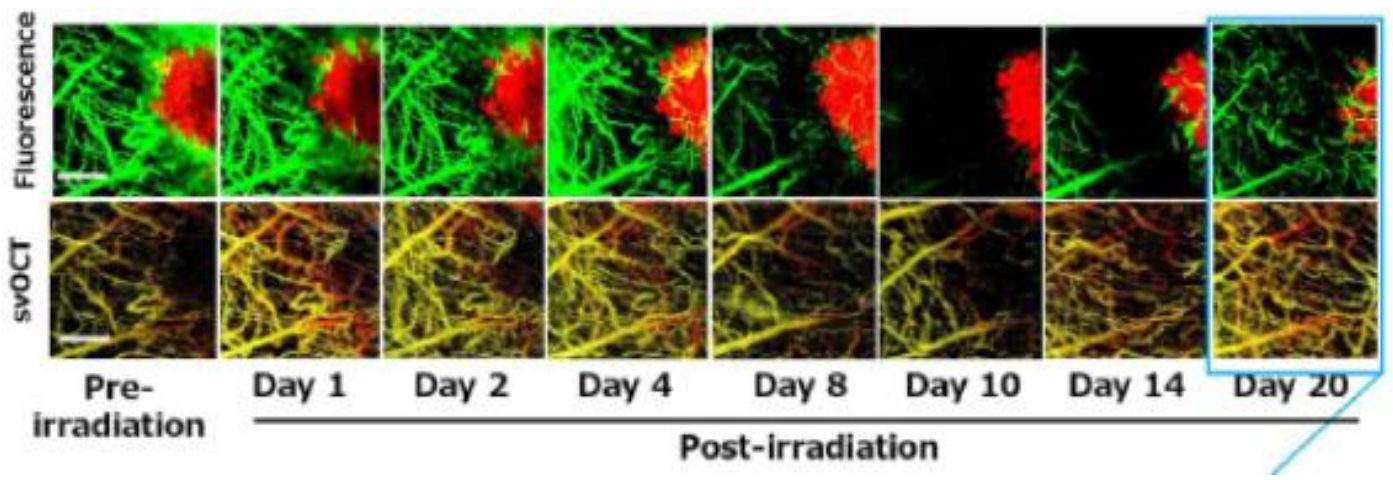

Figure 1-5: Fluorescence and svOCT imaging of response to radiation in tumor and vascular compartments in vivo. Functional changes in perfusion in the tumor microvasculature were observed. Adapted from [51].

Since OCT imaging relies on light backscattering from tissue structures, contrast agents that amplify the scattering in blood can potentially improve the detection of microvasculature morphology and functionality. Light backscattering depends not only on the refractive index difference of the contrast agent particles to the surrounding medium, but also on particle size and shape [52]. Spherical gas-filled microbubbles have been shown to enhance OCT scattering contrast in clear liquids [13].

In this thesis, spherical gas-filled microbubbles were investigated as OCT contrast agents in order to enhance svOCT image contrast of a vessel phantom. Structural and speckle variance OCT images, as well as speckle decorrelation times, were evaluated under both stationary and varying flow conditions. 


\subsection{Optical contrast agents}

Optical contrast agents introduce distinct optical properties to induce detectable changes in native tissue [53]. Current optical contrast agents include indocyanine green (ICG) [54], gold nanoparticles [55]-[58] and gold nanoshells [59]. These contrast agents have some limitations, two types of contrast agents will be described below.

One of the common type of optical contrast agents was indocyanine green, which is clinically used for NIR fluorescence [60]. The short life time of ICG in blood circulation allows repeated applications [54]. However, repeated injection of ICG is not suitable for routine clinical practice [61], [62].

Nanosized metallic absorbing and scattering particles constitute a second well-known class of optical contrast agents [56], [63]. These agents are limited by enhancing the contrast with absorption and scattering in a narrow wavelength band. There are also safety concerns surrounding nanoparticles because they can accumulate in the liver and spleen [64], [65].

The limitations and safety concerns of current optical contrast agents motivated the investigation of microbubbles for optical imaging. Microbubbles are micrometer sized shellencapsulated gas-core spheres which are FDA approved intravascular contrast agents in diagnostic ultrasound, to improve ultrasound image contrast of vessels [16], [66]-[70]. In addition to diagnostic/imaging applications, microbubbles (in combination with therapeutic ultrasound) are being investigated to enhance chemotherapy [71], radiotherapy [72] and thermal therapy with gold nanoparticles [73]. Microbubble contrast agents offer several advantages over current optical contrast agents as described below. 
Definity® microbubbles are composed of a phospholipid shell and perfluoropropane gas core schematic shown in Figure 1-6. The in vivo lifetime of MBs are typically 40 - 45 minutes following injections, MBs shrink and are lost from the blood circulation by releasing the gas into lungs and exhaling [69], [74]. The phospholipid shell also dissolves easily in the blood, resulted in no accumulation in organs [16].

Microbubbles have also been shown to have scattering properties that remain approximately constant over a band of broad optical wavelengths [75], which can be beneficial in multi-wavelength imaging modalities such as DOI and OCT. In addition, microbubbles remain well dispersed after intravascular injection, can flow with blood, and hence generate a contrast effect. Micron sized microbubbles do not leak from the vessels and circulate in the same manner as blood cells. Furthermore, microbubbles local concentration in blood can be controlled by their injection method such as perfusion or bolus [15].

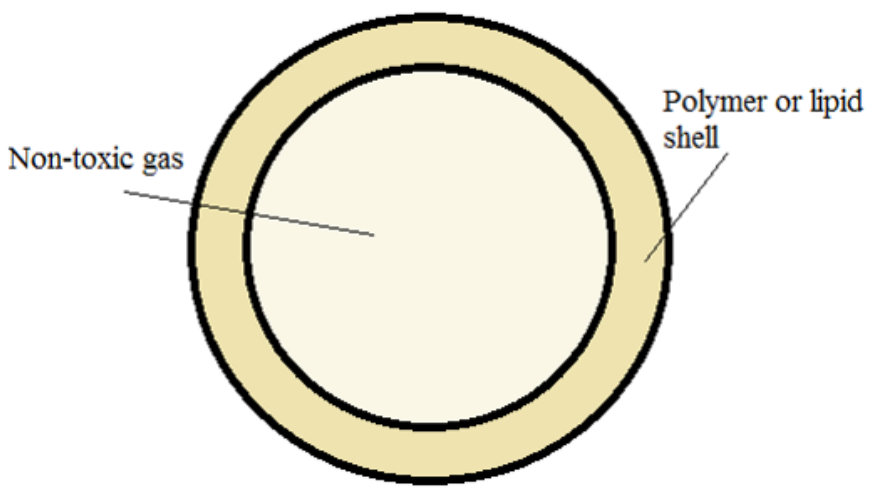

Figure 1-6: Schematic illustration of the microbubble agent particle. 


\subsection{Thesis hypothesis and specific aims}

The hypothesis of this thesis is that microbubbles enhance image contrast in diffuse optical imaging and optical coherence tomography. The objective was to investigate the effect of microbubbles on the optical image contrast. That was done by quantitatively assessing the changes in the optical properties caused by microbubbles in bulk skin phantoms and assessing of OCT image contrast enhancement with microbubbles in blood vessel phantoms.

The specific aims of the research were to:

1. Conduct integrating sphere spectroscopy to measure diffuse reflectance and total transmittance of light propagation in a broad wavelength range (300-1400nm) from a bulk skin tissue phantom with various blood volume fractions without and with microbubble contrast agents at various Definity® injection doses.

2. Estimate the absorption coefficient and reduced scattering coefficient from spectroscopic data using inverse adding doubling and to analyze the changes in these optical properties and image contrast enhancement due to the presence of microbubbles for 20 phantom conditions at $660 \mathrm{~nm}$ and $1310 \mathrm{~nm}$ wavelengths.

3. Perform optical coherence tomography centered on a $1310 \mathrm{~nm}$ wavelength for structural imaging, autocorrelation and speckle variance imaging of blood vessel phantoms to analyze the image contrast enhancement due to the presence of microbubbles. 


\subsection{Overview of the Dissertation}

Chapter 2 describes the methodology of a) spectroscopy, b) OCT and c) skin tissue phantoms which were made for each method separately.

Chapter 3 describes the experimental results of the spectroscopy studies and the estimated optical properties. The effect of various injection doses of microbubbles on contrast enhancement at various blood volume fractions were discussed.

Chapter 4 describes the OCT experimental results to evaluate the image contrast enhancement of the vessel structures in the presence of microbubble contrast agents for different blood flow conditions.

Chapter 5 summarizes the results. The spectroscopy result of contrast enhancement due to the presence of microbubbles at various injection doses were summarized. The OCT image contrast enhancement of the vessel structures in the presence of microbubble were also summarized.

Chapter 6 describes the future work. In future work the Mie simulation results were discussed to analyze the image contrast enhancement due to the presence of microbubbles and compared with the image contrast enhancement due to the presence of microbubbles in $6 \%$ bulk phantom experiments.

Appendix A presents the raw data obtained for total transmittance and diffuse reflectance spectra from the spectroscopy method for the 20 phantom conditions. 


\section{Chapter 2 Materials and Methods}

\subsection{Spectroscopy experiment}

An integrating sphere system, ISS (UV-VIS-NIR Spectrophotometer Shimadzu UV3600, double beam, Japan) consists of a hollow spherical cavity with its interior covered with a reflective coating and two holes for entrance and exit ports [76]. The spectrophotometer system has three detectors: a Photomultiplier tube (PMT) for the ultraviolet (165 nm - 380 $\mathrm{nm})$ and visible regions (380 nm - $780 \mathrm{~nm}$ ), Indium-Gallium-Arsenide (InGaAs) (700 nm $1800 \mathrm{~nm})$ and $\mathrm{PbS}(1600 \mathrm{~nm}-3300 \mathrm{~nm})$ detectors for the near-infrared region over a wide range. The spectrophotometer consists of two light sources; a 50W halogen lamp and a deuterium lamp that is switched freely in accordance with the wavelength in the range 282 to $393 \mathrm{~nm}$. The spectrophotometer grating and detector are switched at $830 \mathrm{~nm}$ and $970 \mathrm{~nm}$ wavelengths, respectively. The integrating sphere system produces a diffuse scattering after light is incident on the coating and distributes equally to all other points inside by multiple scattering reflections. Double beam integrating sphere system uses two light paths; a sample light beam and a reference light beam. The sample was placed in front of the sample light beam and an empty cuvette were placed in front of the reference light beam in this study. Two measurements are made by the sample beam and the reference beam sequentially, the reference beam is used for integrating sphere system corrections, such as a variation of the 
lamp source with wavelength, detector changes, sphere coating defects, or anything that affects the light path.

The Shimadzu UV-3600 with ISS provides the ratio of the normalized values of the TT and DR as the output by computing the ratio of the sample beam to the reference beam. The TT measurement is performed by placing the sample in front of the coherent incident light at entrance port as shown in Figure 2-1(a). The light transmitted from the sample onto the detector and the measured value becomes the total transmittance with respect to the reference beam. DR measurements are performed by placing the sample in front of the coherent incident light at exit port as shown in Figure 2-1(b). The light reflected from the sample onto the detector and the measured value becomes the diffuse reflectance with respect to the reference beam. Two cuvettes were used with one cuvette being a reference that allows most of the effects of specular reflection from surfaces to be corrected and the other cuvette were the phantom sample for both TT and DR.

The TT and DR were measured in this study in order to compute $\mu_{\mathrm{s}}^{\prime}$ and $\mu_{\mathrm{a}}$. Quartz cuvettes (Starna Cells Inc, USA) with $1 \mathrm{~mm}$ light path were used to place the bulk skin phantom solution at the integrating sphere sample port. Quartz is a transmitting medium in the range of $190 \mathrm{~nm}-2500 \mathrm{~nm}$. Spectra were obtained at visible and near infrared wavelengths $(300-1400 \mathrm{~nm})$. This range allows flexibility in choosing measured wavelengths for optical property calculations. The total transmittance and diffuse reflectance spectra for the 20 phantom conditions (four blood concentrations $0.2 \%, 1.5 \%, 3 \%$ and $6 \%$ 
v/v at five Definity® microbubble injection doses $0,25,50,83.3$ and $166 \mu \mathrm{L} / \mathrm{kg}$ ) were obtained with ISS.
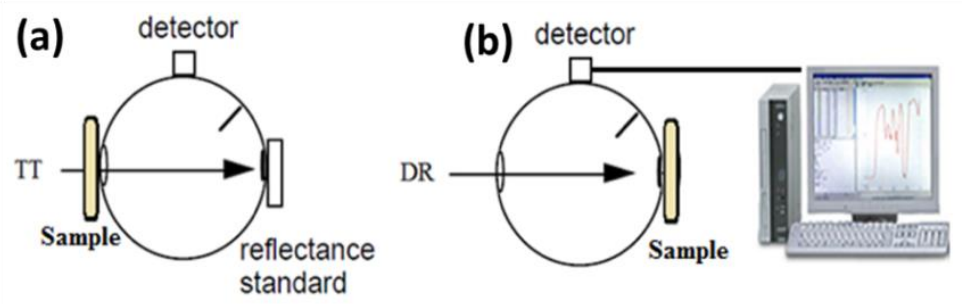

Figure 2-1: Integrating sphere system (ISS). (a) Total transmittance measurement setup. (b) Diffuse reflectance measurement setup. Baffles are placed in the sphere to block the direct path of light from a source port to a detector port. The light source is to the left as shown by the arrows.

\subsubsection{Inverse adding doubling and optical properties}

Inverse adding doubling software [77] developed by Scott Prahl was used to extract the optical properties, $\mu_{\mathrm{s}}{ }^{\prime}$ and $\mu_{\mathrm{a}}$, from DR and TT spectra for low blood concentration and high blood concentration phantom tissue conditions before and after addition of microbubbles at five Definity® injection doses.

The settings to the IAD software were (1) phantom index of refraction was assumed $1.37,(2)$ index of refraction of the top and bottom slides was 1.50 (Quartz glass), (3) sample thickness was $1.00 \mathrm{~mm}$, (4) illumination beam diameter was $7.13 \mathrm{~mm}$ (diameter of $7.13 \mathrm{~mm}$ was selected as a circle beam equivalent with an area of rectangular beam shape), (5) reflectance of the calibration standard was 0.98 (185 - $3300 \mathrm{~nm}),(6)$ number of spheres used during each measurement was 1 . The properties of sphere were Sphere diameter $(60 \mathrm{~mm})$, 
sample port diameter $(18.74 \mathrm{~mm})$, entrance port diameter $(16.73 \mathrm{~mm}$ was selected as a circle port equivalent with an area of rectangular port shape), detector port diameter $(13.12 \mathrm{~mm}$ was selected as a circle port equivalent with an area of rectangular port shape), and reflectivity of the sphere wall (0.98). A large aspect ratios for the sample is needed to let the entire beam hit the sample and avoid the light loss. Sample port diameter $(18.74 \mathrm{~mm})$ is ten times the sample thickness $(1 \mathrm{~mm})$ in this study.

Optical properties, signal enhancement and image contrast of low blood volume fraction and high blood volume fraction of phantom tissue conditions with and without microbubbles are defined by:

$\mu_{\mathrm{s}}^{\prime \mathrm{H}}$ : Reduced scattering coefficient of high blood concentration phantom tissue $\mu_{\mathrm{s}}^{\prime \mathrm{H}, \mathrm{MB}}$ : Reduced scattering coefficient of high blood concentration phantom tissue with MB $\mu_{\mathrm{s}}^{\prime \mathrm{L}}$ : Reduced scattering coefficient of low blood concentration phantom tissue $\mu_{\mathrm{s}}^{\prime L, M B}$ : Reduced scattering coefficient of low blood concentration phantom tissue with MB $\mu_{\mathrm{a}}^{\mathrm{H}}:$ Absorption coefficient of high blood concentration phantom tissue $\mu_{\mathrm{a}}^{\mathrm{H}, \mathrm{MB}}:$ Absorption coefficient of high blood concentration phantom tissue with MB $\mu_{\mathrm{a}}^{\mathrm{L}}$ : Absorption coefficient of low blood concentration phantom tissue $\mu_{\mathrm{a}}^{\mathrm{L}, \mathrm{MB}}$ : Absorption coefficient of low blood concentration phantom tissue with MB $S_{\mathrm{s}}^{\mathrm{L}}=\frac{\mu_{\mathrm{s}}^{\prime \mathrm{L}, \mathrm{MB}}}{\mu_{\mathrm{s}}^{\prime \mathrm{L}}}:$ Reduced scattering signal enhancement of low blood concentration phantom tissue 
$S_{\mathrm{s}}^{\mathrm{H}}=\frac{\mu_{\mathrm{s}}^{\prime \mathrm{H}, \mathrm{MB}}}{\mu_{\mathrm{s}}^{\prime \mathrm{H}}}:$ Reduced scattering signal enhancement of high blood concentration

phantom tissue

$S_{\mathrm{a}}^{\mathrm{L}}=\frac{\mu_{\mathrm{a}}^{\mathrm{L}, \mathrm{MB}}}{\mu_{\mathrm{a}}^{\mathrm{L}}}:$ Absorption signal enhancement of low blood concentration

phantom tissue

$S_{\mathrm{a}}^{\mathrm{H}}=\frac{\mu_{\mathrm{a}}^{\mathrm{H}, \mathrm{MB}}}{\mu_{\mathrm{a}}^{\mathrm{H}}}:$ Absorption signal enhancement of high blood concentration

phantom tissue

$C_{\mathrm{a}}=\frac{\mu_{\mathrm{a}}^{\mathrm{H}}}{\mu_{\mathrm{a}}^{\mathrm{L}}}:$ Absorption contrast

$C_{\mathrm{a}}^{\mathrm{MB}}=\frac{\mu_{\mathrm{a}}^{\mathrm{H}, \mathrm{MB}}}{\mu_{\mathrm{a}}^{\mathrm{L}, \mathrm{MB}}}:$ Absorption contrast with $\mathrm{MB}$

$\frac{C_{\mathrm{a}}^{\mathrm{MB}}}{C_{\mathrm{a}}}:$ Absorption contrast enhancement

$C_{\mathrm{s}}=\frac{\mu_{\mathrm{s}}^{\prime \mathrm{H}}}{\mu_{\mathrm{s}}^{\prime \mathrm{L}}}:$ Reduced scattering contrast

$C_{\mathrm{s}}^{\mathrm{MB}}=\frac{\mu_{\mathrm{s}}^{\mathrm{H}, \mathrm{MB}}}{\mu_{\mathrm{s}}^{\mathrm{L}, \mathrm{MB}}}:$ Reduced scattering contrast with MB

$\frac{C_{\mathrm{s}}^{\mathrm{MB}}}{C_{\mathrm{s}}}:$ Reduced scattering contrast enhanecment

To study the reduced scattering coefficient, $\mu_{\mathrm{s}}^{\prime \mathrm{L}}, \mu_{\mathrm{s}}^{\mathrm{L}, \mathrm{MB}}, \mu_{\mathrm{s}}^{\prime \mathrm{H}}, \mu_{\mathrm{s}}^{\prime \mathrm{H}, \mathrm{MB}}$ values of 20 phantoms were plotted versus the wavelength range $300-1400 \mathrm{~nm}$. The $S_{\mathrm{s}}^{\mathrm{L}}$ and $S_{\mathrm{s}}^{\mathrm{H}}$ was 
plotted versus blood concentrations for two chosen wavelengths $660 \mathrm{~nm}$ and $1310 \mathrm{~nm}$. The reduced scattering contrast enhancement $\frac{C_{\mathrm{S}}^{\mathrm{MB}}}{C_{\mathrm{s}}}$ were presented at two wavelengths.

To study the absorption coefficient, $\mu_{\mathrm{a}}^{\mathrm{L}}, \mu_{\mathrm{a}}^{\mathrm{L}, \mathrm{MB}}, \mu_{\mathrm{a}}^{\mathrm{H}}, \mu_{\mathrm{a}}^{\mathrm{H}, \mathrm{MB}}$ values of the 20 phantoms were also plotted versus wavelength range $300-1400 \mathrm{~nm}$. The $S_{\mathrm{a}}^{\mathrm{L}}$ and $S_{\mathrm{a}}^{\mathrm{H}}$ was plotted versus blood concentrations for two chosen wavelengths $660 \mathrm{~nm}$ and $1310 \mathrm{~nm}$. The reduced scattering contrast enhancement $\frac{C_{\mathrm{a}}^{\mathrm{MB}}}{C_{\mathrm{a}}}$ were also presented at the two wavelengths.

\subsubsection{Bulk tissue phantom solution (Intralipid, Human Blood, PBS)}

Diffuse Optical Imaging (DOI) detects light intensity integrated over the depth from bulk tissue to monitor spatial variations in the optical properties. Phantoms mimicking bulk tissue were used to study the effect of MBs on the optical properties. Four phantom solutions were made by mixing intralipid ( $5 \%$ v/v, diluted from $20 \%$ Stock Sigma-Aldrich, St. Louis, MO, USA), human blood $(0.2 \%, 1.5 \%, 3 \%, 6 \%$ v/v) and Phosphate-buffered saline (PBS). In this study the bulk tissue phantom with a low blood concentration $(0.2 \% \mathrm{v} / \mathrm{v})$ mimic normal tissue [27], [28] and higher blood concentrations $(1.5 \%-6 \% \mathrm{v} / \mathrm{v})$ mimics cancerous tissue [30], [78], [79].

\subsubsection{Microbubbles}

Definity® (Lantheus Medical Imaging, Billerica, MA), an ultrasound microbubble contrast agent, was used in this study. Undiluted Definity® has a concentration of $\sim 1.2 \times$ 
$10^{10} \frac{1}{m L}$ [80] with mean diameters in the range of 1.1-3.3 $\mu \mathrm{m}$ [81]. Based on equation 1 , the larger the size of scatterer (microbubble), the larger the scattering coefficient which results in higher contrast enhancement. There is a size limit of $\sim 8 \mu \mathrm{m}$ diameter of MB for in vivo use in order for the MBs to cross the capillaries [16]. The current clinical preferred size of microbubbles is around $3 \mu \mathrm{m}$ [16]. The ultrasound clinical imaging dose of Definity is $10-$ $100 \mu \mathrm{L} / \mathrm{kg}$ [82],[83]. Studies in primates proved that up to $10 \mathrm{ml} / \mathrm{kg}$ of Definity can be safely injected without affecting blood pressure [83], [84]. In order to calculate the Definity® volume fractions, $\rho_{\text {Def }}$, to add MBs into the bulk tissue phantoms the following formula was used:

$$
\rho_{\text {Def }}=B_{f} \frac{V_{\mathrm{I}}}{V_{\mathrm{B}}}
$$

where $V_{\mathrm{I}}$ is Definity ${ }^{\circledR}$ microbubble injection volume, $V_{\mathrm{B}}$ is the blood volume in the human body and $B_{f}$ is blood volume fraction in the bulk tissue phantom. Equation 12 converts Definity® microbubble injection volume to Definity® volume fraction $(v / v)$ in the phantom. $V_{\mathrm{I}}$ is the multiplication of Definity ${ }^{\circledR}$ injection dose, $D_{\mathrm{I}}$, to body mass in kilogram, $W$, given by:

$$
V_{\mathrm{I}}=D_{\mathrm{I}} W
$$

Equation 13 converts Definity® microbubble injection doses $(\mu \mathrm{L} / \mathrm{kg})$ to Definity® microbubble injection volume. In our calculation, a $60 \mathrm{~kg}$ patient has $5000 \mathrm{ml}$ blood volume. Following is an example of our calculation for $0.2 \% \mathrm{v} / \mathrm{v}$ blood phantom and a $25 \mu \mathrm{L} / \mathrm{kg}$ microbubble injection dose. Utilizing equation 12 and substituting Definity® microbubble 
injection volume, the Definity® microbubble volume fraction $v / v$ in the phantom with $0.2 \%$ blood is:

$$
\rho_{\text {Def }}=B_{f} \frac{D_{\mathrm{I}} W}{V_{\mathrm{B}}}=0.2 \% \times \frac{25 \frac{\mu L}{\mathrm{~kg}} \times 60 \mathrm{~kg}}{5 \times 10^{6} \mu L}=6 \times 10^{-7}
$$

This calculation was done for all 20 phantom conditions and is summarized in Table 2-1, Table 2-2, Table 2-3 and Table 2-4. 
Table 2-1: Volume calculations in phantom 1 with $0.2 \% \mathrm{v} / \mathrm{v}$ human blood. The first column of the table shows the Definity ${ }^{\circledR}$ microbubble injection doses $\left(\boldsymbol{D}_{\mathbf{I}}\right)$. The second column represents the Definity ${ }^{\circledR}$ volume fractions in tissue $\left(\boldsymbol{\rho}_{\text {Def }}\right)$. The third column shows the Definity® volume in the phantom solution. The fourth, fifth and seventh columns state the volume of intralipid $\left(\boldsymbol{V}_{\mathrm{IL}}\right), 0.2 \%$ Blood $\left(\boldsymbol{V}_{\mathbf{0 . 2} \%-\mathrm{B}}\right)$, and total phantom for the relevant $\boldsymbol{D}_{\mathbf{I}}$. The sixth column represents the effective volume of PBS $\left(\boldsymbol{V}_{\mathbf{P B S}}{ }_{\text {eff }}\right)$ in phantom 1.

\begin{tabular}{|l|l|l|l|l|l|l|}
\hline$D_{\mathrm{I}}(\mu \mathrm{L} / \mathrm{kg})$ & $\rho_{\text {Def }}$ & $\begin{array}{l}V_{\text {Def }}(\mathrm{L}) \\
\pm 1 \mathrm{E}-08\end{array}$ & $\begin{array}{l}V_{\mathrm{IL}}(\mathrm{L}) \\
\pm 1 \mathrm{E}-08\end{array}$ & $\begin{array}{l}V_{0.2 \%-\mathrm{B}}(\mathrm{L}) \\
\pm 1 \mathrm{E}-08\end{array}$ & $\begin{array}{l}V_{\mathrm{PBS}}(\mathrm{L}) \\
\pm 1 \mathrm{E}-03\end{array}$ & $\begin{array}{l}V_{\text {Tot }}(\mathrm{L}) \\
\pm 1 \mathrm{E}-03\end{array}$ \\
\hline 0 & $0.00 \mathrm{E}+00$ & $0.00 \mathrm{E}+00$ & $5.00 \mathrm{E}-05$ & $2.00 \mathrm{E}-06$ & $9.480000 \mathrm{E}-04$ & $1.00 \mathrm{E}-03$ \\
\hline 25 & $6.00 \mathrm{E}-07$ & $6.0 \mathrm{E}-07$ & $5.00 \mathrm{E}-02$ & $2.00 \mathrm{E}-03$ & $9.479994 \mathrm{E}-01$ & $1.00 \mathrm{E}+00$ \\
\hline 50 & $1.20 \mathrm{E}-06$ & $1.20 \mathrm{E}-06$ & $5.00 \mathrm{E}-02$ & $2.00 \mathrm{E}-03$ & $9.479988 \mathrm{E}-01$ & $1.00 \mathrm{E}+00$ \\
\hline 83.3 & $2.00 \mathrm{E}-06$ & $2.00 \mathrm{E}-06$ & $5.00 \mathrm{E}-02$ & $2.00 \mathrm{E}-03$ & $9.479980 \mathrm{E}-01$ & $1.00 \mathrm{E}+00$ \\
\hline 166 & $3.98 \mathrm{E}-06$ & $4.00 \mathrm{E}-06$ & $5.00 \mathrm{E}-02$ & $2.00 \mathrm{E}-03$ & $9.479960 \mathrm{E}-01$ & $1.00 \mathrm{E}+00$ \\
\hline
\end{tabular}

Table 2-2: Volume calculations in phantom 2 with $1.5 \% \mathrm{v} / \mathrm{v}$ human blood. The first column of the table shows the Definity® microbubble injection doses $\left(D_{\mathrm{I}}\right)$. The second column represents the Definity ${ }^{\circledR}$ volume fractions in tissue $\left(\rho_{\text {Def }}\right)$. The third column shows the Definity® volume in the phantom solution. The fourth, fifth and seventh columns state the volume of intralipid $\left(V_{\mathrm{IL}}\right), 1.5 \%$ Blood $\left(V_{1.5 \%-\mathrm{B}}\right)$, and total phantom for the relevant $D_{\mathrm{I}}$. The sixth column represents the effective volume of $\mathrm{PBS}\left(V_{\mathrm{PBS}} \mathrm{eff}_{\text {ff }}\right)$ in phantom 2.

\begin{tabular}{|l|l|l|l|l|l|l|}
\hline$D_{\mathrm{I}}(\mu \mathrm{L} / \mathrm{kg})$ & $\rho_{\text {Def }}$ & $\begin{array}{l}V_{\text {Def }}(\mathrm{L}) \\
\pm 1 \mathrm{E}-08\end{array}$ & $\begin{array}{l}V_{\mathrm{IL}}(\mathrm{L}) \\
\pm 1 \mathrm{E}-08\end{array}$ & $\begin{array}{l}V_{1.5 \%-\mathrm{B}}(\mathrm{L}) \\
\pm 1 \mathrm{E}-08\end{array}$ & $\begin{array}{l}V_{\mathrm{PBS}}(\mathrm{L}) \\
\pm 1 \mathrm{E}-03\end{array}$ & $\begin{array}{l}V_{\text {Tot }}(\mathrm{L}) \\
\pm 1 \mathrm{E}-03\end{array}$ \\
\hline 0 & $0.00 \mathrm{E}+00$ & $0.00 \mathrm{E}+00$ & $5.00 \mathrm{E}-05$ & $1.50 \mathrm{E}-05$ & $9.350000 \mathrm{E}-04$ & $1.00 \mathrm{E}-03$ \\
\hline 25 & $4.50 \mathrm{E}-06$ & $4.5 \mathrm{E}-06$ & $5.00 \mathrm{E}-02$ & $1.50 \mathrm{E}-02$ & $9.349955 \mathrm{E}-01$ & $1.00 \mathrm{E}+00$ \\
\hline 50 & $9.00 \mathrm{E}-06$ & $9.00 \mathrm{E}-06$ & $5.00 \mathrm{E}-02$ & $1.50 \mathrm{E}-02$ & $9.349910 \mathrm{E}-01$ & $1.00 \mathrm{E}+00$ \\
\hline 83.3 & $1.50 \mathrm{E}-05$ & $1.50 \mathrm{E}-06$ & $5.00 \mathrm{E}-03$ & $1.50 \mathrm{E}-03$ & $9.349850 \mathrm{E}-02$ & $1.00 \mathrm{E}-01$ \\
\hline 166 & $2.99 \mathrm{E}-05$ & $3.00 \mathrm{E}-06$ & $5.00 \mathrm{E}-03$ & $1.50 \mathrm{E}-03$ & $9.349701 \mathrm{E}-02$ & $1.00 \mathrm{E}-01$ \\
\hline
\end{tabular}


Table 2-3: Volume calculations in phantom 3 with 3\% v/v human blood. The first column of the table shows the Definity® injection doses $\left(D_{\mathrm{I}}\right)$. The second column represents the Definity ${ }^{\circledR}$ volume fractions in tissue $\left(\rho_{\text {Def }}\right)$. The third column shows the Definity® volume in the phantom solution. The fourth, fifth and seventh columns state the volume of intralipid $\left(V_{\mathrm{IL}}\right), 3 \%$ Blood $\left(V_{3 \%-\mathrm{B}}\right)$, and total phantom for the relevant $D_{\mathrm{I}}$. The sixth column represents the effective volume of $\mathrm{PBS}\left(V_{\mathrm{PBS}_{\text {eff }}}\right)$ in phantom 3.

\begin{tabular}{|l|l|l|l|l|l|l|}
\hline$D_{\mathrm{I}}(\mu \mathrm{L} / \mathrm{kg})$ & $\rho_{\text {Def }}$ & $\begin{array}{l}V_{\text {Def }}(\mathrm{L}) \\
\pm 1 \mathrm{E}-08\end{array}$ & $\begin{array}{l}V_{\mathrm{IL}}(\mathrm{L}) \\
\pm 1 \mathrm{E}-08\end{array}$ & $\begin{array}{l}V_{3 \%-\mathrm{B}}(\mathrm{L}) \\
\pm 1 \mathrm{E}-08\end{array}$ & $\begin{array}{l}V_{\mathrm{PBS}} \\
\pm 1 \mathrm{E}-03\end{array}$ & $\begin{array}{l}V_{\text {Tot }}(\mathrm{L}) \\
\pm 1 \mathrm{E}-03\end{array}$ \\
\hline 0 & $0.00 \mathrm{E}+00$ & $0.00 \mathrm{E}+00$ & $5.00 \mathrm{E}-05$ & $3.00 \mathrm{E}-05$ & $9.200000 \mathrm{E}-04$ & $1.00 \mathrm{E}-03$ \\
\hline 25 & $9.00 \mathrm{E}-06$ & $9.0 \mathrm{E}-06$ & $5.00 \mathrm{E}-02$ & $3.00 \mathrm{E}-02$ & $9.199910 \mathrm{E}-01$ & $1.00 \mathrm{E}+00$ \\
\hline 50 & $1.80 \mathrm{E}-05$ & $1.80 \mathrm{E}-06$ & $5.00 \mathrm{E}-03$ & $3.00 \mathrm{E}-03$ & $9.199820 \mathrm{E}-02$ & $1.00 \mathrm{E}-01$ \\
\hline 83.3 & $3.00 \mathrm{E}-05$ & $3.00 \mathrm{E}-06$ & $5.00 \mathrm{E}-03$ & $3.00 \mathrm{E}-03$ & $9.199700 \mathrm{E}-02$ & $1.00 \mathrm{E}-01$ \\
\hline 166 & $5.98 \mathrm{E}-05$ & $6.00 \mathrm{E}-06$ & $5.00 \mathrm{E}-03$ & $3.00 \mathrm{E}-03$ & $9.199402 \mathrm{E}-02$ & $1.00 \mathrm{E}-01$ \\
\hline
\end{tabular}

Table 2-4: Volume calculations in phantom 4 with $6 \% \mathrm{v} / \mathrm{v}$ human blood. The first column of the table shows the Definity ${ }^{\circledR}$ microbubble injection doses $\left(D_{\mathrm{I}}\right)$. The second column represents the Definity ${ }^{\circledR}$ volume fractions in tissue $\left(\rho_{\text {Def }}\right)$. The third column shows the Definity ${ }^{\circledR}$ volume in the phantom solution. The fourth, fifth and seventh columns state the volume of intralipid $\left(V_{\mathrm{IL}}\right), 6 \%$ Blood $\left(V_{6 \%-\mathrm{B}}\right)$, and total phantom for the relevant $D_{\mathrm{I}}$. The sixth column represents the effective volume of PBS $\left(V_{\mathrm{PBS}_{\text {eff }}}\right)$ in phantom 4.

\begin{tabular}{|l|l|l|l|l|l|l|}
\hline$D_{\mathrm{I}}(\mu \mathrm{L} / \mathrm{kg})$ & $\rho_{\text {Def }}$ & $\begin{array}{l}V_{\text {Def }}(\mathrm{L}) \\
\pm 1 \mathrm{E}-08\end{array}$ & $\begin{array}{l}V_{\mathrm{IL}}(\mathrm{L}) \\
\pm 1 \mathrm{E}-08\end{array}$ & $\begin{array}{l}V_{6 \%-\mathrm{B}}(\mathrm{L}) \\
\pm 1 \mathrm{E}-08\end{array}$ & $\begin{array}{l}V_{\mathrm{PBS}}(\mathrm{Lff} \\
\pm 1 \mathrm{E}-03\end{array}$ & $\begin{array}{l}V_{\text {Tot }}(\mathrm{L}) \\
\pm 1 \mathrm{E}-03\end{array}$ \\
\hline 0 & $0.00 \mathrm{E}+00$ & $0.00 \mathrm{E}+00$ & $5.00 \mathrm{E}-05$ & $6.00 \mathrm{E}-05$ & $8.900000 \mathrm{E}-04$ & $1.00 \mathrm{E}-03$ \\
\hline 25 & $1.80 \mathrm{E}-05$ & $1.8 \mathrm{E}-06$ & $5.00 \mathrm{E}-03$ & $6.00 \mathrm{E}-03$ & $8.899820 \mathrm{E}-02$ & $1.00 \mathrm{E}-01$ \\
\hline 50 & $3.60 \mathrm{E}-05$ & $3.60 \mathrm{E}-06$ & $5.00 \mathrm{E}-03$ & $6.00 \mathrm{E}-03$ & $8.899640 \mathrm{E}-02$ & $1.00 \mathrm{E}-01$ \\
\hline 83.3 & $6.00 \mathrm{E}-05$ & $6.00 \mathrm{E}-06$ & $5.00 \mathrm{E}-03$ & $6.00 \mathrm{E}-03$ & $8.899400 \mathrm{E}-02$ & $1.00 \mathrm{E}-01$ \\
\hline 166 & $1.20 \mathrm{E}-04$ & $1.20 \mathrm{E}-06$ & $5.00 \mathrm{E}-04$ & $6.00 \mathrm{E}-04$ & $8.898805 \mathrm{E}-03$ & $1.00 \mathrm{E}-02$ \\
\hline
\end{tabular}




\subsubsection{Optical stability of MBs solution}

The time variance of the photometric value at $550 \mathrm{~nm}$ wavelength (maximum peak sensitivity wavelength for PMT detector) was measured for diluted microbubbles to investigate the stability of the MB solution. The spectra of $2.5 \%$ Definity® microbubble (can be equivalent to the $2 \mathrm{~mL} / \mathrm{kg}$ Definity ${ }^{\circledR}$ microbubble injection dose) stability in distilled and purified water is shown in Figure 2-2 as an example. The transmittance change in first 5 minutes is less than $0.1 \%$. That indicates the microbubble redistribution within the optical sampling zone is not significant over the time of a single sample data collection of TT in 4 minutes.

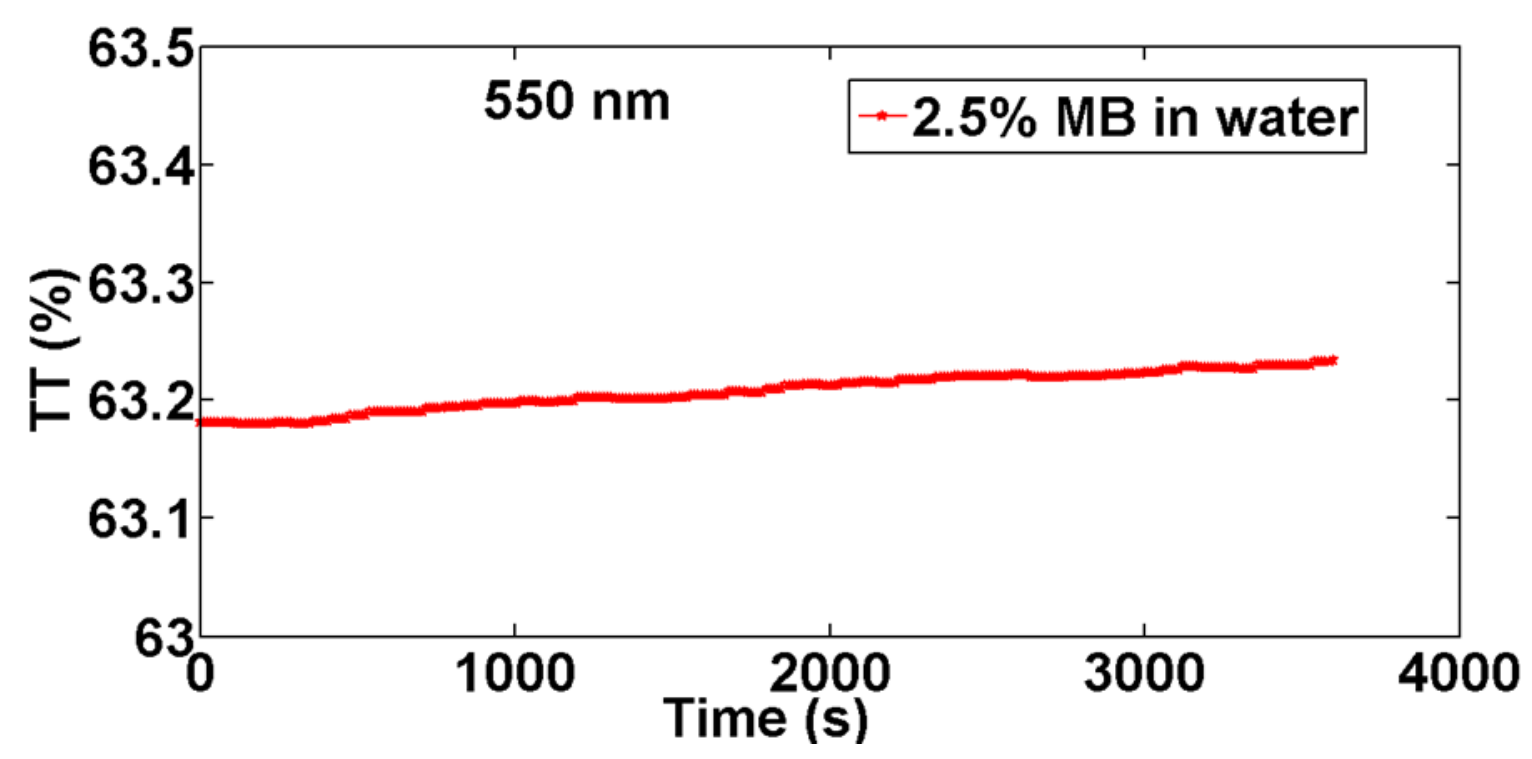

Figure 2-2: Time course graph to investigate MBs stability diluted in water. Total transmittance change in first 5 minutes is less than $0.1 \%$ at wavelength $550 \mathrm{~nm}$. 


\subsubsection{Ethic approval for use of human blood}

Ethics approval was granted in 2015 by the Research Ethics Boards of Ryerson University and the Canadian Blood Services. All experiments were conducted using whole blood donated by healthy volunteers recruited by the Canadian Blood Services' Network Center for Applied Development (Vancouver, BC, Canada). The whole blood was one week old and contained 14\% Citrate Phosphate Dextrose anticoagulant in $1 \mathrm{~L}$ blood bag.

As mentioned, the average blood content in healthy skin tissue were considered approximately $0.2 \% \mathrm{v} / \mathrm{v}$ which assumed to be uniformly distributed in skin [29]. Blood volume fraction is larger in malignant skin tissues compared to the corresponding healthy ones [31].

\subsubsection{Optimal wavelength selection}

Optical properties are wavelength dependent and DOI and OCT utilize light in the near infrared region to measure the optical properties of tissue. The choice of a specific wavelength band is dependent on the absorption and scattering property of the tissue of interest. A wavelength range of $650-1400 \mathrm{~nm}$ is well suited for DOI and OCT [85] where tissue transparency is relatively high. $1310 \mathrm{~nm}$ light is commonly used for highly scattering tissues such as skin because of low absorption and scattering at this wavelength, resulting in improved depth penetration. The choice of wavelength may also depend on the availability light sources rather than any theoretical considerations. For example, due to relatively low priced light sources $632.8 \mathrm{~nm}$ are commonly used in DOI [86]. Wavelengths of $660 \mathrm{~nm}$ and $1310 \mathrm{~nm}$ were chosen in this study to evaluate variations in the optical properties, signal 
enhancement and DOI contrast enhancement of the bulk tissue due to the presence of microbubbles. $1310 \mathrm{~nm}$ was also chosen to evaluate the OCT contrast enhancement of the blood due to the presence of microbubbles.

\subsubsection{Statistical analysis method}

The effect of four microbubble doses on the $\mu_{\mathrm{a}}^{\prime}$ and $\mu_{\mathrm{a}}$ of each of the phantom was assessed statistically using one-tailed independent sample t-test between "without MB" and “with MB" for same blood concentration with a significance level at 0.05 . The one-tailed independent sample t-test between two concentrations of blood were also conducted for the same microbubbles dose with a significance level at 0.05 , which is a standard in the analysis of clinical trials [87]. The normality of the data sets was tested using Shapiro-Wilk test in SPSS software (IBM SPSS statistics 24) and data was found to be normally distributed.

\subsection{Optical coherence tomography method}

A swept source OCT system [88] was used in this thesis. A $36 \mathrm{kHz}$ short cavity laser source with a polygon-based tuneable filter and wavelength centred at $1310 \mathrm{~nm}$ had a sweep range of $110 \mathrm{~nm}$ and an average output power of $40 \mathrm{~mW}$. The system contained a 50/50 Mach-Zender interferometer and an imaging probe mounted on 3-axis micro-positioning stage in the sample arm. A dual-balanced photo detector was used in the output arm of the interferometer for DC signal component removal. A fiber Bragg grating provided the A-scan trigger at the beginning of each laser sweep. An OCT signal recalibration was performed with a standard Mach-Zender recalibration interferometer to generate linear k-space data 
from the raw data sampled with a $125 \mathrm{MS} / \mathrm{s}$ data acquisition card. After the data was equally spaced in k-space, it was inversely Fourier transformed for further analysis. The axial resolution (in air) of the system was $8 \mu \mathrm{m}$. The experimental setup is shown in Figure 2-3. In this study microbubbles are investigated as intravascular OCT contrast agents. Four scattering tissue phantoms with two embedded microtubes $(300 \mu \mathrm{m}$ and $600 \mu \mathrm{m})$ were fabricated to model vascular blood flow. One microtube was filled with human blood, and the other with a mixture of human blood+MB as shown in Figure 2-3.

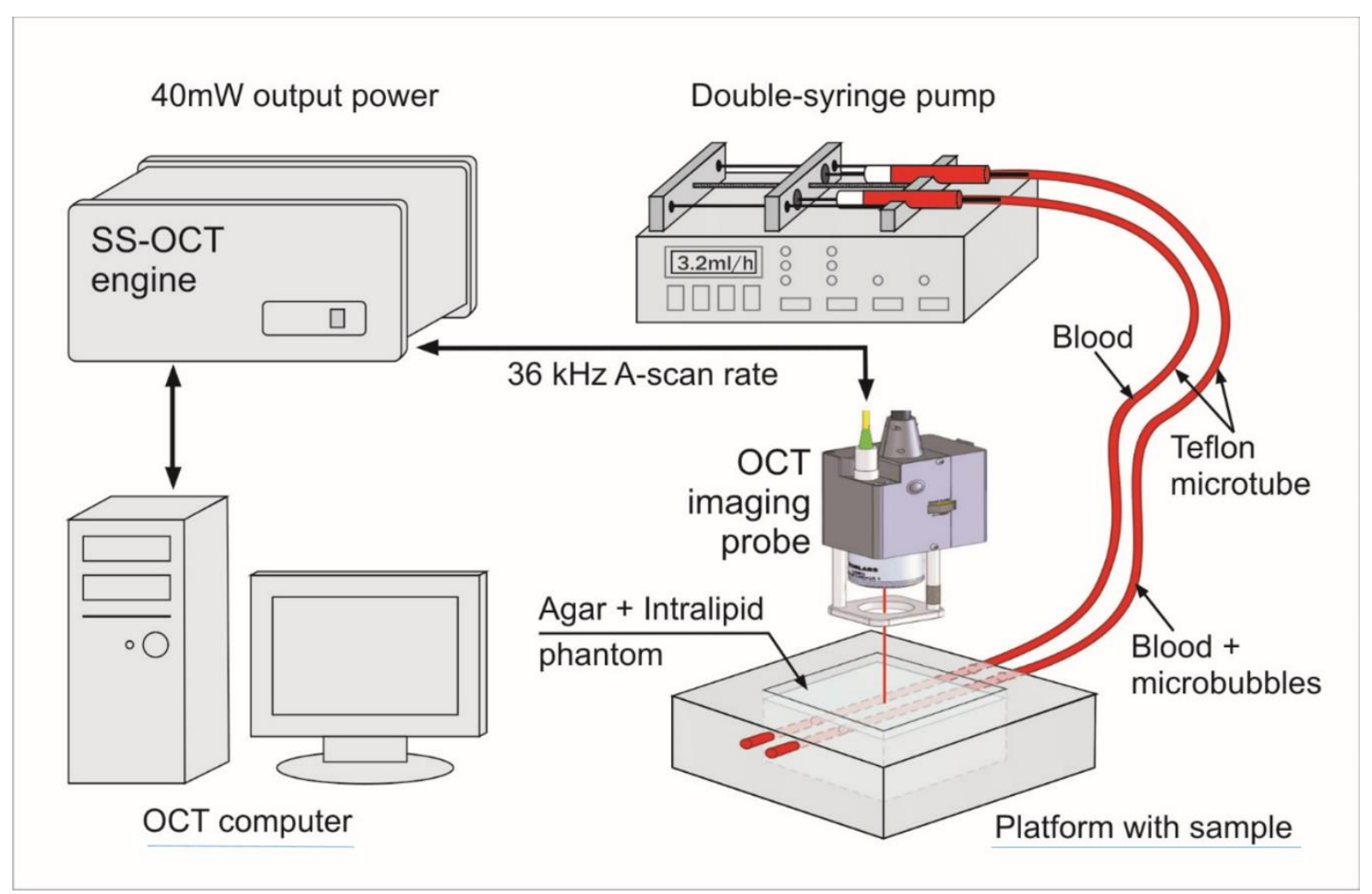

Figure 2-3: OCT Experimental setup.

OCT imaging was performed for both stationary and various flow velocity conditions for blood (left microtube on subsequent images) and blood+MB mixture (right microtube) 
achieved by double syringe pump. Data were recorded using Thorlabs software (Thorlabs Inc., Newton, NJ) in 1-, 2- and 3-dimensional modes. OCT was used to assess the image contrast enhancement of blood vessel phantoms before and after adding MBs to human blood. This phantom experiment helped us to study the potential of using MBs as optical contrast agents to enhance the OCT visualisation of blood vessels in micron size.

\subsubsection{Structural OCT image}

By combining adjacent axial OCT A-scans, a two dimensional structural image can be created which is commonly used for depicting vessel structure morphology. The first structural image (cross sectional image) was in ophthalmology and depicted a human eye; enabling the analysis of details of tissue structures [12]. The source of structural OCT image contrast is the refractive index mismatches of the optical scatterers. In this thesis a typical OCT cross sectional structural image is presented to identify the microtubes via contrast visibility in the phantom. Comparing the structural image with the other OCT imaging techniques such as speckle variance helps to understand the MB-enhanced OCT mechanism.

2D images (B-scans) of each phantom were acquired with $4 \mathrm{~mm}$ of lateral scanning. Matlab software (Matlab, Mathworks, Natick, MA, USA) was used for data processing. Images of both blood and blood $+\mathrm{MB}$ microtubes were used to quantify the difference in phantom contrasts. Since the majority of the signal from the bottom of the microtube was low due to the high absorption of blood, the ROI was chosen as the top-half circular section of the microtube lumen shown on Figure 2-4. The averaged ROI intensity was used to 
quantify the contrast by Weber equation:

$$
C_{\mathrm{W}}=\frac{I-I_{0}}{I_{0}}
$$

where $I$ is the average intensity within ROI and $I_{0}$ is the average intensity of the background $\mathrm{ROI}_{0}$. The background $\mathrm{ROI}_{0}$ was chosen to be in the middle of the phantom between the microtubes, at the same depth shown in Figure 2-4.

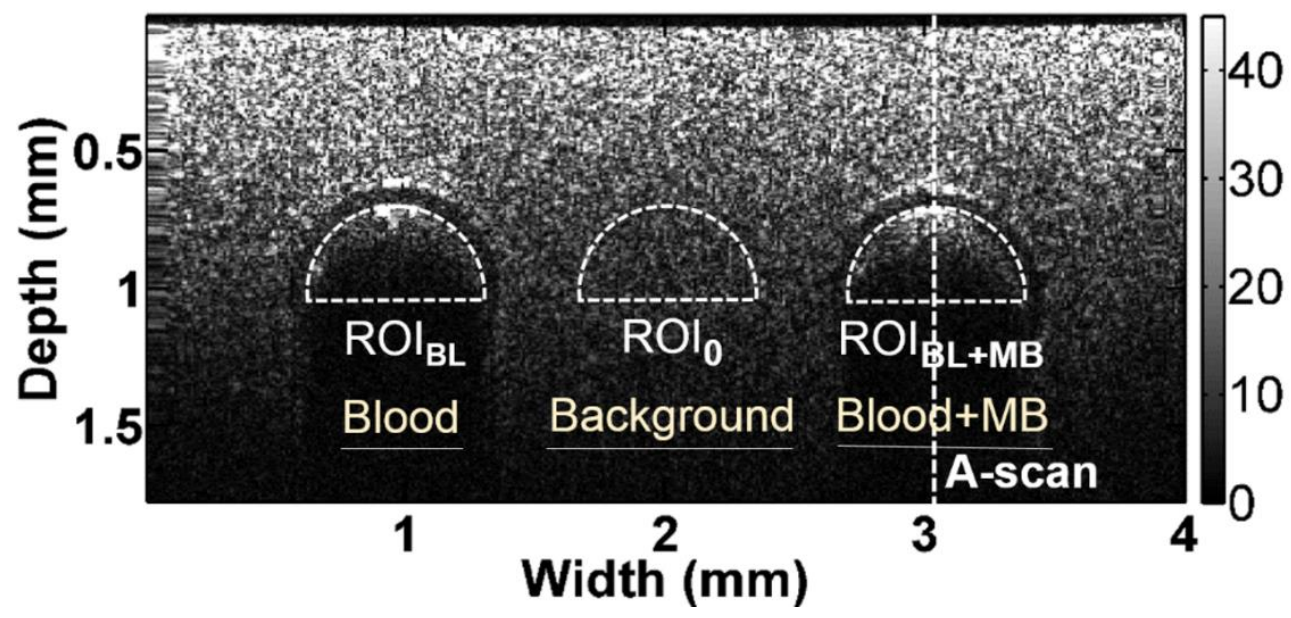

Figure 2-4: Typical structural B-scan of the phantom. The left microtube was filled with blood, and the right with blood+MBs (2.5\% volume fraction of a stock suspension were injected into the blood microtube). ROIs of blood and blood+MB mixture are labeled with half-circles at the top circular section of microtube lumens. Background ROI was chosen at the same depth as shown. The vertical dashed line indicates the location of the acquired A-scans.

\subsubsection{Autocorrelation}

A-scans were acquired from both microtubes in order to quantify microbubbleinduced differences in OCT signal intensities. The autocorrelation function, defined in equation 10, was calculated from 18 pixels along the chosen A-line within the region of 
interest (ROI) of the corresponding microtube. The average of speckle decorrelation times (1/e level) of these 18 pixels were then recorded and are shown in the results section. For each phantom, A-scans were recorded continuously for 8 seconds with the optical beam positioned at the centre of the chosen microtube (with blood and blood+MB) at various average flow velocities $(0,0.5,1,2,3,5,8$, and $12 \mathrm{~mm} / \mathrm{s})$. Each resultant record of 288,000 A-scans was divided into 240 intervals of $N=1200$ A-scans with $33 \mathrm{~ms}$ acquisition time. ACFs were computed for each interval and then averaged.

\subsubsection{Speckle variance OCT images}

3D OCT images were acquired in speckle variance (sv) mode in order to obtain sv average intensity projections for a $3 \times 1 \times 1 \mathrm{~mm}^{3}$ data volume as previously described [88], with the number of sequential same-location B-scans, $N=8$ defined in equation 11, with $25 \mathrm{~ms}$ step size in the slow-axis $(\mathrm{Y})$ direction. To achieve higher SNR, the gate length $(N)$ was optimized and $N=8$ was found (1) fast enough for lower BTM (bulk tissue phantom motion) [50] and (2) sufficiently slow to ensure complete inter-frame decorrelation for pixels representing blood [50]. Statistical analysis was performed using SPSS statistics software, using results from the four identical independent phantoms for any given experimental point. Results with $p<0.05$ were considered statistically significant.

\subsubsection{Skin tissue phantoms for OCT}

To model biological tissue, solid phantoms were made by heating 1\% TCBS agar 
(Sigma-Aldrich, MO, USA) and 2\% v/v Intralipid (stock solution with $20 \%$ intralipid concentration, Sigma-Aldrich, St. Louis, MO, USA) diluted in distilled water. Intralipid mimics the scattering properties of epidermis skin tissue [89]. Agar solidifies the resultant suspension upon cooling. The heated mixture was cooled in chambers containing two microtubes (Zeus medical tubing, Orangeburg, SC 29115 USA) to simulate blood vessels shown in Figure 2-5. Four identical independent phantom chambers contained two microtubes with internal diameters of $600 \mu \mathrm{m}$, and $300 \mu \mathrm{m}$ were produced. A double-syringe high-precision pump (Model NE-4002X, New Era Pump Systems, Farmingdale, NY, USA) was used to produce blood flow in two microtubes simultaneously at various average flow velocities. The average blood flow velocities in both microtubes were $0,0.5,1,2,3,5,8$, and $12 \mathrm{~mm} / \mathrm{s}$ (corresponding to venules, capillaries and arterioles [90], [91]). Blood flow was laminar in the microtube, which refers to streamline movement of blood. In laminar flow the blood flow velocity is zero for the layer in contact with the tube wall and highest at the center of the tube lumen. Therefore, average flow velocity is defined as the average speed though a cross section which is half of the maximum velocity.

OCT measurements under both no-flow and flow conditions were conducted. One syringe was filled with blood, the other - with the mixture of blood (same blood concentration as the other syrange) and microbubbles (MBs). Rotating magnets inside both syringes were used to mix the blood solution and prevent the microbubbles from floating up during the experiments. 


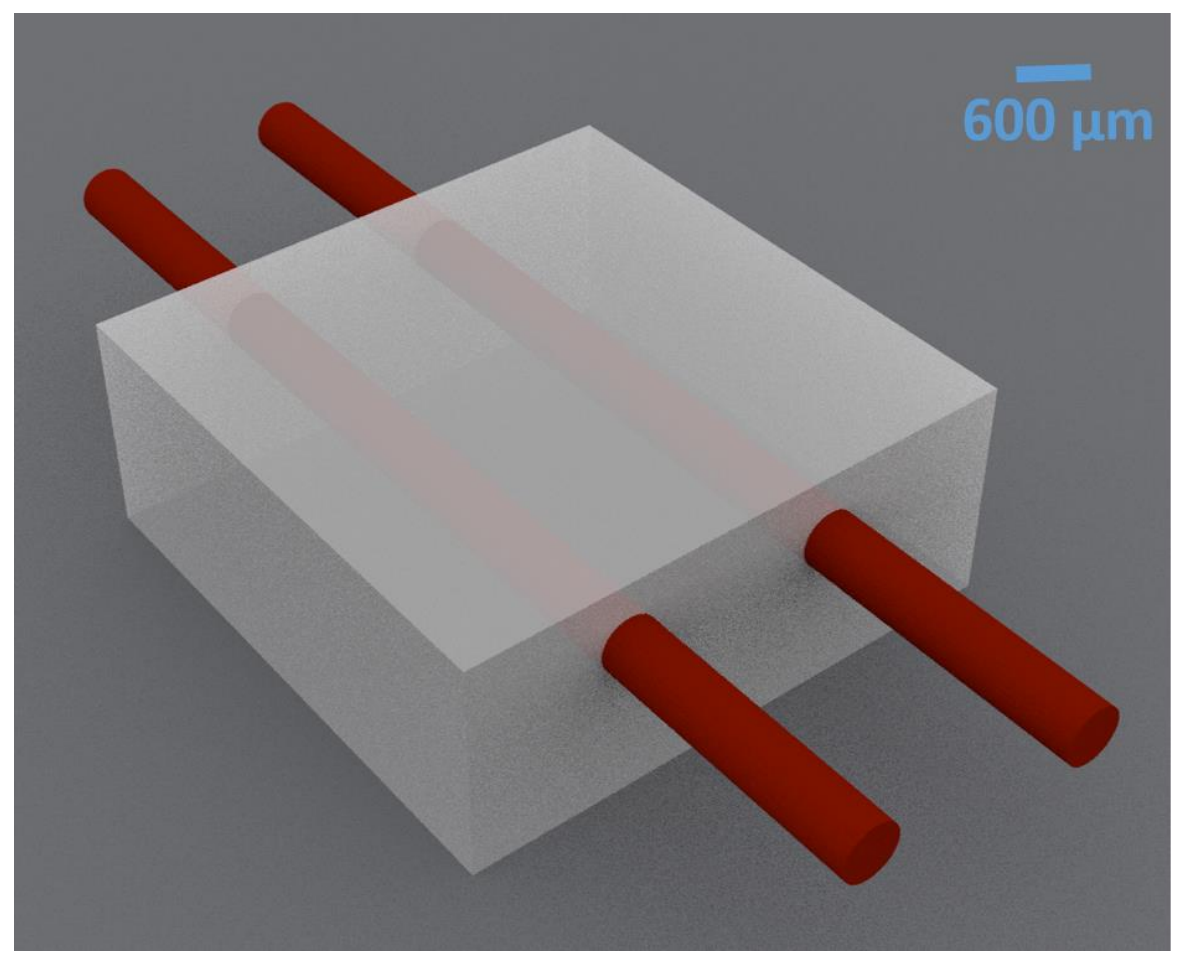

Figure 2-5: Schematic of two embedded blood vessel skin phantom fabricated for OCT experiment.

\subsubsection{Microbubbles in OCT experiments}

Definity® microbubble (perflutren lipid microspheres, Lantheus Medical Imaging, Billerica, MA), were used in OCT experiments [75]. A 2.5\% volume fraction of Definity® stock suspension was injected into the blood microtubes. The $2.5 \%$ microbubbles volume fraction is equivalent to the $2 \mathrm{~mL} / \mathrm{kg}$ Definity ${ }^{\circledR}$ microbubble injection dose based on the equation 12, considering a $60 \mathrm{~kg}$ patient with $5000 \mathrm{~mL}$ blood in body. The considered injection dose for OCT experiment is less than the maximum tolerated dose $10 \frac{\mathrm{mL}}{\mathrm{kg}}$ [83], [84].

A higher volume fraction of Definity® microbubble were used in OCT compared to 
DOI experiments. The MBs applied to create an increase in contrast must be at least $2.5 \%$ Definity ${ }^{\circledR}$ volume fraction to reach a contrast enhancement of $\sim 1.1$ times in structural OCT images (which is the minimum contrast enhancement required to detect OCT image modification). 


\section{Chapter 3 Tissue optical properties in}

\section{presence of microbubbles}

\subsection{Optical properties}

The absorption and reduced scattering coefficient spectra for the 20 phantom conditions (four blood concentrations $0.2 \%, 1.5 \%, 3 \%$ and $6 \% \mathrm{v} / \mathrm{v}$ at five Definity ${ }^{\circledR}$ microbubble injection doses $0,25,50,83.3,166 \mu \mathrm{L} / \mathrm{kg}$ ) are shown as mean $\pm \mathrm{SD}$ from three identical independent phantoms over $300-1400 \mathrm{~nm}$ wavelengths in Figure 3-2 and Figure 3-8. The standard deviations (SD) are shown with interval of every $40 \mathrm{~nm}$ wavelengths. In addition, the signal-enhancement in $\mu_{\mathrm{s}}{ }^{\prime}$ and $\mu_{\mathrm{a}}$ due to the presence of microbubbles at two wavelengths $660 \mathrm{~nm}$ and $1310 \mathrm{~nm}$ versus blood concentration are shown in Figure 3-4 and Figure 3-10, respectively. Furthermore, the reduced scattering contrast enhancement and absorption contrast enhancement versus Definity ${ }^{\circledR}$ microbubble injection doses are shown in Figure 3-6 and Figure 3-12, respectively. The total transmittance (TT) and diffuse reflectance (DR) spectra for the 20 phantom conditions shown as mean \pm SD from three identical independent phantoms are presented in appendix A.

\subsection{Reduced scattering coefficient $\left(\mu_{\mathrm{s}}{ }^{\prime}\right)$}

The reduced scattering coefficient spectra for the 20 phantom conditions are shown as mean $\pm \mathrm{SD}$ from three identical independent phantoms in Figure 3-2. The reduced scattering 
coefficients of the bulk skin-phantom is wavelength dependent and decreased with wavelength. In addition, around $410 \mathrm{~nm}$ (Soret band) and $542 \mathrm{~nm}$ and $576 \mathrm{~nm}$ (Q bands), the spectrum deviates from a monotonic dependence, which is more apparent at higher blood concentrations; this is due to hemoglobin absorption bands [27]. The $\mu_{\mathrm{s}}{ }^{\prime}$ deviations from a monotonic dependence increases with the blood concentration (Figure 3-2(d)). This behaviour is explained by anomalous light dispersion which coincides with the region of maximum absorption [92], [93]. The reduced scattering coefficient at $830 \mathrm{~nm}$ and $970 \mathrm{~nm}$ wavelengths decreases abruptly due to changes in the spectroscope grating and detector wavelength. The reduced scattering coefficient results of the skin bulk tissue phantom in this thesis are in general agreement with those given in the literature for human skin shown in Figure 3-1 [27]. 


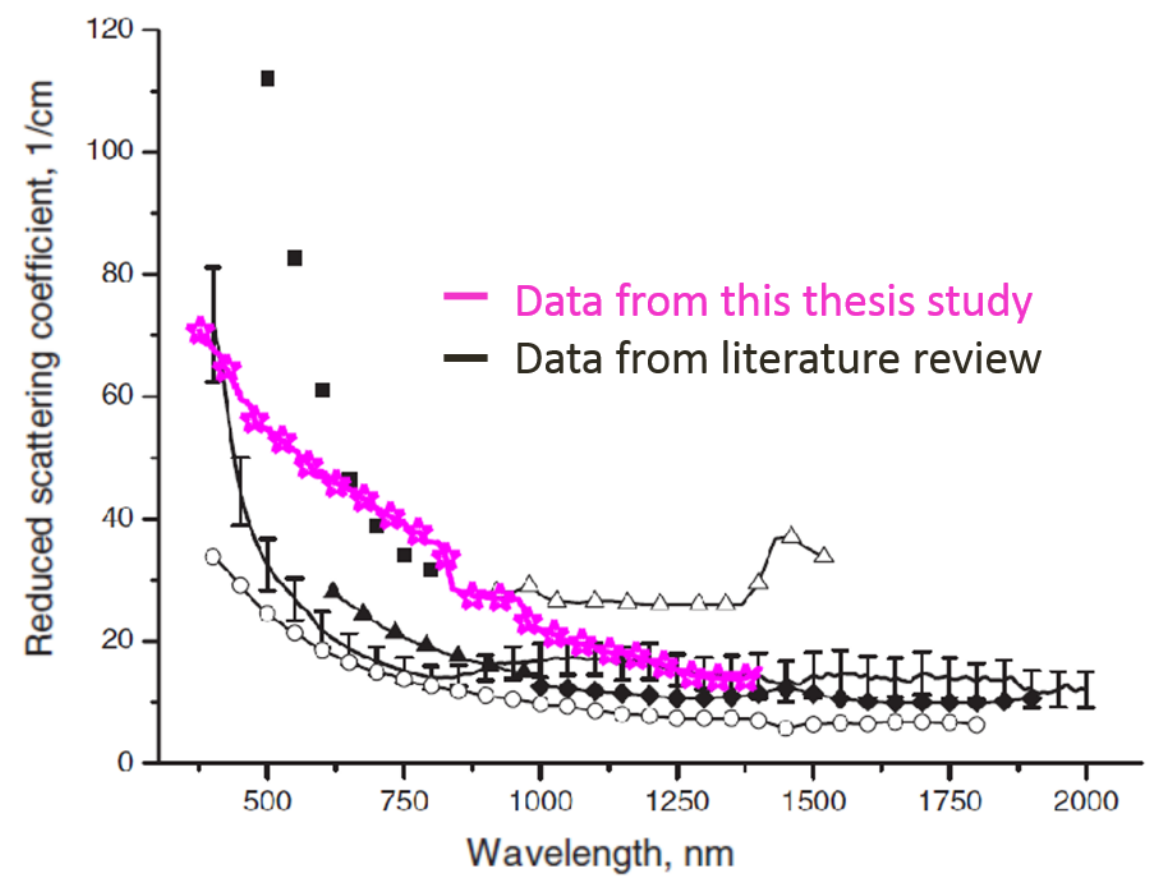

Figure 3-1: Reduced scattering coefficient spectra measured in this thesis for the tissue phantom with low blood concentration $(0.2 \% \mathrm{v} / \mathrm{v})$ in color (Asterisk) compared with reduced scattering coefficient spectra of human skin in vitro from the literature review in black adapted from [27]. Reduced scattering coefficient results in this thesis are in general agreement with published values.

We expected that the reduced scattering coefficient increases with increasing blood concentrations, where the scattering coefficient is proportional to the particle concentration and increases proportionally to the volume fraction of the blood as observed in the longer wavelength (Figure 3-2). However, a smaller $\mu_{\mathrm{s}}{ }^{\prime}$ value are observed with increased blood concentration at the blood absorption peaks $(410,542$ and $576 \mathrm{~nm})$. This can also be explained by anomalous light dispersion due to the high absorption [93] that produces a significant decrease of the anisotropy factor and the scattering coefficient within the absorption band [27]. 
In the presence of four Definity® microbubble injection doses, the reduced scattering coefficient increases with the $D_{\mathrm{I}}$ for higher blood concentrations (3\% v/v and $6 \% \mathrm{v} / \mathrm{v}$ blood). There is a statistical difference in reduced scattering coefficient of bulk tissue phantom with and without MBs with significance level at 0.05 . Increasing the $D_{\mathrm{I}}$ provide significant changes in $\mu_{\mathrm{s}}{ }^{\prime}$ for higher blood concentration $(6 \% \mathrm{v} / \mathrm{v})$. Analysis of the microbubble contribution to the reduced scattering coefficient is discussed in the following section 3.2.1. 

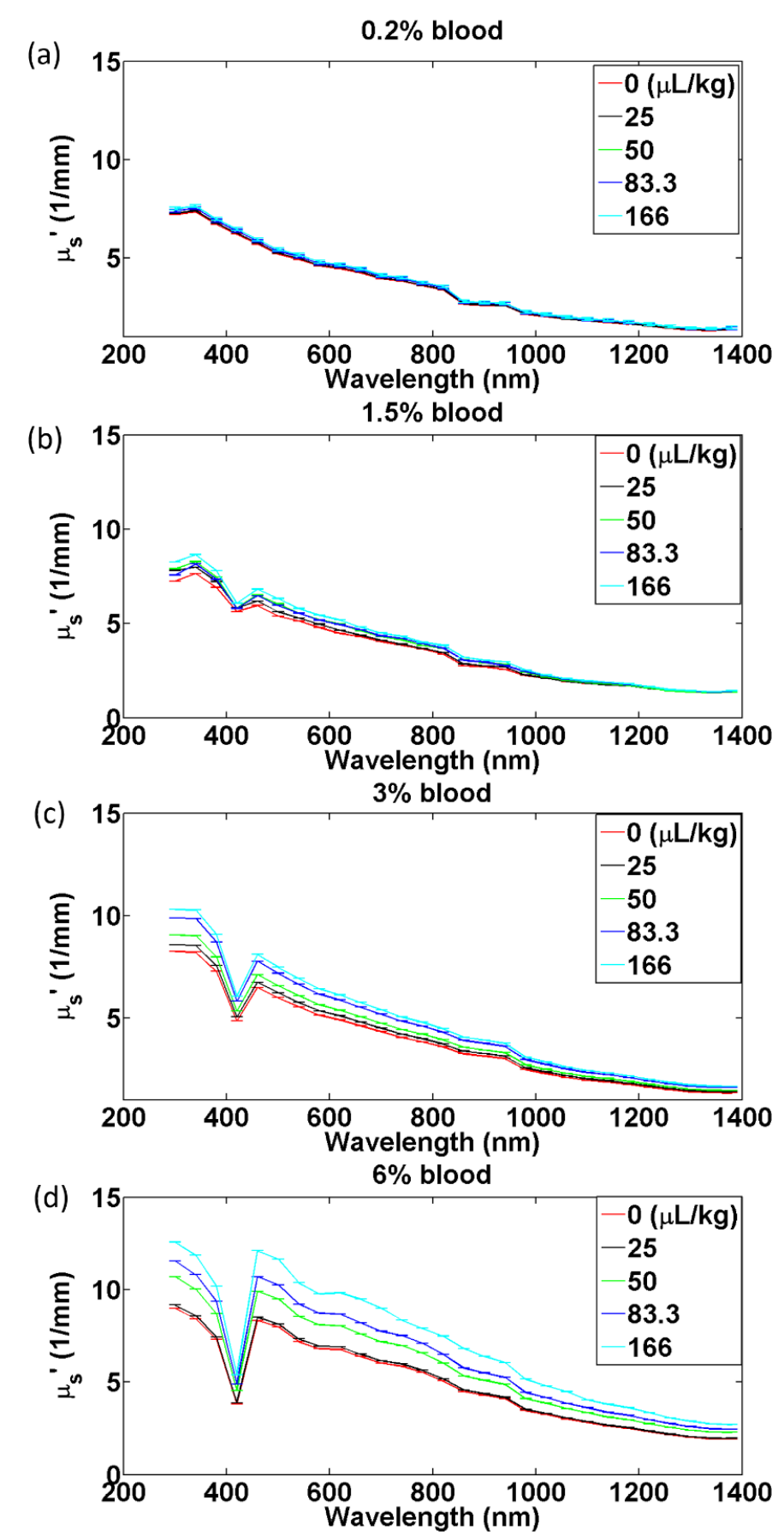

Figure 3-2: The reduced scattering coefficient for the 20 phantom conditions (four blood concentrations at five Definity ${ }^{\circledR}$ microbubble injection doses $(0,25,50,83.3,166 \mu \mathrm{L} / \mathrm{kg}$ )) (a) $0.2 \%$ blood, (b) $1.5 \%$ blood, (c) $3 \%$ blood, (d) $6 \%$ blood. The error bars correspond to the values of standard deviation (SD) of three samples. 


\subsubsection{The effect of microbubbles on $\mu_{\mathrm{s}}{ }^{\prime}$ at wavelengths $660 \mathrm{~nm}$ and $1310 \mathrm{~nm}$}

The reduced scattering coefficient versus four blood concentrations are shown in Figure 3-3 at wavelengths $660 \mathrm{~nm}$ and $1310 \mathrm{~nm}$. The corresponding $\mu_{\mathrm{s}}{ }^{\prime}$ enhancement for low blood concentration $\left(S_{\mathrm{s}}^{\mathrm{L}}\right)$ and high blood concentration $\left(S_{\mathrm{s}}^{\mathrm{H}}\right)$ are shown in Figure 3-4.

In general, a higher $\mu_{s}^{\prime}$ value was achieved at $660 \mathrm{~nm}$ compared to $1310 \mathrm{~nm}$ for the low blood concentration phantom tissue (Figure 3-3) which is consistent with the spectral behaviour of the scattering properties of normal biological tissues [27]. A maximum reduced scattering coefficient was observed at a max concentrations of MBs and blood used in this study.

At $660 \mathrm{~nm}$, a $\mu_{\mathrm{s}}{ }^{\prime}$ of $4.93,5.33,5.57,6.33$ and $6.68(1 / \mathrm{mm})$ was measured at microbubble doses of $0,25,50,83.3$ and $166 \mu \mathrm{L} / \mathrm{kg}$ (Figure 3-3a) corresponding to a signal enhancement of 1.08, 1.13, 1.28 and 1.35 times (Figure 3-4a) at 6\% blood, respectively. At $1310 \mathrm{~nm}$ and for the $6 \%$ blood phantom, $\mu_{\mathrm{s}}{ }^{\prime}$ of $1.98,2.02,2.36,2.55$ and $2.81(1 / \mathrm{mm})$ was observed at microbubble doses of $0,25,50,83.3$ and $166 \mu \mathrm{L} / \mathrm{kg}$ (Figure 3-3b) corresponding to signal enhancement of 1.02, 1.19, 1.28 and 1.41 times (Figure 3-4b), respectively. 
(a)

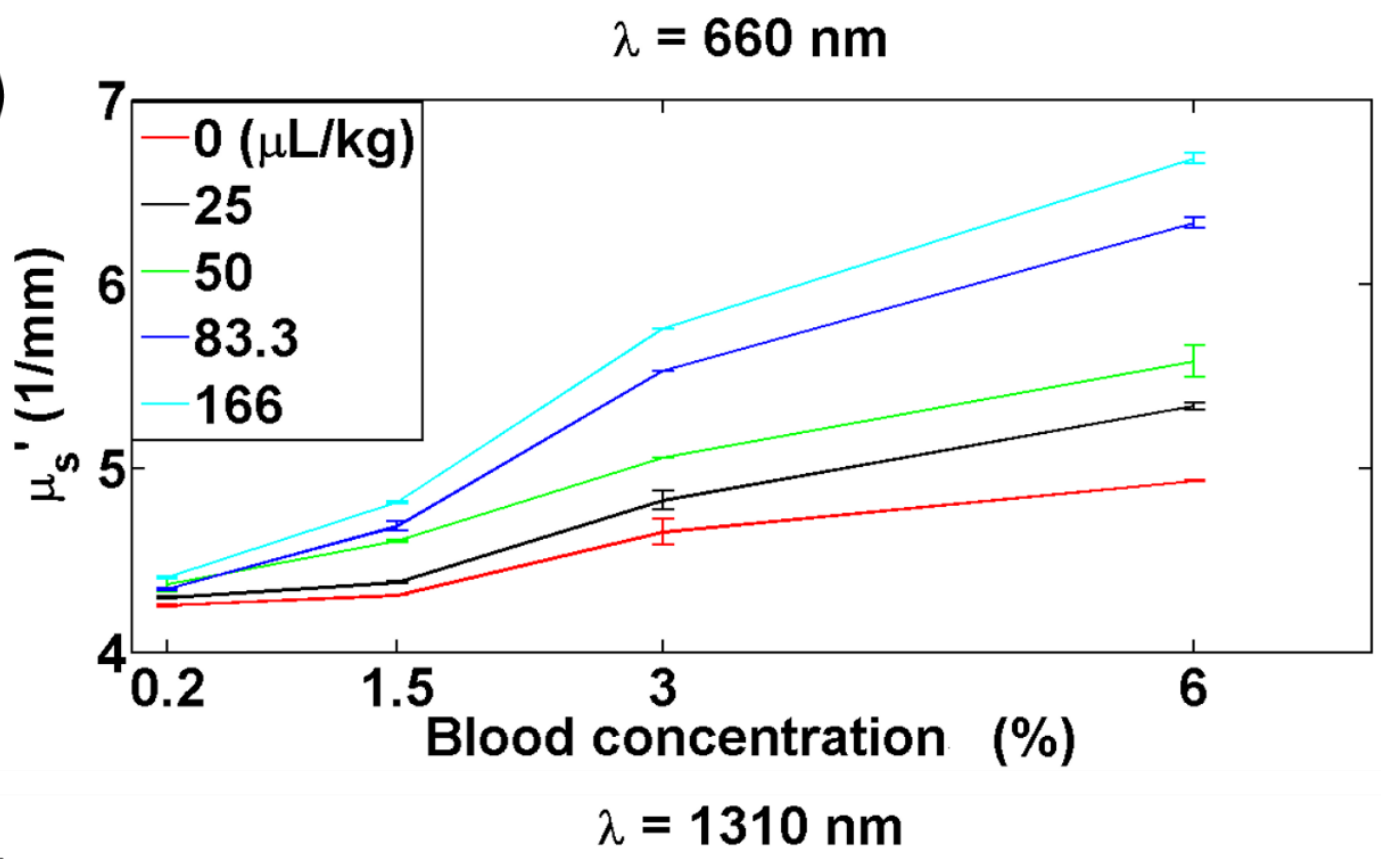

(b)

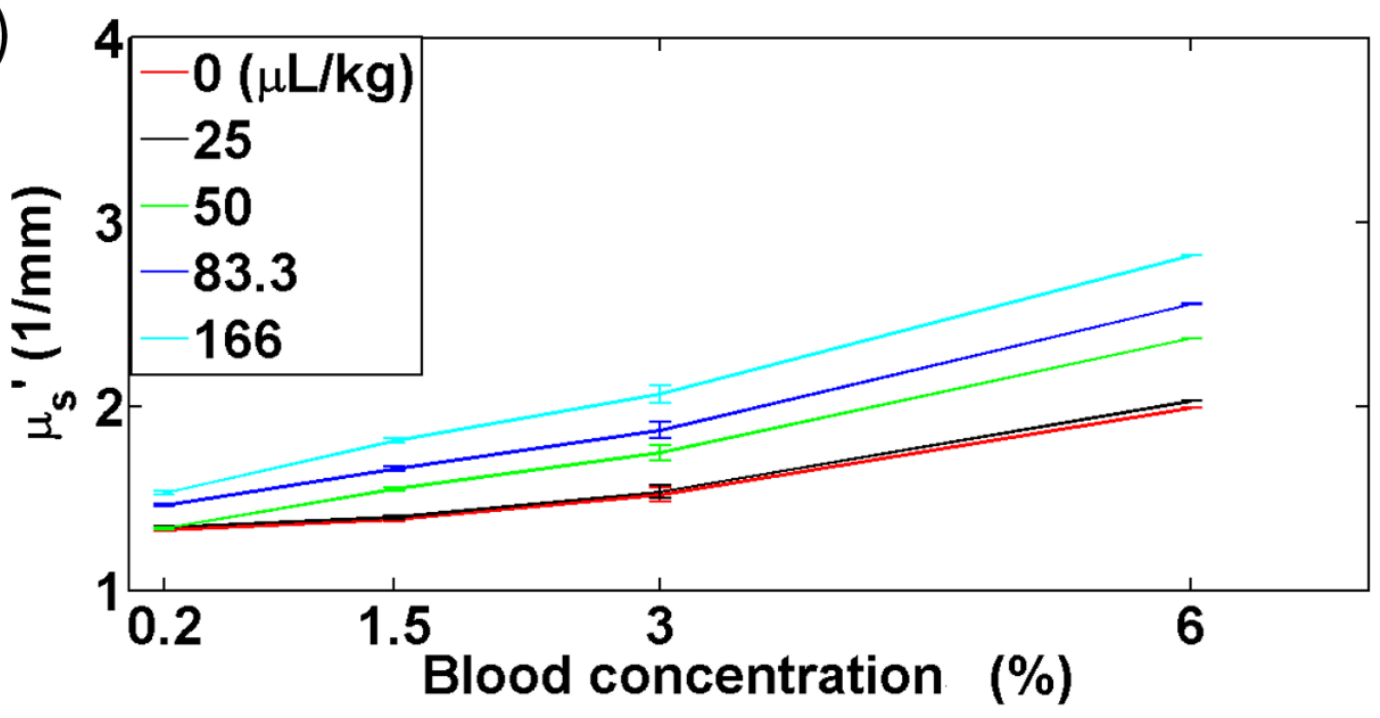

Figure 3-3: The reduced scattering coefficient vs blood concentrations $(0.2 \%, 1.5 \%, 3 \%$ and $6 \%)$ at five Definity ${ }^{\circledR}$ microbubble injection doses $(0,25,50,83.3,166 \mu \mathrm{L} / \mathrm{kg})$ at wavelengths of (a) $660 \mathrm{~nm}$ and (b) 1310 $\mathrm{nm}$. The error bars correspond to the standard deviation (SD). Solid lines are used to guide the eye. 


\section{$660 \mathrm{~nm}$}
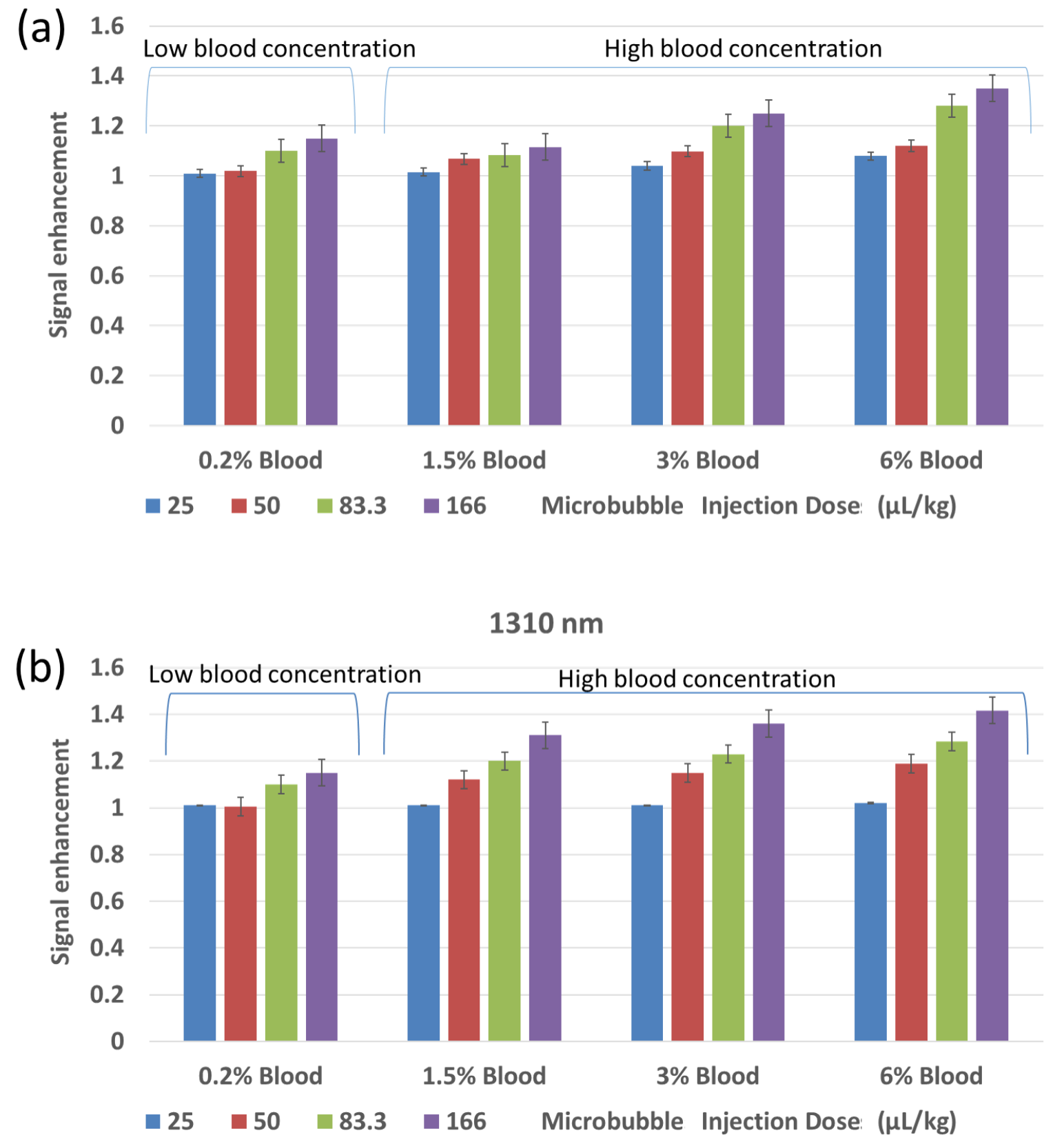

Figure 3-4: The reduced scattering signal enhancement, $S_{S}$, is plotted for four Definity® injection doses of microbubbles $(25,50,83.3$, and $166 \mu \mathrm{L} / \mathrm{kg}$ ) at wavelengths of (a) $660 \mathrm{~nm}$ and (b) $1310 \mathrm{~nm}$. The error bars correspond to the values of standard deviation (SD). 


\subsubsection{Reduced scattering contrast and reduced scattering contrast enhancement}

To assess the potential of utilizing MBs in differentiating tissues with low and high blood concentrations using DOI, reduced scattering contrast $\left(C_{\mathrm{s}}\right.$ and $\left.C_{\mathrm{s}}^{\mathrm{MB}}\right)$ and reduced scattering contrast enhancement $\frac{C_{\mathrm{S}}^{\mathrm{MB}}}{C_{\mathrm{S}}}$ were calculated and shown in Figure 3-5 and Figure 3-6, respectively.

In the absence of MBs at $660 \mathrm{~nm}$, reduced scattering contrast $\left(C_{\mathrm{s}}\right)$ was approximately $\sim 1$ between phantoms with low blood concentration $(0.2 \% \mathrm{v} / \mathrm{v})$ and high blood concentrations $(1.5 \%$ and $3 \% \mathrm{v} / \mathrm{v}) . C_{\mathrm{s}}$ was approximately $\sim 1.17$ for $6 \% \mathrm{v} / \mathrm{v}$ blood as shown in Figure 3-5(a). In the absence of MBs at $1310 \mathrm{~nm}$, reduced scattering contrast was approximately $\sim 1$ and 1.1 between phantoms with low blood concentration $(0.2 \% \mathrm{v} / \mathrm{v})$ and high blood concentrations with $1.5 \%$ and $3 \%$ v/v, respectively as shown in Figure 3-5(b). The $C_{\mathrm{s}}$ was approximately $~ 1.42$ for $6 \% \mathrm{v} / \mathrm{v}$ blood at $1310 \mathrm{~nm}$ (Figure 3-5(b)). In general, the contrast between phantoms with low blood concentration $(0.2 \% \mathrm{v} / \mathrm{v})$ and high blood concentrations $(1.5 \%$ and $3 \% \mathrm{v} / \mathrm{v})$ was negligible in the absence of microbubbles except for the $6 \% \mathrm{v} / \mathrm{v}$ blood concentration at the chosen wavelengths.

In the presence of MBs at $660 \mathrm{~nm}$ (Figure 3-5(a)), the reduced scattering contrast $\left(C_{\mathrm{s}}^{\mathrm{MB}}\right) \sim 1.05$ were achieved between phantoms with $0.2 \% \mathrm{v} / \mathrm{v}$ blood and $1.5 \% \mathrm{v} / \mathrm{v}$ blood for all Definity® microbubble doses. Whereas $C_{\mathrm{S}}^{\mathrm{MB}} \sim 1.11,1.16,1.27$ and 1.3 were achieved corresponding to contrast between phantoms with $0.2 \% \mathrm{v} / \mathrm{v}$ blood and $3 \% \mathrm{v} / \mathrm{v}$ blood at microbubble doses of $25,50,83.3$ and $166 \mu \mathrm{L} / \mathrm{kg}$, respectively. The $C_{\mathrm{s}}^{\mathrm{MB}}$ was larger for $6 \%$ 
v/v blood concentrations with approximately $\sim 1.24,1.27,1.45$ and 1.5 at microbubble doses of 25, 50, 83.3 and $166 \mu \mathrm{L} / \mathrm{kg}$, respectively (Figure 3-5(a)).

In the presence of MBs at $1310 \mathrm{~nm}\left(\right.$ Figure 3-5 (b)), the $C_{\mathrm{s}}^{\mathrm{MB}} \sim 1.04,1.16,1.14$ and 1.19 were achieved between phantoms with $0.2 \% \mathrm{v} / \mathrm{v}$ blood and $1.5 \% \mathrm{v} / \mathrm{v}$ blood at microbubble doses of $25,50,83.3$ and $166 \mu \mathrm{L} / \mathrm{kg}$, respectively. Whereas, $C_{\mathrm{s}}^{\mathrm{MB}} \sim 1.29,1.29$, 1.26 and 1.33 observed corresponding to $3 \% \mathrm{v} / \mathrm{v}$ blood concentrations at microbubble doses of $25,50,83.3$ and $166 \mu \mathrm{L} / \mathrm{kg}$, respectively. The $C_{\mathrm{s}}^{\mathrm{MB}}$ was larger for $6 \% \mathrm{v} / \mathrm{v}$ blood concentrations $\sim 1.51,1.77,1.75$ and 1.84 was observed at microbubble doses of $25,50,83.3$ and $166 \mu \mathrm{L} / \mathrm{kg}$, respectively (Figure 3-5 (b)).

In addition, the reduced scattering contrast enhancement, $\frac{C_{\mathrm{S}}^{\mathrm{MB}}}{C_{\mathrm{S}}}$, was plotted versus Definity® microbubbles doses in Figure 3-6. At $660 \mathrm{~nm}$ (Figure 3-6a), $\frac{C_{\mathrm{s}}^{\mathrm{MB}}}{C_{\mathrm{s}}}$ of approximately 1 was observed at all microbubble doses corresponding to $1.5 \% \mathrm{v} / \mathrm{v}$ blood concentration. The $\frac{C_{\mathrm{S}}^{\mathrm{MB}}}{C_{\mathrm{S}}}$ of $1.02,1.07,1.17$ and 1.21 was observed at microbubble doses of $25,50,83.3$ and 166 $\mu \mathrm{L} / \mathrm{kg}$ corresponding to $3 \% \mathrm{v} / \mathrm{v}$ blood concentration (Figure $3-6 \mathrm{a}$ ). The $\frac{C_{\mathrm{s}}^{\mathrm{MB}}}{C_{\mathrm{s}}}$ of $1.07,1.09$, 1.26 and 1.3 was observed at microbubble doses of $25,50,83.3$ and $166 \mu \mathrm{L} / \mathrm{kg}$ corresponding to $6 \% \mathrm{v} / \mathrm{v}$ blood concentration (Figure 3-6a).

At $1310 \mathrm{~nm}$ (Figure 3-6b), $\frac{C_{\mathrm{s}}^{\mathrm{MB}}}{C_{\mathrm{s}}}$ of approximately 1.1 was observed at all microbubble doses corresponding to $1.5 \% \mathrm{v} / \mathrm{v}$ blood concentration. The $\frac{C_{\mathrm{s}}^{\mathrm{MB}}}{C_{\mathrm{s}}}$ of $1.02,1.11,1.14$ and 1.21 was observed at microbubble doses of $25,50,83.3$ and $166 \mu \mathrm{L} / \mathrm{kg}$ corresponding to $3 \%$ blood 
concentration (Figure 3-6a). The $\frac{C_{\mathrm{s}}^{\mathrm{MB}}}{C_{\mathrm{s}}}$ of 1.06, 1.09, 1.2 and 1.23 was observed at microbubble doses of $25,50,83.3$ and $166 \mu \mathrm{L} / \mathrm{kg}$ (Figure 3-6a) corresponding to $6 \%$ blood concentration. Interestingly, a higher reduced scattering contrast enhancement was achieved at $660 \mathrm{~nm}$ compared to $1310 \mathrm{~nm}$ for the phantoms with high blood concentrations.

Generally, the presence of MBs causes a reduced scattering contrast enhancement and this effect increases with Definity ${ }^{\circledR}$ microbubble injection doses and blood concentrations. Thus, the potential utility of these MBs appears enhanced by increasing the Definity® injection doses at tissues contains high blood concentrations mimicking a cancerous tissue. 

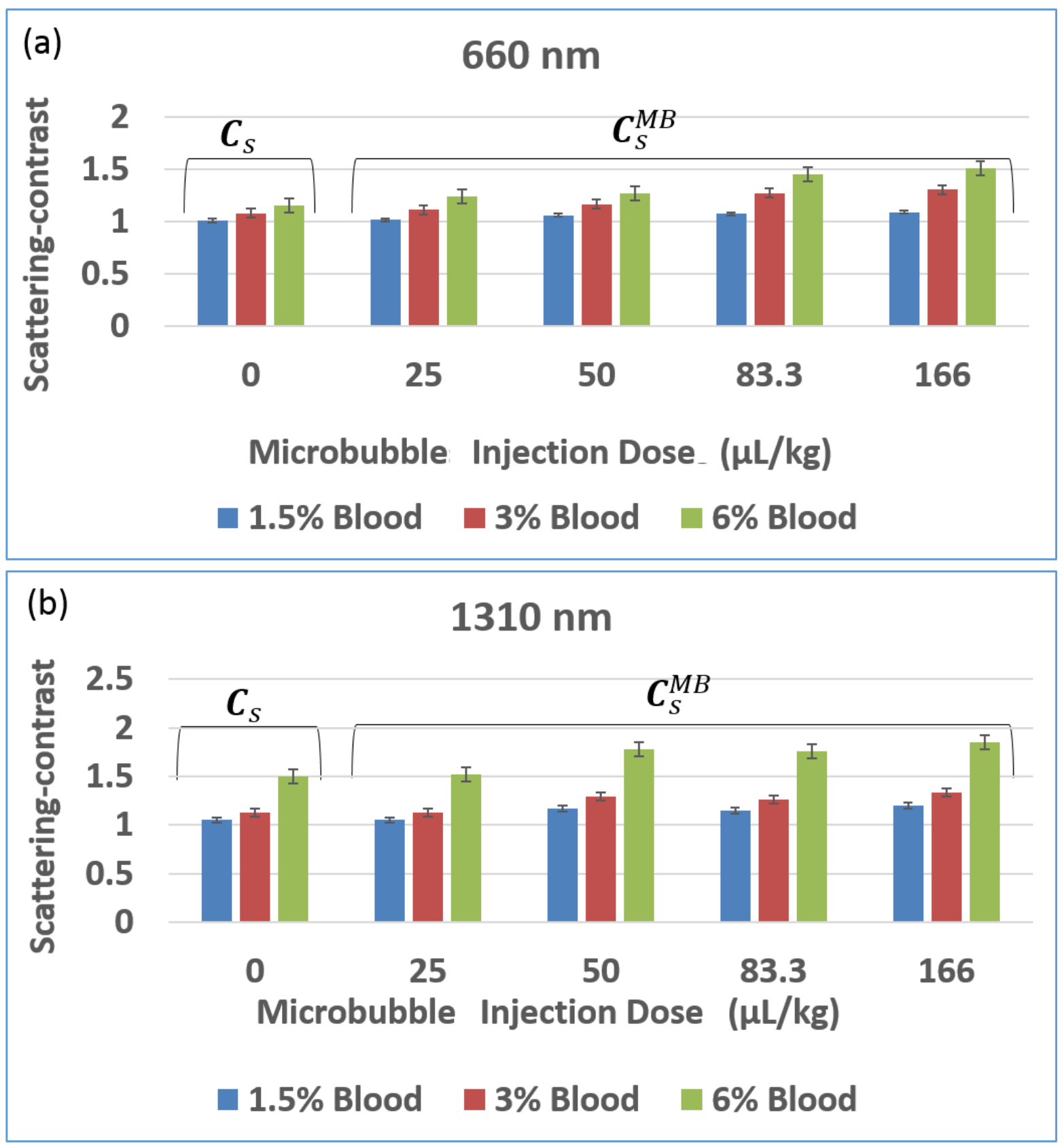

Figure 3-5: The reduced scattering contrast between low blood concentration $(0.2 \% \mathrm{v} / \mathrm{v})$ and high blood concentrations $(1.5 \%, 3 \%$ and $6 \% \mathrm{v} / \mathrm{v})$ tissue phantom at various Definity ${ }^{\circledR}$ microbubble injection doses $(0,25$, $50,83.3$ and 166) is plotted at wavelengths of (a) $660 \mathrm{~nm}$ and (b) $1310 \mathrm{~nm}$. The error bars correspond to the values of standard deviation (SD). 

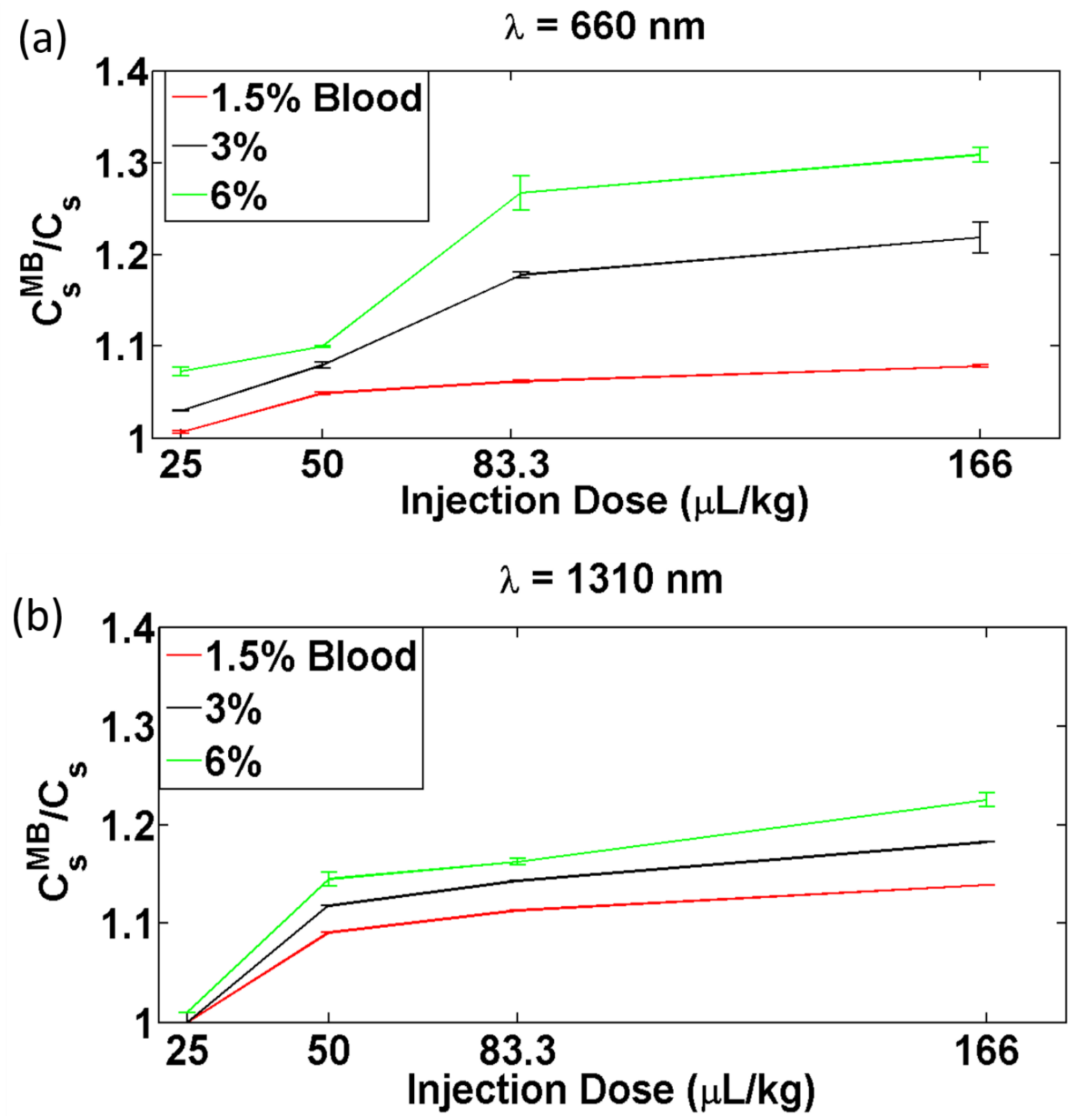

Figure 3-6: The reduced scattering contrast enhancement vs various Definity ${ }^{\circledR}$ microbubble injection doses (25, $50,83.3$ and $166 \mu \mathrm{L} / \mathrm{kg}$ ) is plotted at wavelengths of (a) $660 \mathrm{~nm}$ and (b) $1310 \mathrm{~nm}$. The error bars correspond to the values of standard deviation (SD). Solid lines are used to guide the eye. 


\subsection{Absorption coefficient $\left(\mu_{\mathrm{a}}\right)$}

The absorption coefficient $\mu_{\mathrm{a}}$ for the 20 phantom conditions are shown in Figure 3-8. The absorption coefficient changes significantly as a function of wavelength, similar to the spectral behaviour of the absorption properties of skin tissues [27] with $0.2 \% \mathrm{v} / \mathrm{v}$ blood concentration in Figure 3-8(b).

In the range $300-650 \mathrm{~nm}$, the major absorber of light in tissues is blood, which shows distinctive, wavelength-dependent characteristics depending on its concentration. In this range of the spectrum, the well-known peaks of blood at $410 \mathrm{~nm}$ (Soret band), $542 \mathrm{~nm}$ and $576 \mathrm{~nm}$ (Q bands) [94] are observed. As blood concentration increases, the intensity of these peaks increases (Figure 3-8(d)). Water is transparent in the range of visible region and it becomes absorbing in the near-infrared region. In the near-infrared region, the main chromophores in skin are the water and the lipids of epidermis. In this region the absorption bands of water at $965 \mathrm{~nm}, 1200 \mathrm{~nm}$ and 1400nm [94] are observed in Figure 3-8, which are larger than those presented in the literature for human skin [27]. The observed discrepancies are related to differences in the water content of the bulk tissue phantom that may lead to the overestimation of the absorption coefficient in near-infrared region compared to human skin. Absorption coefficient results in this thesis are in a general agreement with those given in the literature [27] for the absorption coefficient of normal skin tissue shown in Figure 3-7(b). 

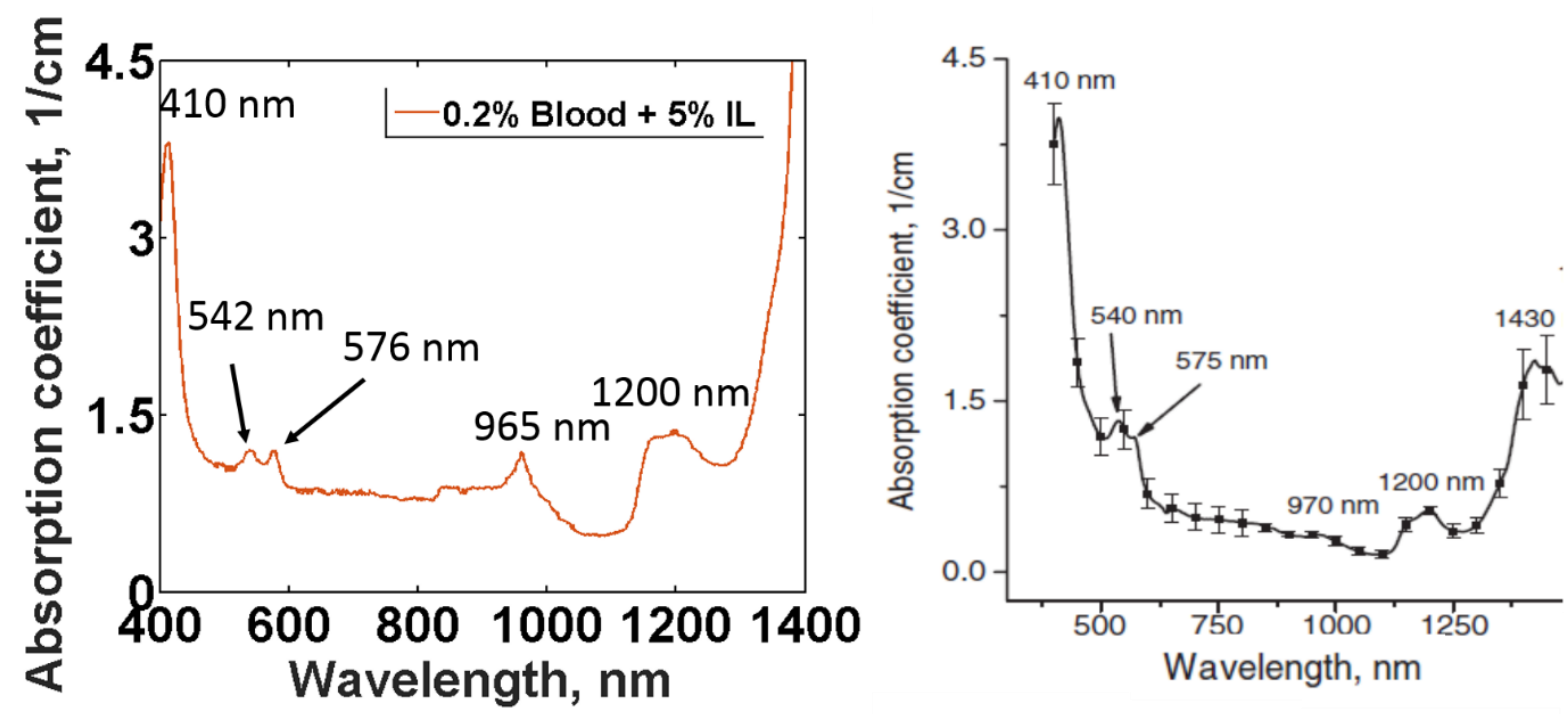

Figure 3-7: (a) Absorption coefficient spectra measured in this thesis for the tissue phantom with low blood concentration $(0.2 \% \mathrm{v} / \mathrm{v})$, (b) Published absorption coefficient spectra of human skin [27]. Absorption coefficient results in this thesis are in general agreement with published values.

The absorption coefficient of the four phantoms were measured using various $D_{\mathrm{I}}$ and are shown in Figure 3-8 with and without MBs. There is a statistical difference in absorption coefficient of bulk tissue phantom with and without MBs with significance level at 0.05 . Analysis of the microbubble contribution to the absorption coefficient is discussed in the following section 3.3.1. 

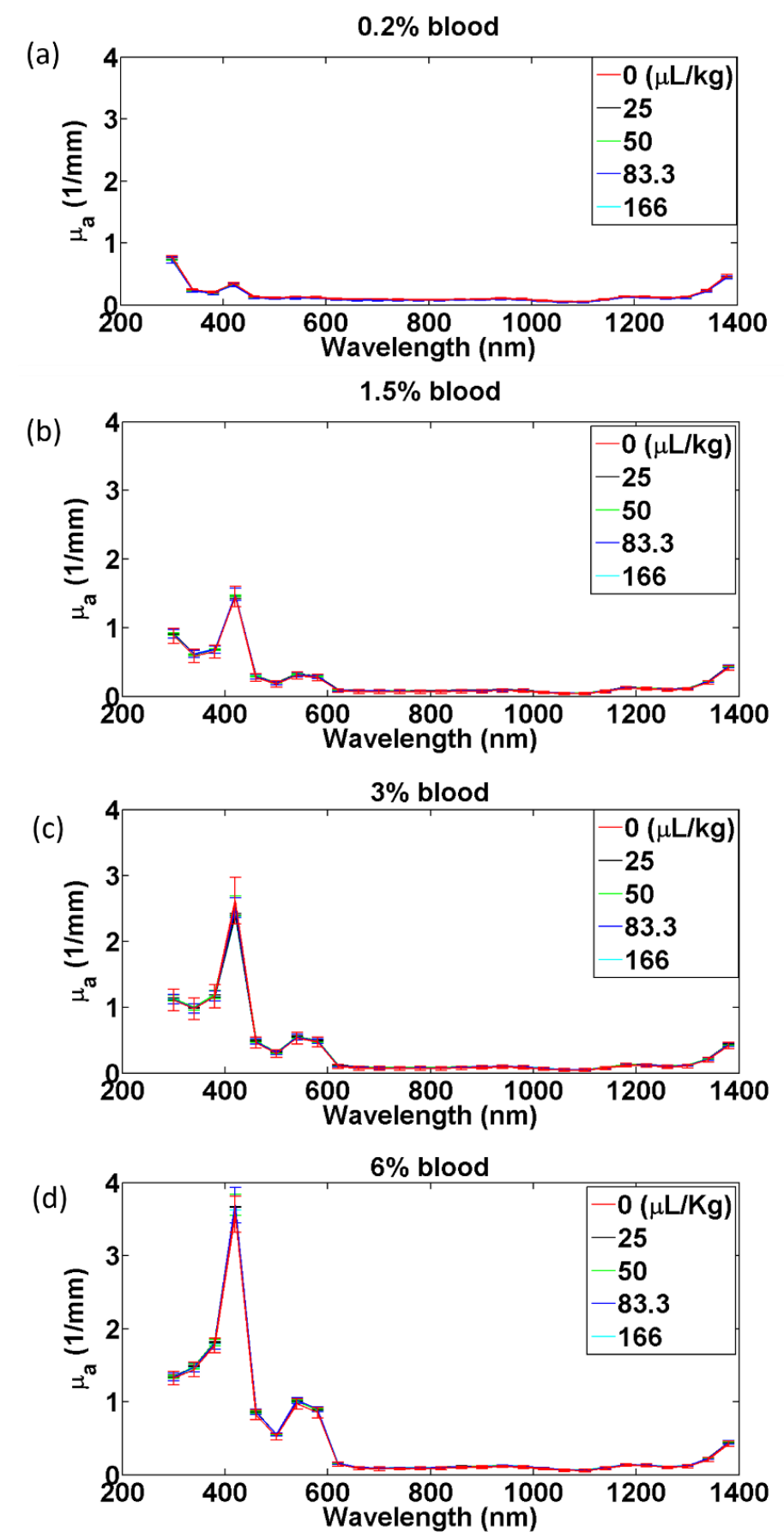

Figure 3-8: The absorption coefficient for the 20 phantom conditions (four blood concentrations at five Definity ${ }^{\circledR}$ microbubble injection doses $(0,25,50,83.3,166 \mu \mathrm{L} / \mathrm{kg}$ )) (a) $0.2 \%$ blood, (b) $1.5 \%$ blood, (c) $3 \%$ blood, (d) $6 \%$ blood. The error bars correspond to the values of standard deviation (SD). 


\subsubsection{The effect of microbubbles on $\mu_{\mathrm{a}}$ at wavelengths $660 \mathrm{~nm}$ and $1310 \mathrm{~nm}$}

The absorption coefficient versus four blood concentrations at five Definity® microbubble injection doses are shown in Figure 3-9 at two wavelengths (660 and $1310 \mathrm{~nm})$. The corresponding $\mu_{\mathrm{a}}$ signal enhancement for low blood concentration $\left(S_{\mathrm{a}}^{\mathrm{L}}\right)$ and high blood concentration $\left(S_{\mathrm{a}}^{\mathrm{H}}\right)$ are shown in Figure 3-9 at the two wavelengths.

At $660 \mathrm{~nm}$, a $\mu_{\mathrm{a}}$ of approximately $\sim 0.08,0.09,0.11$ and $0.15(1 / \mathrm{mm})$ was measured at blood concentrations of $0.2 \%, 1.5 \%, 3 \%$ and $6 \%$, respectively (Figure 3-9(a)), for all $D_{\mathrm{I}}$ corresponding to signal enhancement of 1 (Figure 3-10(a)). At $1310 \mathrm{~nm}$, a $\mu_{a}$ of approximately $\sim 0.13(1 / \mathrm{mm})$ was observed at blood concentrations of $0.2 \%, 1.5 \%, 3 \%$ and $6 \%$, respectively, corresponding to signal enhancement of 1 shown in Figure 3-10(b).

In summary, there is a statistical difference in absorption coefficient with and without MBs, however, the absorption signal enhancement, $S_{\mathrm{a}}^{\mathrm{L}}$ and $S_{\mathrm{a}}^{\mathrm{H}}$, were similar for all phantom conditions with no statistical difference at both wavelengths. 
(a)
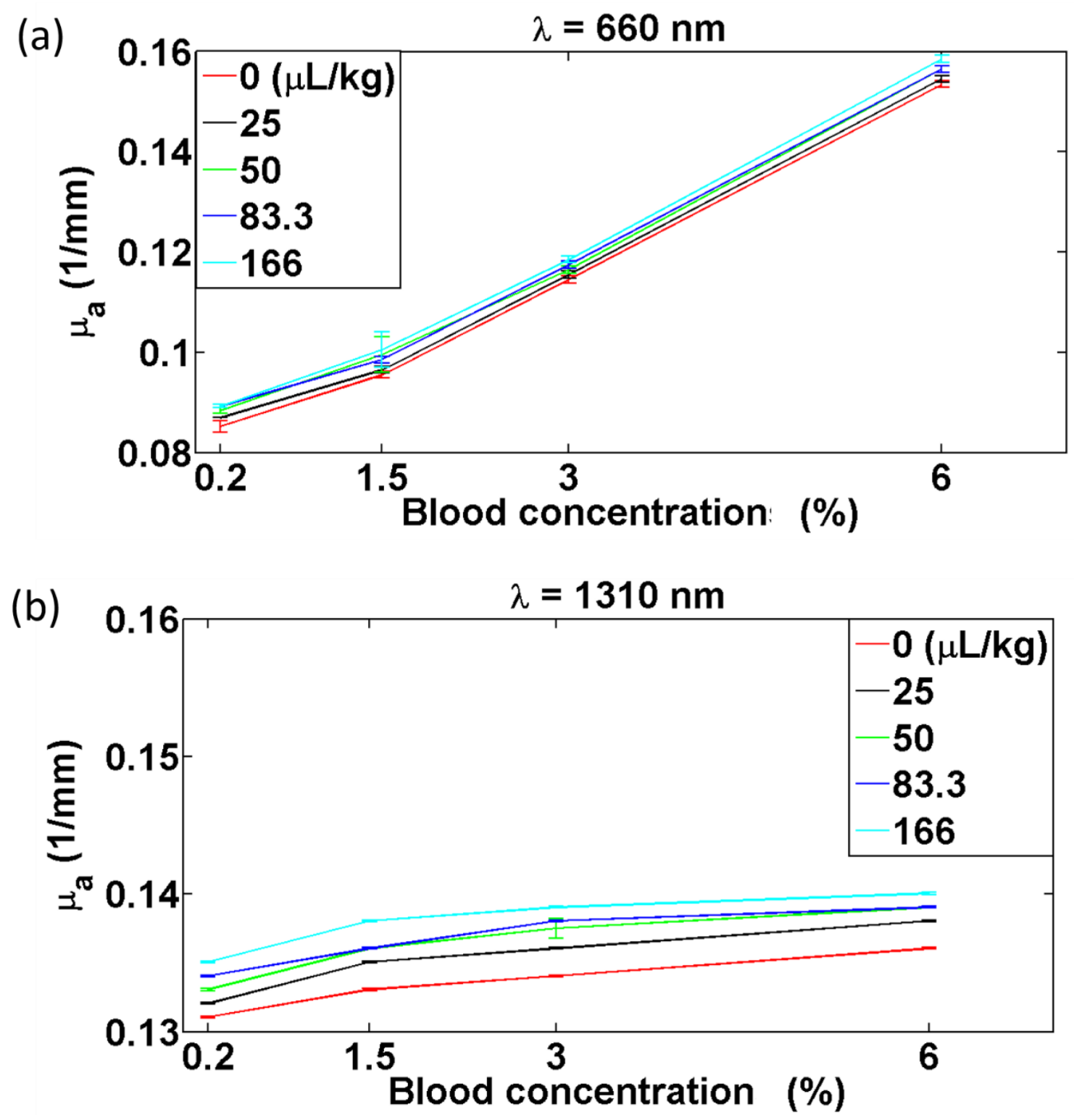

Figure 3-9: The absorption coefficient vs blood concentrations $(0.2 \%, 1.5 \%, 3 \%$ and $6 \%)$ at five Definity ${ }^{\circledR}$ microbubble injection doses $(0,25,50,83.3,166 \mu \mathrm{L} / \mathrm{kg}$ ) at wavelengths of (a) $660 \mathrm{~nm}$ and (b) $1310 \mathrm{~nm}$. The error bars correspond to the values of standard deviation (SD). Solid lines are used to guide the eye are a guide to the eye. 
$660 \mathrm{~nm}$
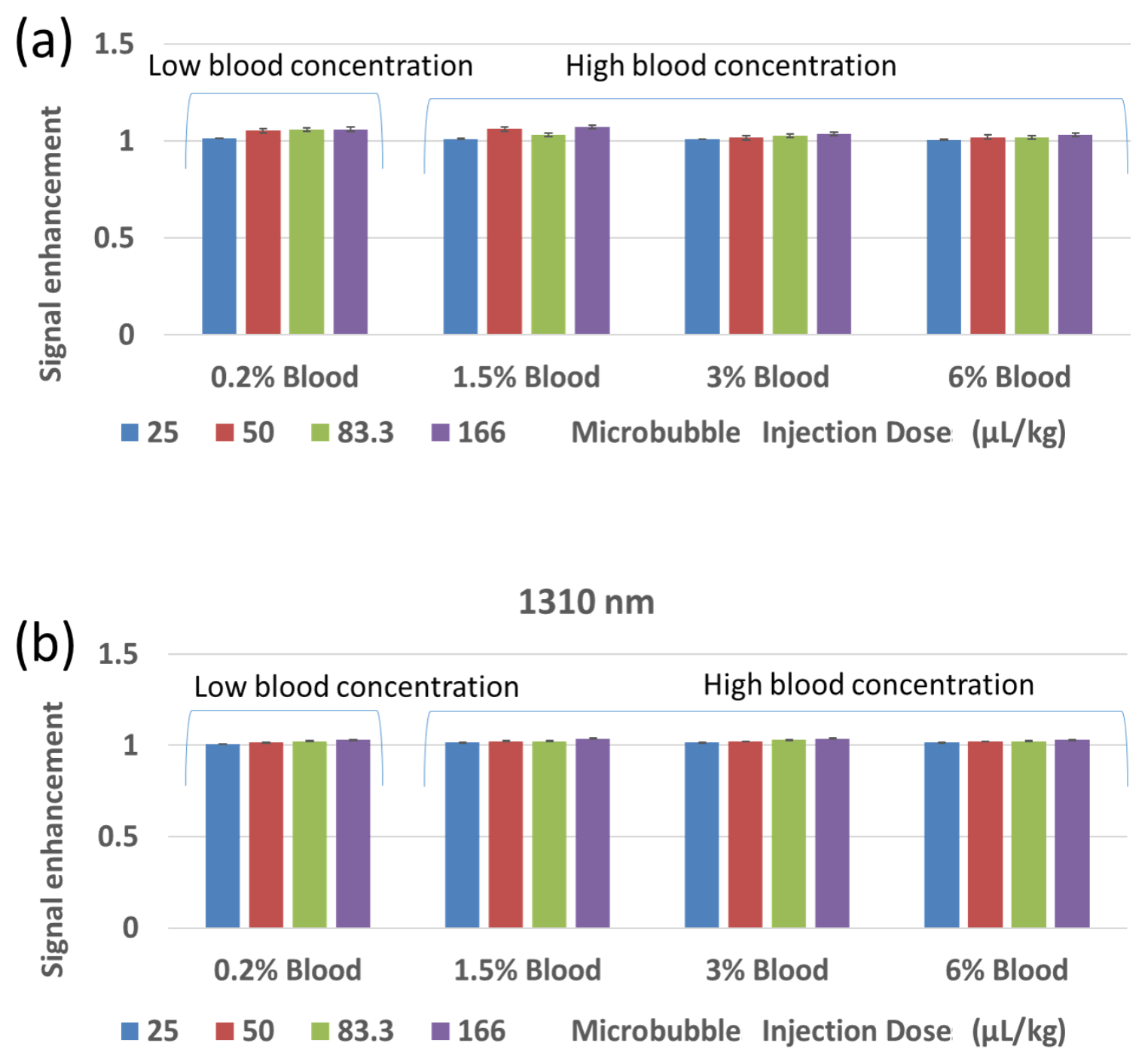

Figure 3-10: The absorption signal enhancement, $S_{\mathrm{a}}$, is plotted for four Definity ${ }^{\circledR}$ injection doses of microbubbles $(25,50,83.3,166 \mu \mathrm{L} / \mathrm{kg}$ ) at wavelengths of (a) $660 \mathrm{~nm}$ and (b) $1310 \mathrm{~nm}$. The error bars correspond to the values of standard deviation (SD). 


\subsubsection{Absorption contrast and absorption contrast enhancement}

To assess the potential of utilizing MBs in differentiating tissues with low and high blood concentrations using DOI at $1310 \mathrm{~nm}$ and $660 \mathrm{~nm}$ wavelengths, absorption contrast $\left(C_{\mathrm{a}}\right.$ and $\left.C_{\mathrm{a}}^{\mathrm{MB}}\right)$ and absorption contrast enhancement, $\frac{C_{\mathrm{a}}^{\mathrm{MB}}}{C_{\mathrm{a}}}$, were calculated and shown in Figure 3-11 and Figure 3-12, respectively. The absorption contrasts depend on the blood concentrations and wavelengths, and they are independent of the Definity ${ }^{\circledR}$ microbubble injection doses.

In the absence of MBs at $660 \mathrm{~nm}$, absorption contrast $\left(C_{\mathrm{a}}\right)$ was approximately $\sim 1.1$, 1.3 and 1.7 between phantoms with low blood concentration $(0.2 \% \mathrm{v} / \mathrm{v})$ and high blood concentrations $(1.5 \%, 3 \%$ and $6 \% \mathrm{v} / \mathrm{v})$ respectively (Figure $3-11(\mathrm{a}))$. In the presence of MBs, $C_{\mathrm{a}}$ was approximately $\sim 1.1,1.3$ and 1.7 at $1.5 \%, 3 \%$ and $6 \% \mathrm{v} / \mathrm{v}$ blood, respectively for any given $D_{\mathrm{I}}$. Generally, there is no notable change in absorption contrast in the presence of microbubbles for all phantom tissue conditions at both wavelengths (Figure 3-11).

The absorption contrast were significant between low blood concentration and high blood concentration at $660 \mathrm{~nm}$ and was independent of MBs. However, the absorption contrast in presence and absence of MBs were not significant at the $1310 \mathrm{~nm}$ wavelength.

The absorption contrast enhancement $\frac{C_{\mathrm{a}}^{\mathrm{MB}}}{C_{\mathrm{a}}}$ was plotted versus four microbubbles doses at two wavelengths in Figure 3-12 (a,b). As we expected, the absorption contrast enhancement $\frac{C_{\mathrm{a}}^{\mathrm{MB}}}{C_{\mathrm{a}}}$ stays constant $\sim 1$ with Definity ${ }^{\circledR}$ microbubble injection doses at both wavelengths. That means there is no absorption contrast enhancement due to the Definity® 
microbubble injection. Thus, the potential utility of these MBs as optical contrast agent to enhance the bulk tissue absorption contrast appears negligible. 

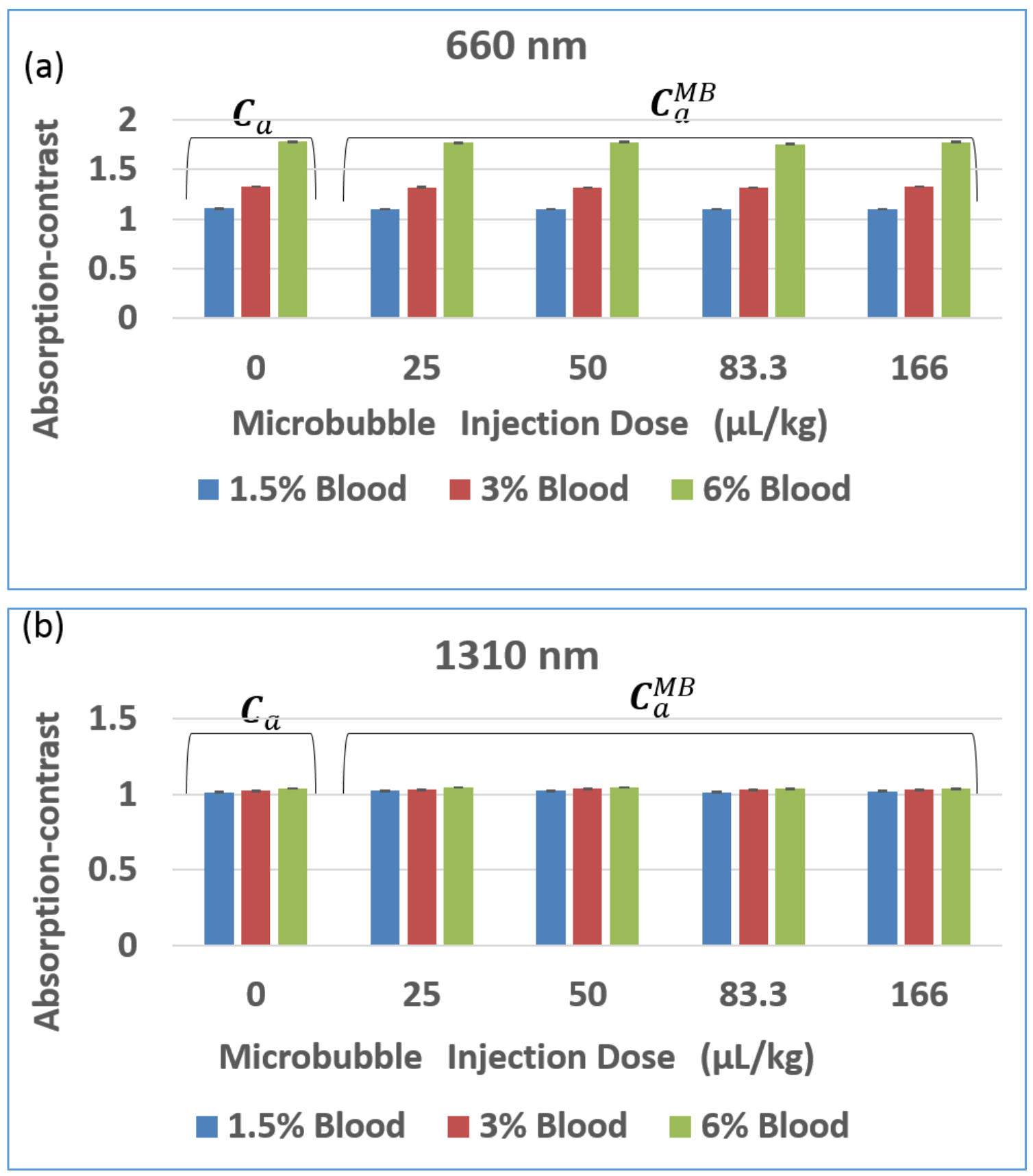

Figure 3-11: The absorption contrast between low blood concentration $(0.2 \% \mathrm{v} / \mathrm{v})$ and high blood concentrations $(1.5 \%, 3 \%$ and $6 \% \mathrm{v} / \mathrm{v})$ tissue phantom at various Definity ${ }^{\circledR}$ microbubble injection doses $(0,25,50,83.3$ and 166) is plotted at wavelengths of (a) $660 \mathrm{~nm}$ and (b) $1310 \mathrm{~nm}$. The error bars correspond to the values of standard deviation $(\mathrm{SD})$. 

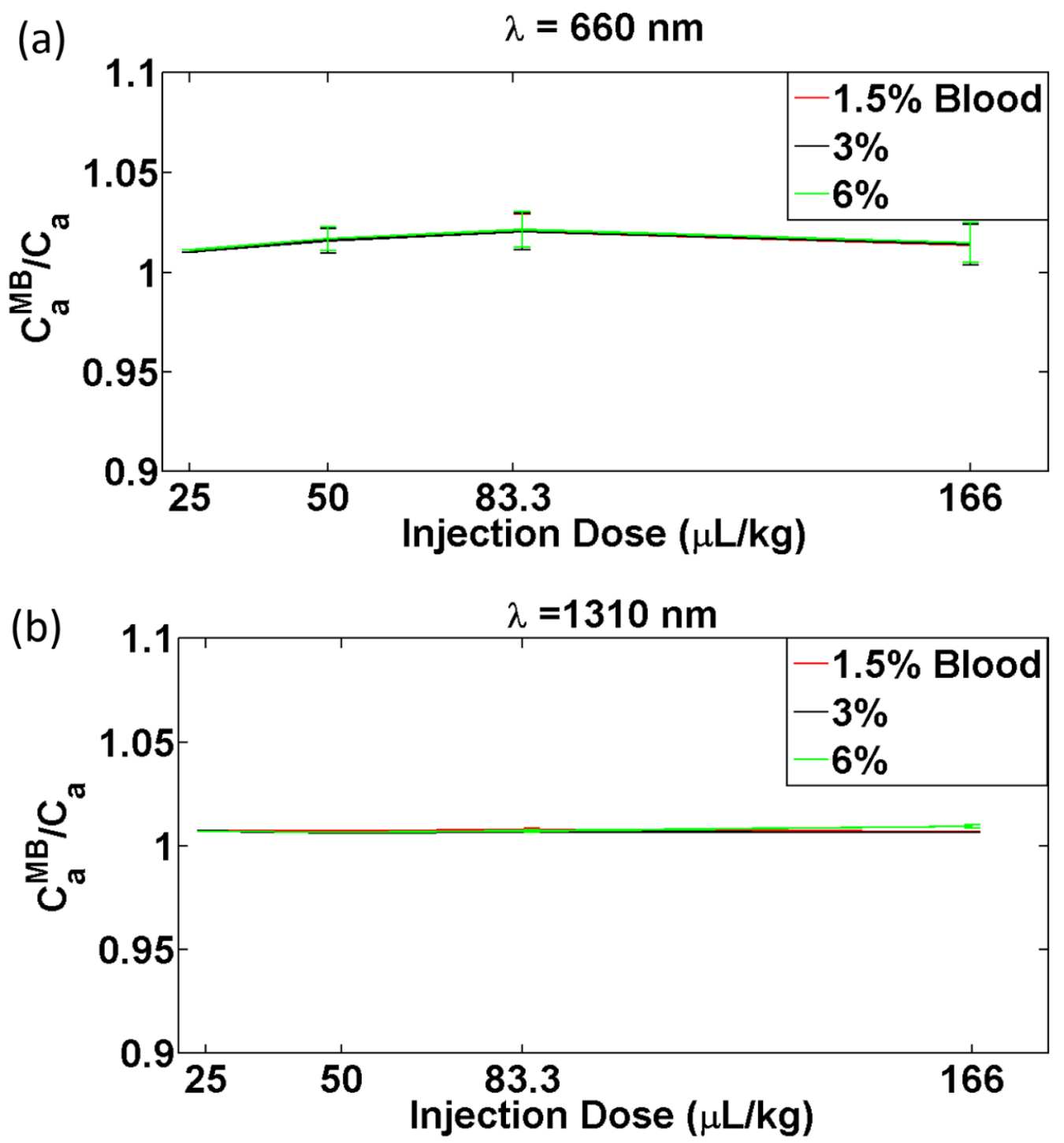

Figure 3-12: The absorption contrast enhancement vs various Definity ${ }^{\circledR}$ microbubble injection doses $(25,50$, 83.3 and 166) is plotted at wavelengths of (a) $660 \mathrm{~nm}$ and (b) $1310 \mathrm{~nm}$. The error bars correspond to the values of standard deviation (SD). Solid lines are used to guide the eye. 


\section{Chapter 4 Microvascular contrast}

\section{enhancement in optical coherence}

\section{tomography using microbubbles ${ }^{1}$}

\subsection{One dimension decorrelation analysis}

The average of speckle decorrelation times (1/e level of ACFs) of OCT signals with and without MBs at no-flow and varying flow conditions are plotted in Figure 4-1. As expected, the decorrelation time decreases with average blood flow velocity. The decorrelation times were typically $\sim 15 \mathrm{~ms}$ at the no-flow condition, decreasing to $\sim 1 \mathrm{~ms}$ for average blood flow velocities $>5 \mathrm{~mm} / \mathrm{s}$. The presence of $\mathrm{MB}$ causes faster decorrelation, and this differential effect diminishes with increasing blood velocities. The reason for the faster decorrelation times in presence of MBs may be that MBs have a smaller average diameter (of $\sim 2.2 \mu \mathrm{m}$ ) than RBCs, which increases the rapidity of temporal variation in the signal intensity fluctuations.

${ }^{1}$ This chapter is based on an original article published as: H. Assadi, V. Demidov, R. Karshafian, A. Douplik, and I. A. Vitkin, "Microvascular contrast enhancement in optical coherence tomography using microbubbles," Journal of Biomedical Optics, vol. 21, no. 7, p. 76014, Jul. 2016. 
This effect is more pronounced in the no-flow regime (Brownian motion) where larger particles (red blood cells) undergo slower movement than the scatterers in the flowing regime. Thus, the potential utility of these MB contrast agents appears enhanced in the slower flow regimes. This may be relevant for improved visualization of smaller vessels $(10-50$ $\mu \mathrm{m}$ in diameter) with lower blood velocities with svOCT imaging.

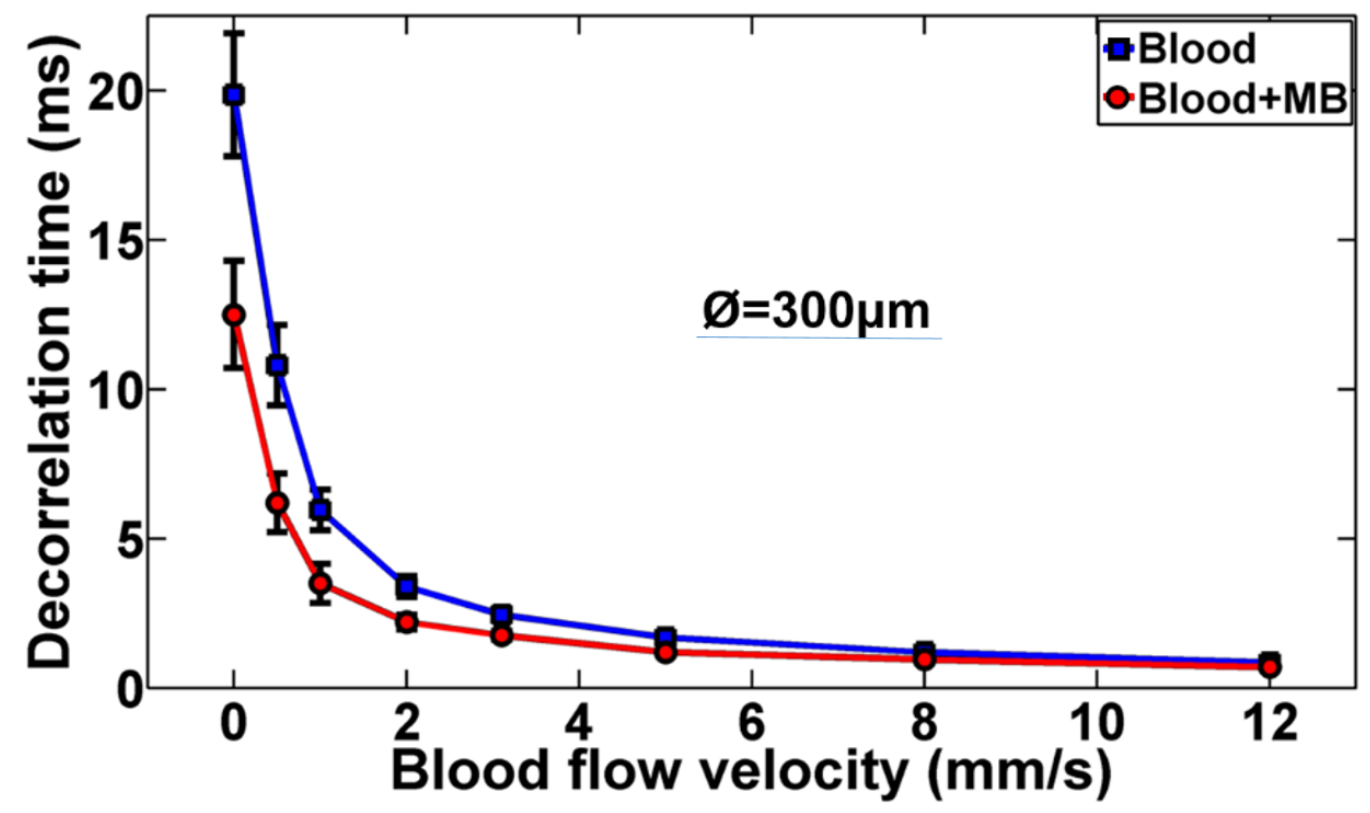

Figure 4-1: Decorrelation time plots for blood and blood+MB mixture under eight flow conditions in $300 \mu \mathrm{m}$ tube. The error bars correspond to the values of standard deviation (SD).

\subsection{Contrast enhancement of 2D structural images}

Structural OCT images, corresponding image contrasts and ratios of blood+MB to blood contrasts acquired for different flow conditions are shown in Figure 4-2. Although structural snapshot images show little visual evidence of MB contrast enhancement in Figure 4-2 (a,d), their averaged ROI intensities used for Weber contrast $C_{\mathrm{W}}$ calculation (equation 
15) clearly demonstrate the contrast difference for both microtube diameters in Figure 4-2(b, e). Dynamic OCT signal changes better reflect the contrast difference as shown in the standard deviation image (Figure 4-2(c)), calculated from 8 subsequent structural images at $0.5 \mathrm{~mm} / \mathrm{s}$ average blood flow velocity.

Similar to the temporal 1D analysis, the level of enhancement in Figure 4-2(b,e) diminishes with increasing flow, but does not disappear (asymptote to unity) even for fast flows; as seen, there are still differences in the blue versus red histogram bars. The $\sim 2$-times difference in contrast values between $300 \mu \mathrm{m}$ and $600 \mu \mathrm{m}$ diameter microtubes (note the different vertical scales in Figure 4-2(b) and (e)) can be explained by the chosen contrast evaluation method. The OCT signal is lower at the bottom of the chosen half-circles of microtube lumens for $600 \mu \mathrm{m}$ diameter microtubes in comparison to $300 \mu \mathrm{m}$ diameter ones. As contrast evaluation is based on averaged ROI intensity, more low intensity pixels in the larger microtube's center due to low SNR will result in lower contrast value.

The contrast enhancement (height of red histogram bars divided by height of blue ones) in Figure 4-2(f) stems from the fact that contrast in OCT structural images is based on the refractive index mismatches in the interrogated material. By introducing MB to the blood, the refractive index mismatches increase thereby increasing the light scattering which yields additional structural image contrast, compared to blood-only conditions.

In the stationary regime the MBs float to the top of the microtubes and increases the refractive index mismatches between tube's boarder and surrounding area. By increasing the average blood flow velocity, the dynamic of the microbubble refractive index has less effect, causing negligible effect on the contrast. What is important here is a higher structural image 
contrast in the presence of $\mathrm{MB}$ in all experiments; this effect is more pronounced at low average blood flow velocities and smaller microtubes. Findings in 1D and 2D OCT results now set the stage for dynamic OCT image contrast investigation, as per studies discussed as follows.
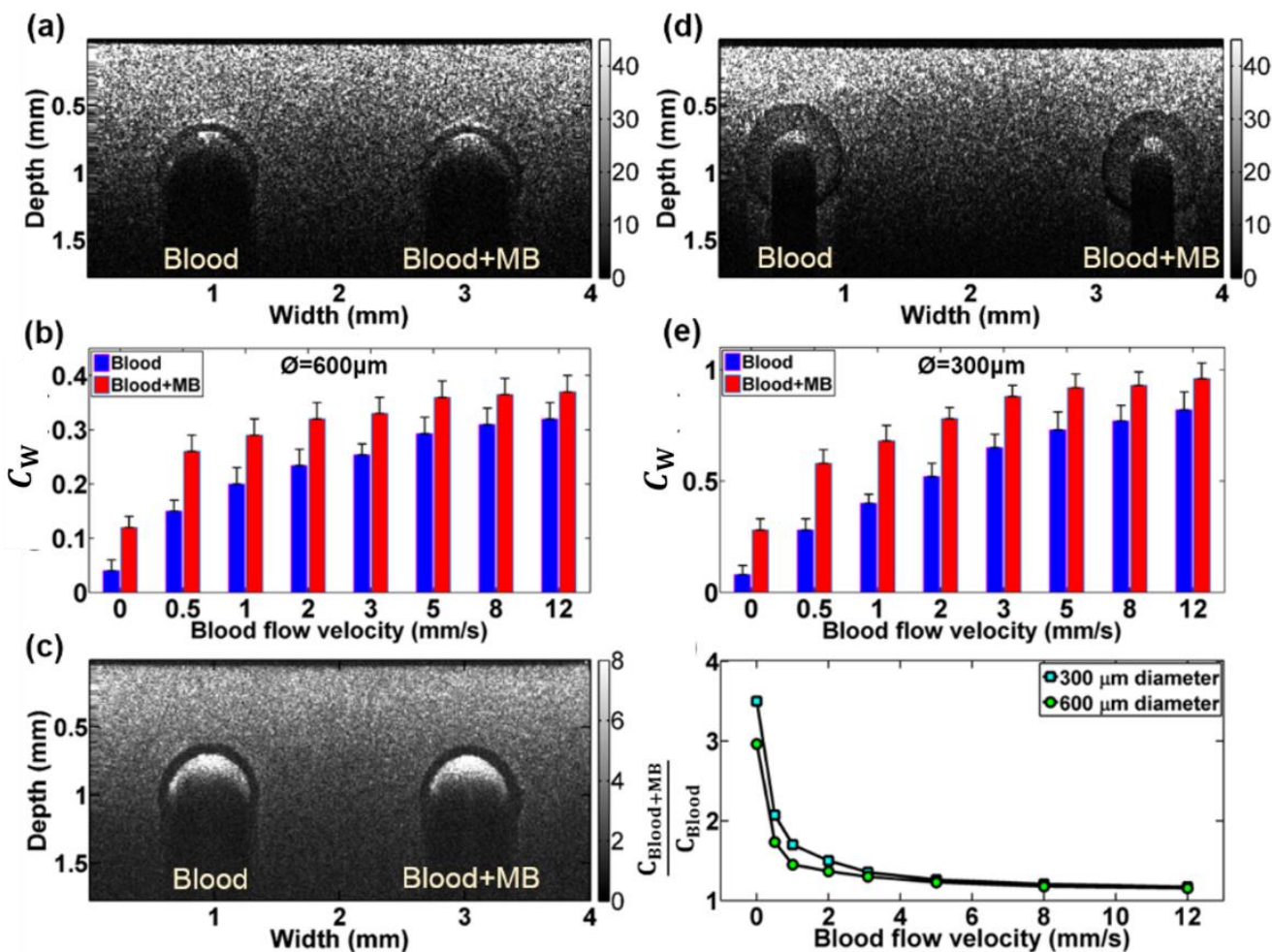

Figure 4-2: Structural images, corresponding contrast of blood and blood+MB mixture and ratios of blood+MB to blood contrasts under eight flow conditions (a) structural image of the phantom with $600 \mu \mathrm{m}$ microtubes at $0.5 \mathrm{~mm} / \mathrm{s}$ average blood flow velocity; (b) structural image contrast for $600 \mu \mathrm{m}$ microtube phantom at various average blood flow velocities $(0,0.5,1,2,3,5,8,12 \mathrm{~mm} / \mathrm{s})$; (c) standard deviation image calculated from eight sequential structural images at $0.5 \mathrm{~mm} / \mathrm{s}$ blood flow velocity; (d) structural image of the phantom with $300 \mu \mathrm{m}$ microtubes at $0.5 \mathrm{~mm} / \mathrm{s}$ average blood flow velocity; (e) structural image contrast for $300 \mu \mathrm{m}$ microtube phantom at various average blood flow velocities $(0,0.5,1,2,3,5,8,12 \mathrm{~mm} / \mathrm{s})$; (f) Ratio of blood+MB / blood structural contrasts for both microtube diameters. 


\subsection{Contrast enhancement of 2D speckle variance (sv OCT) images}

As pointed out in the Methods section, in the svOCT mode the B-scan acquisition time was set to $25 \mathrm{~ms}$ between the $N=8$ frames. This was (1) fast enough that signals from stationary agar did not decorrelate between frames for the svOCT signal to approach zero, and (2) sufficiently slow to ensure complete inter-frame decorrelation (high svOCT signal) for pixels representing blood. Figure 4-3(a,c) show the svOCT images corresponding to the structural images in Figure 4-2(a,d) at $0.5 \mathrm{~mm} / \mathrm{s}$ average blood flow velocity. As seen, there are more bright pixels in the lumen area of $300 \mu \mathrm{m}$ diameter microtubes in comparison to $600 \mu \mathrm{m}$ ones, likely due to low OCT signal at greater depths in bigger microtubes. Similar to structural contrast case, this also caused $\sim$ 2-times difference between corresponding sv contrasts in the two microtubes (Figure 4-3(b,d)); note the different vertical scales. Assessment of the ratio between blood+MB and blood contrasts (Figure 4-3(e)) revealed a slightly higher contrast for smaller diameter microtube at low flows (similar trends to the structural contrast ratio metric above). 

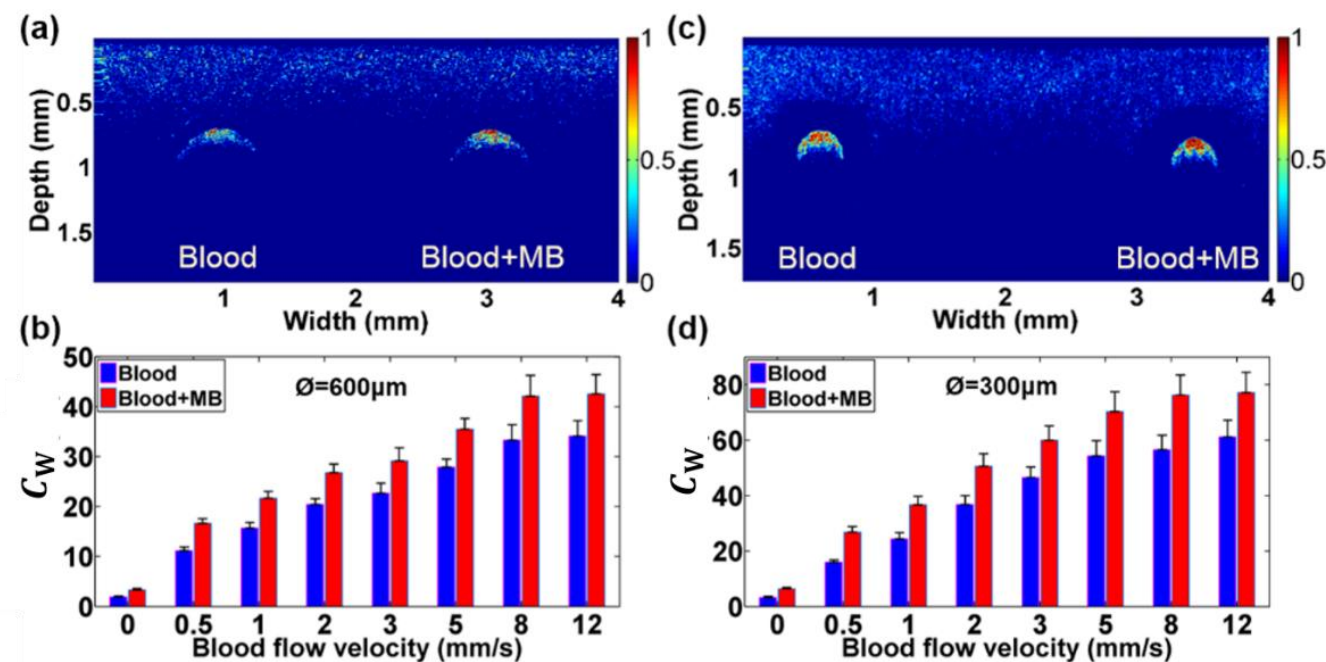

(d)

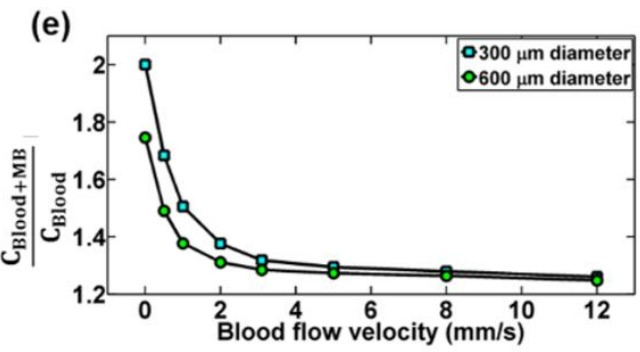

Figure 4-3: (a) svOCT image of the phantom with $600 \mu \mathrm{m}$ microtubes calculated from 8 subsequent structural images at $0.5 \mathrm{~mm} / \mathrm{s}$ average blood flow velocity; (b) svOCT image contrast for $600 \mu \mathrm{m}$ microtubes plotted as a function of average blood flow velocity; (c) svOCT image of the phantom with $300 \mu \mathrm{m}$ microtubes calculated from 8 subsequent structural images at $0.5 \mathrm{~mm} / \mathrm{s}$ average blood flow velocity; (d) svOCT image contrast for $300 \mu \mathrm{m}$ microtubes plotted as a function of average blood flow velocity; (e) Ratio of blood+MB / blood sv contrasts for both microtube diameters plotted as a function of average blood flow velocity.

In a consideration of the potential practical implementation of svOCT vascular contrast enhancement with $\mathrm{MB}$ added to the blood stream, we present en-face (x-y lateral dimensions) average intensity projections of volumetric phantom scans in Figure 4-4. There are eight projections for different flow conditions of a phantom with embedded $600 \mu \mathrm{m}$ microtubes. The average velocities are indicated in each panel, and the flow direction is 
labeled with black arrows. The average contrast values for these panels with deviations from phantom to phantom (error bars) can be found in Figure 4-3 (b). It is noticeable that as the average flow velocity increases, the contrast enhancement decreases. The possible reason for higher contrast enhancement at low flow velocties may be due to MBs contribution to the Brownian motion at low flows more than RBCs due to MB smaller size (as mentioned in svOCT result). Whereas, at higher flow velocities (> $3 \mathrm{~mm} / \mathrm{s}$ ) RBCs contribution to backscattered OCT signal more than MBs. One of the recent reports on OCT study of diffusive versus flow contributions to backscattered OCT signal at low flows for small particle sizes supports this hypothesis [95]. At higher velocities the flow contribution to OCT scattering dominated over diffusive (Brownian motion) effects [95]. In our experiments, higher flow velocity leads to increase the role of $\mathrm{RBC}$, dominating over $\mathrm{MB}$ contribution and therefore diminishing the difference between blood and blood+MB mixture contrasts in both snapshot structural OCT and dynamic svOCT images. Indeed, the common trends observed from different analysis methods shown in Figure 4-2(b, e), Figure 4-3(b, d) and Figure 4-4 support the suggested mechanisms. 


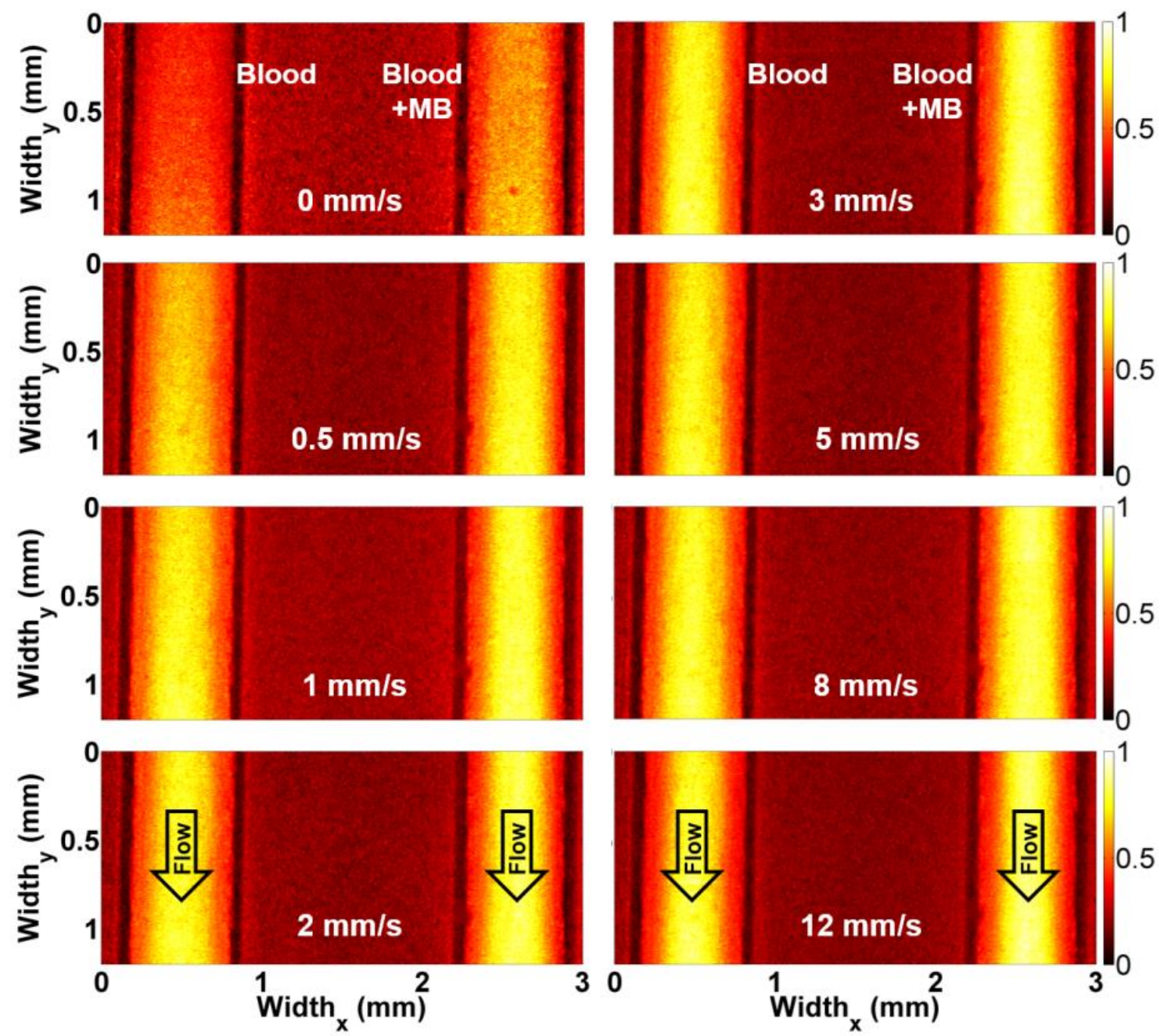

Figure 4-4: En-face (x-y lateral dimensions) svOCT average intensity projections of volumetric phantom scans. Color bar is normalized value to the maximum intensity. Eight projections corresponding to eight flow conditions in $600 \mu \mathrm{m}$ diameter microtubes with blood (left microtube) and blood+MB mixture (right microtube). Image intensities are normalized to the maximum value. The flow direction is labeled with black arrows. The OCT slow scanning axis is anti-parallel to the flow direction. 


\section{Chapter 5 Summary and Conclusions}

This dissertation presented evidence in support of the use of microbubbles to enhance optical imaging contrast of microvasculature morphology, which can result in improving cancer detection using diffuse optical imaging and optical coherence tomography. This section summarizes the significant findings and conclusions of the work.

To the best of my knowledge, there is no information in the literature about the differentiation between low blood concentration and high blood concentration tissue optical properties in the presence of microbubbles. The general feasibility of optical tissue differentiation by MB-enhanced DOI has been shown in this work. I also assessed, for the first time, the effect of microbubbles on the svOCT image contrast of blood vessels, demonstrating the feasibility of using MB-enhanced OCT to differentiate small vessels from surrounding tissue at various blood flow velocities.

In Chapter 3, in order to investigate potential applications of MB-enhanced DOI, the reduced scattering coefficient and absorption coefficient for the 20 phantom conditions (four blood concentrations $0.2 \%, 1.5 \%, 3 \%$ and $6 \% \mathrm{v} / \mathrm{v}$ at five Definity ${ }^{\circledR}$ microbubble injection doses $0,25,50,83.3,166 \mu \mathrm{L} / \mathrm{kg}$ ) were measured by the inverse adding-doubling method based on the diffuse reflectance and total transmittance measurements in the range of 300$1400 \mathrm{~nm}$ wavelength. I found that MB-enhanced DOI imaging may differentiate between 
tissues with low and high blood concentrations by enhancing scattering contrast and not absorption contrast.

The reduced scattering coefficient depends on microbubble dose and its value increases with blood concentration as investigated in section 3.2. The reduced scattering coefficient and reduced scattering contrast enhancement, $\frac{C_{\mathrm{S}}^{\mathrm{MB}}}{C_{\mathrm{S}}}$, increased in the presence of MBs, and this effect was more pronounced ( 1.3 times) at the high blood concentrations (6\% v/v; mimicking cancerous tissue) and high MBs injection dose $(166 \mu \mathrm{L} / \mathrm{kg})$ used in this study. The reduced scattering contrast enhancement was dependent on wavelength and a higher $\frac{C_{\mathrm{s}}^{\mathrm{MB}}}{C_{\mathrm{s}}}$ value achieved at $660 \mathrm{~nm}$ compared to $1310 \mathrm{~nm}$ in this study.

There was a statistical difference in absorption coefficient with and without MBs, however, the absorption contrast enhancement were similar for all phantom conditions with no statistical difference as investigated in section 3.2. Without MBs, DOI can differentiate between low and high blood concentrations based on absorption contrast. The addition of microbubbles do not further improve the contrast between them as shown in Figure 3-11. However, knowledge of (1) absorption contrast without microbubbles and (2) reduced scattering contrast with MBs will improve detection of microvasculature functionality.

Generally, the presence of MBs causes a reduced scattering contrast enhancement and this effect increases with Definity® microbubble injection dose and blood concentrations. Thus, the potential utility of these MBs appears enhanced by increasing the Definity® injection doses into tissues to detect the region of interest with higher blood concentrations. 
The experimental results for intravascular OCT image contrast enhancement by MBs were investigated in Chapter 4. Swept-source structural and speckle variance svOCT images, as well as speckle decorrelation times, were evaluated under stationary and varying blood flow conditions with MBs. Faster decorrelation times and higher structural and svOCT image contrasts were detected in the presence of $\mathrm{MB}$ in all experiments. The effects were most pronounced in the svOCT imaging mode, and uniformly diminished with increasing average flow velocity. I found that MB-enhanced OCT imaging can differentiate between flowing blood and stationary blood by enhancing svOCT imaging contrast. In addition, the contrast enhancement is more pronounced for smaller microtubes $(300 \mu \mathrm{m})$ and slower blood mean velocities, that corresponds to capillaries, compared to bigger vessels $(600 \mu \mathrm{m})$. This confirms the feasibility for the development of an OCT contrast mechanism that generates physiological information related to average blood flow velocity in addition to morphological structure of small vessels in svOCT.

The clinical implementation of MB-enhanced OCT may improve cancer detection and treatment monitoring by detecting dynamical blood flow properties (such as average blood flow velocity) in the microvasculature. These smallest microvessels are difficult to detect otherwise, yet are important for early pathology detection. In the clinical settings, physiological information gained from MB-enhanced OCT may potentially help to discover the blocked/stagnant microvessels. For example, the microvascular response to cancer treatment can be tracked through the vascular functionality such as dynamical blood flow. Pre-imaging the vasculature, adding MB and then the imaging vasculature again may reveal "compromised" stagnant/blocked vessels with unchanged contrast (no MB) versus 
"functioning" increased-contrast vessels (with MB). It is worth mentioning that the highest MBs injection dose in this phantom study for DOI $(166 \mu \mathrm{L} / \mathrm{kg})$ and OCT $(2 \mathrm{~mL} / \mathrm{kg})$ is below the maximum tolerated dose $(10 \mathrm{~mL} / \mathrm{kg})$ that can be relevant for improved detection of abnormal tissues with MB-enhanced DOI and MB-enhanced OCT techniques.

Our findings suggest that microbubbles have diagnostic potential in image contrast enhancement of diffuse optical imaging and optical coherence tomography. 


\section{Chapter 6 Future Work}

\subsection{Simulation study}

Simulations were used in order to study an optimum MB design (such as size and material) and to improve the optical image contrast. The methodology and preliminary results are discussed below.

\subsubsection{Calculating optical properties by Mie theory}

Scattering of light by spherical objects is described by Mie theory [96]. The interaction due to scattering can be described by Mie theory through the scattering cross section and the phase function, which in principle is applicable at any size of scatterer [96].

he Mie theory is a solution to Maxwell's equations that describes the scattering of an electromagnetic plane wave by a homogeneous sphere with a refractive index, $n$, in a medium with refractive index,$n_{\text {med }}$ [96]. The solution takes the plane wave as a form of an infinite series of spherical waves repeats. That solution is written with separate equations for the radial and angular dependency. This methodology was considered as a single spherical particle with known refractive index. The Mie calculation were used to extract the optical properties ( $\sigma_{\mathrm{s}}$ and $g$ ) of tissue phantoms at various microbubble injection doses. The calculated optical properties from Mie calculation were then compared with the calculated optical properties from IAD results in this section. 


\subsubsection{Methods}

Mie calculator [97] was used to simulate the anisotropy factor, $g_{i}$, and scattering cross section, $\sigma_{i}$, of a single $\mathrm{MB}$, a single $\mathrm{RBC}$ and a single IL scatterer in order to calculate the reduced scattering coefficients of the bulk phantom for given concentrations of each scatterer type. The total reduced scattering coefficient of the bulk phantom solution with MB was calculated with a linear summation of the reduced scattering coefficient of every scatterer as follows:

$$
\mu_{\mathrm{s}, \mathrm{tot}}^{\prime}=\sum_{i}\left(1-g_{i}\right) \varepsilon_{i} \sigma_{i}=\mu_{\mathrm{s}, \mathrm{IL}}^{\prime}+\mu_{\mathrm{s}, \mathrm{RBC}}^{\prime}+\mu_{\mathrm{s}, \mathrm{MB}}^{\prime}
$$

The $\sigma_{i}$ and $g_{i}$ of each scatterer, $i$, (IL, RBC, and MB) were calculated with on-line Mie calculator. The equation 16 is valid if the diffusion regime and isotropic scattering applied. Since the sample thickness is approximately several reduced scattering mean free paths (the reciprocal of the reduced scattering coefficient, $l_{\mathbf{s}^{\prime}}$ ), then the isotropic scattering is the dominant process in this study. That means the reduced scattering cross section of a mixture can be derived from the individual values of scattering cross sections and their concentrations in equation 16 [98].

The number of IL per unit volume, $\varepsilon_{\mathrm{IL}}$, were calculated (Table 6-2) for a $5 \% \mathrm{v} / \mathrm{v}$ concentration contains in the bulk tissue phantom and a mean diameter of $0.214 \mu \mathrm{m}$ [89]. The refractive index of IL was chosen 1.36 [99] and the medium refractive index was taken as 1.33 for plasma [100]. To simplify the Mie simulation, the RBC was considered as a spherical scatterer with a mean diameter of $5.5 \mu \mathrm{m}[101]$ and refractive index equal to 1.4 [100],[102]. The number of RBC per unit volume were calculated in Table 6-2 for a low 
blood concentration $(0.2 \% \mathrm{v} / \mathrm{v})$ and high blood concentration $(6 \% \mathrm{v} / \mathrm{v})$ bulk tissue phantom considering that normal human blood consists of red blood cells with concentration $\sim 5 \times$ $10^{9} \frac{1}{m L}[103]$. To simplify the Mie simulation, the MB was considered as a sphere with a gas core without a shell [104]. Considering the MB as a single sphere with a gas core is a valid approximation since the thin shell $(\sim 30 \mathrm{~nm})$ does not have a strong effect on the scattering and one can neglect coating to simplify the simulation [104]. The refractive index of MB was chosen to be that of to the gas core $~ 1.1$ [104] and the medium was consider plasma [100]. The number of MB per unit volume were calculated for low blood concentration $(0.2 \% \mathrm{v} / \mathrm{v})$ and high blood concentration $(6 \% \mathrm{v} / \mathrm{v})$ bulk tissue phantom at four microbubble injection doses $(25,50,83.3$ and $166 \mu \mathrm{L} / \mathrm{kg})$ shown in Table 6-2. The undiluted Definity® has a concentration of $\sim 1.2 \times 10^{10} \frac{1}{m L}$ [80] with mean diameter of $2.2 \mu \mathrm{m}$ [81] which was also confirmed by bright field microscopy shown in Figure 6-1. The Mie calculator input parameters were summarized and shown in the following Table 6-1. 


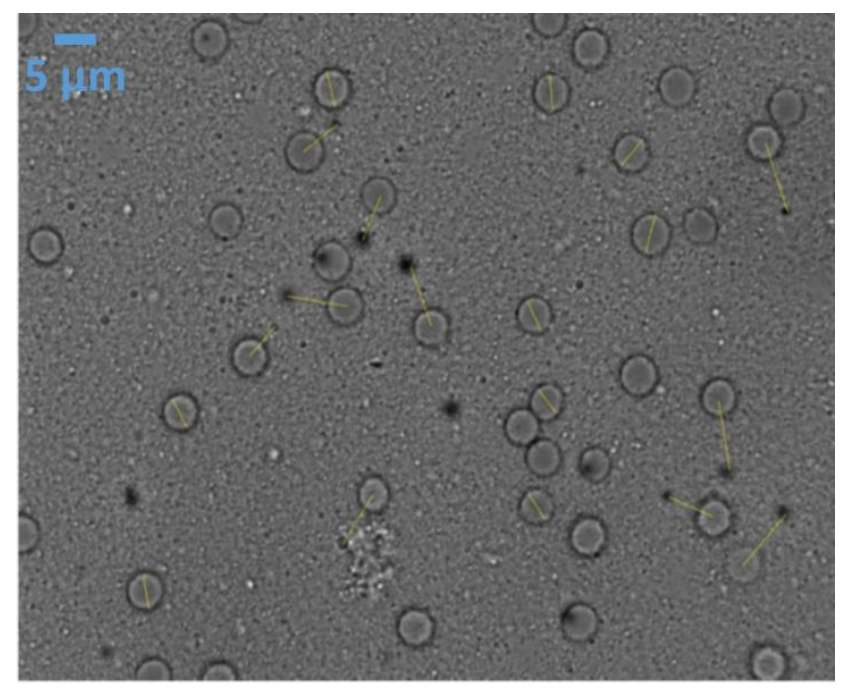

Figure 6-1: Bright field microscopy (Zeiss AxioObserver, objective 40X(0.6), Zeiss Live Cell,) of phantom 4, microbubbles are observed as black spheres, $\mathrm{RBC}$ are observed as bright spheres and IL presents at background. The average distance between MBs and RBCs scatters is $9 \mu \mathrm{m}$. The mean diameter of MB is $2.2 \mu \mathrm{m}$ and RBC is $5.5 \mu \mathrm{m}$.

Table 6-1: Mie calculator input parameters.

\begin{tabular}{|l|l|l|l|}
\hline Scatterer & $D(\mu \mathrm{m})$ & $n$ medium & $n_{\text {Particle }}$ \\
\hline IL & 0.21 & 1.33 & 1.36 \\
\hline RBC & 5.50 & 1.33 & 1.40 \\
\hline MB & 2.20 & 1.33 & 1.10 \\
\hline
\end{tabular}


Table 6-2: Number of scatterers per unit volume. The first column of the table shows the Definity® microbubble injection doses. The second column represents the number of IL per unit volume calculated for a $5 \% \mathrm{v} / \mathrm{v}$ concentration. The third and fourth column represent the number of RBC per unit volume calculated for a high blood concentration $(6 \% \mathrm{v} / \mathrm{v})$ and low blood concentration $(0.2 \% \mathrm{v} / \mathrm{v})$. The fifth and sixth column represent the number of MB per unit volume calculated for a high blood concentration ( $6 \% \mathrm{v} / \mathrm{v})$ and low blood concentration $(0.2 \% \mathrm{v} / \mathrm{v})$

\begin{tabular}{|l|l|l|l|l|l|}
\hline $\begin{array}{c}\mathrm{D}_{\mathrm{I}} \\
\mu \mathrm{L} / \mathrm{kg}\end{array}$ & $\varepsilon_{\mathrm{IL}}\left(\frac{1}{\mu \mathrm{m}^{3}}\right)$ & $\varepsilon_{\mathrm{RBC}}^{\mathrm{H}}\left(\frac{1}{\mu \mathrm{m}^{3}}\right)$ & $\begin{array}{l}\varepsilon_{\mathrm{RBC}}^{\mathrm{L}} \\
\left(\frac{1}{\mu \mathrm{m}^{3}}\right)\end{array}$ & $\begin{array}{l}\varepsilon_{\mathrm{MB}}^{\mathrm{H}} \\
\left(\frac{1}{\mu \mathrm{m}^{3}}\right)\end{array}$ & $\begin{array}{l}\varepsilon_{\mathrm{MB}}^{\mathrm{L}} \\
\left(\frac{1}{\mu \mathrm{m}^{3}}\right)\end{array}$ \\
\hline 25 & $1.00 \mathrm{E}+01$ & $3.00 \mathrm{E}-04$ & $1.00 \mathrm{E}-05$ & $2.00 \mathrm{E}-07$ & $7.00 \mathrm{E}-09$ \\
\hline 50 & $1.00 \mathrm{E}+01$ & $3.00 \mathrm{E}-04$ & $1.00 \mathrm{E}-05$ & $4.00 \mathrm{E}-07$ & $1.40 \mathrm{E}-08$ \\
\hline 83.3 & $1.00 \mathrm{E}+01$ & $3.00 \mathrm{E}-04$ & $1.00 \mathrm{E}-05$ & $7.00 \mathrm{E}-07$ & $2.40 \mathrm{E}-08$ \\
\hline 166 & $1.00 \mathrm{E}+01$ & $3.00 \mathrm{E}-04$ & $1.00 \mathrm{E}-05$ & $1.40 \mathrm{E}-06$ & $4.80 \mathrm{E}-08$ \\
\hline
\end{tabular}

\subsubsection{Preliminary results}

The Mie calculated $g$ and $\sigma$ at wavelengths $660 \mathrm{~nm}$ and $1310 \mathrm{~nm}$ were summarized in Table 6-3 and Table 6-7, respectively. Based on the mentioned tables, as the size of the scatterer increases, $g$ approaches 1 and becomes more highly forward scattering. For example, a larger $\mathrm{g}$ value is observed for RBC compared to MB. Scattering cross section, $\sigma$, for a single RBC is $77.25 \mu m^{2}$ and $34.8 \mu m^{2}$ at $660 \mathrm{~nm}$ and $1310 \mathrm{~nm}$, respectively. Scattering cross section, $\sigma$, for a single MB is $9.48 \mu m^{2}$ and $6.92 \mu m^{2}$ at $660 \mathrm{~nm}$ and 1310 $\mathrm{nm}$, respectively. The $\mathrm{RBC}$ has a larger $\sigma$ compared to the $\mathrm{MB}$, and the $\sigma$ is larger for both particles at $660 \mathrm{~nm}$ compared to $1310 \mathrm{~nm}$. Scattering cross section, $\sigma$, for a single IL scatterer is $3.80 \times 10^{-5} \mu \mathrm{m}^{2}$ and $3.90 \times 10^{-6} \mu \mathrm{m}^{2}$ at $660 \mathrm{~nm}$ and $1310 \mathrm{~nm}$, respectively which is much smaller than either the RBC or MB. The reduced scattering coefficients for each scatterer were calculated at $660 \mathrm{~nm}$ and $1310 \mathrm{~nm}$, shown in Table 6-4, Table 6-5, Table 6-8 
and Table 6-9. The total reduced scattering coefficients for the bulk phantom with and without MB were calculated with a linear summation of the reduced scattering coefficients of each scatterer at high and low blood concentrations shown in Table 6-6 and Table 6-10 for $660 \mathrm{~nm}$ and $1310 \mathrm{~nm}$ wavelength, respectively. The calculated reduced scattering contrast enhancements of the bulk phantom at $660 \mathrm{~nm}$ and $1310 \mathrm{~nm}$ were also summarized in Table 6-6 and Table 6-10, respectively.

Table 6-3: Mie calculation of anisotropy factor and scattering cross section at $660 \mathrm{~nm}$.

\begin{tabular}{|l|c|c|}
\hline$\lambda=660 \mathrm{~nm}$ & $g$ & $\sigma_{\text {sca }}\left(\mu \mathrm{m}^{2}\right)$ \\
\hline IL & 0.31 & $3.80 \times 10^{-5}$ \\
\hline RBC & 0.99 & 77.25 \\
& & \\
\hline MB & 0.94 & 9.13 \\
& & \\
\hline
\end{tabular}

Table 6-4: Calculation of reduced scattering coefficient for IL scatterers and RBCs at $660 \mathrm{~nm}$. The first column of the table represents the number of IL scatterers per unit volume calculated for a $5 \% \mathrm{v} / \mathrm{v}$ concentration. The second column represents the reduced scattering coefficient of IL. The third column represents the number of RBCs per unit volume calculated for a high blood concentration $(6 \% \mathrm{v} / \mathrm{v})$. The fourth column represents the reduced scattering coefficient of RBCs calculated for a high blood concentration. The fifth column represents the number of RBCs per unit volume calculated for a low blood concentration $(0.2 \% \mathrm{v} / \mathrm{v})$. The sixth column represents the reduced scattering coefficient of RBCs calculated for a low blood concentration.

\begin{tabular}{|l|l|l|l|l|l|}
\hline$\varepsilon_{\mathrm{IL}}\left(\frac{1}{\mu \mathrm{m}^{3}}\right)$ & $\mathrm{IL}(5 \% \mathrm{v} / \mathrm{v})$ & $\varepsilon_{\mathrm{RBC}}^{\mathrm{H}}(6 \%)$ & $\mathrm{RBC}(6 \%)$ & $\varepsilon_{\mathrm{RBC}}^{\mathrm{L}}(0.2 \%)$ & $\mathrm{RBC}(0.2 \%)$ \\
& $\mu_{\mathrm{s}}^{\prime} \mathrm{mm}^{-1}$ & $\left(\frac{1}{\mu \mathrm{m}^{3}}\right)$ & $\mu_{\mathrm{s}}^{\prime \mathrm{H}} \mathrm{mm}^{-1}$ & $\left(\frac{1}{\mu \mathrm{m}^{3}}\right)$ & $\mu_{\mathrm{s}}^{\mathrm{L}^{2}} \mathrm{~mm}^{-1}$ \\
\hline $1.00 \mathrm{E}+01$ & $2.62 \mathrm{E}-01$ & $3.00 \mathrm{E}-04$ & $2.31 \mathrm{E}-01$ & $1.00 \mathrm{E}-05$ & $7.72 \mathrm{E}-03$ \\
\hline
\end{tabular}


Table 6-5: Calculation of reduced scattering coefficient for MB scatterers at $660 \mathrm{~nm}$. The first column of the table shows the Definity ${ }^{\circledR}$ microbubble injection doses. The second column represents the number of MBs per unit volume calculated for a high MB concentration. The third column represents the reduced scattering coefficient of MBs calculated for a high MB concentration. The fourth column represents the number of MBs per unit volume calculated for a low MB concentration. The fifth column represents the reduced scattering coefficient of MBs calculated for a low MB concentration.

\begin{tabular}{|l|l|l|l|l|}
\hline \multicolumn{1}{|c|}{$\mathrm{D}_{\mathrm{I}}$} & $\varepsilon_{\mathrm{MB}}^{\mathrm{H}}\left(\frac{1}{\mu \mathrm{m}^{3}}\right)$ & $\begin{array}{l}\mathrm{MB} \\
\mu_{\mathrm{s}}^{\prime \mathrm{H}} \mathrm{mm}^{-1}\end{array}$ & $\varepsilon_{\mathrm{MB}}^{\mathrm{L}}\left(\frac{1}{\mu \mathrm{m}^{3}}\right)$ & $\mathrm{MB}$ \\
\hline 25 & $2.00 \mathrm{E}-07$ & $1.09 \mathrm{E}-04$ & $7.00 \mathrm{E}-09$ & $3.83 \mathrm{E}-06$ \\
\hline 50 & $4.00 \mathrm{E}-07$ & $2.19 \mathrm{E}-04$ & $1.40 \mathrm{E}-08$ & $7.66 \mathrm{E}-06$ \\
\hline 83.3 & $7.00 \mathrm{E}-07$ & $3.83 \mathrm{E}-04$ & $2.40 \mathrm{E}-08$ & $1.31 \mathrm{E}-05$ \\
\hline 166 & $1.40 \mathrm{E}-06$ & $7.66 \mathrm{E}-04$ & $4.80 \mathrm{E}-08$ & $2.62 \mathrm{E}-05$ \\
\hline
\end{tabular}


Table 6-6: Calculation of the total reduced scattering coefficient for each bulk phantom at $660 \mathrm{~nm}$. The first column of the table shows the Definity® microbubble injection doses. The second column represents the total reduced scattering coefficient of the bulk phantom without MBs for a high blood concentration $(6 \% \mathrm{v} / \mathrm{v})$. The third column represents the total reduced scattering coefficient of the bulk phantom with MBs for a high blood concentration $(6 \% \mathrm{v} / \mathrm{v})$. The fourth column represents the total reduced scattering coefficient of the bulk phantom without MBs for a low blood concentration $(0.2 \% \mathrm{v} / \mathrm{v})$. The fifth column represents the total reduced scattering coefficient of the bulk phantom with MBs for a low blood concentration $(0.2 \% \mathrm{v} / \mathrm{v})$. The sixth column represents the reduced scattering contrast of the bulk phantom without MBs. The seventh column represents the reduced scattering contrast of the bulk phantom with MBs. The eighth column represents the reduced scattering contrast enhancement of the bulk phantom.

\begin{tabular}{|c|c|c|c|c|c|c|c|}
\hline $\begin{array}{c}\mathrm{D}_{\mathrm{I}} \\
\mu \mathrm{L} / \mathrm{kg}\end{array}$ & $\begin{array}{c}\mu_{\mathrm{s}, \text { tot }}^{\prime \mathrm{H}} \\
\mathrm{mm}^{-1}\end{array}$ & $\begin{array}{l}\mu_{\mathrm{s}, \mathrm{tot}}^{\prime \mathrm{H}, \mathrm{MB}} \\
\mathrm{mm}^{-1}\end{array}$ & $\begin{array}{c}\mu_{\mathrm{s}, \text { tot }}^{\prime \mathrm{L}} \\
\mathrm{mm}^{-1}\end{array}$ & $\begin{array}{l}\mu_{\mathrm{s}, \mathrm{Mot}}^{\prime \mathrm{L}, \mathrm{MB}} \\
\mathrm{mm}^{-1}\end{array}$ & $\begin{array}{l}C_{\mathrm{S}} \\
=\frac{\mu_{\mathrm{s}, \mathrm{tot}}^{\prime \mathrm{H}}}{\mu_{\mathrm{s}, \mathrm{tot}}^{\mathrm{L}}}\end{array}$ & $\begin{array}{l}C_{\mathrm{s}}^{\mathrm{MB}} \\
=\frac{\mu_{s}^{\prime \mathrm{H}, \mathrm{MB}}}{\mu_{\mathrm{s}}^{\prime \mathrm{L}, \mathrm{MB}}}\end{array}$ & $\frac{C_{\mathrm{s}}^{\mathrm{MB}}}{C_{\mathrm{s}}}$ \\
\hline 25 & 4.93E-01 & $5.00 \mathrm{E}-01$ & $2.90 \mathrm{E}-01$ & $2.90 \mathrm{E}-01$ & 1.68 & 1.72 & 1.02 \\
\hline 50 & $4.93 \mathrm{E}-01$ & $5.10 \mathrm{E}-01$ & $2.90 \mathrm{E}-01$ & $2.90 \mathrm{E}-01$ & 1.68 & 1.75 & 1.04 \\
\hline 83.3 & $4.93 \mathrm{E}-01$ & $5.20 \mathrm{E}-01$ & 2.90E-01 & $2.90 \mathrm{E}-01$ & 1.68 & 1.79 & 1.06 \\
\hline 166 & 4.93E-01 & $5.60 \mathrm{E}-01$ & $2.90 \mathrm{E}-01$ & $2.90 \mathrm{E}-01$ & 1.68 & 1.93 & 1.14 \\
\hline
\end{tabular}


Table 6-7: Mie calculation of anisotropy factor and scattering cross section at $1310 \mathrm{~nm}$.

\begin{tabular}{|l|l|l|}
\hline$\lambda=1310 \mathrm{~nm}$ & \multicolumn{1}{|c|}{$g$} & $\sigma_{\text {sca }}\left(\mu \mathrm{m}^{2}\right)$ \\
\hline IL & 0.07 & $3.90 \times 10^{-6}$ \\
\hline RBC & 0.98 & 34.88 \\
& & \\
\hline MB & 0.93 & 6.23 \\
& & \\
\hline
\end{tabular}

Table 6-8: Calculation of reduced scattering coefficient for IL scatterers and RBCs at $1310 \mathrm{~nm}$. The first column of the table represents the number of IL scatterers per unit volume calculated for a $5 \% \mathrm{v} / \mathrm{v}$ concentration. The second column represents the reduced scattering coefficient of IL. The third column represents the number of RBCs per unit volume calculated for a high blood concentration $(6 \% \mathrm{v} / \mathrm{v})$. The fourth column represents the reduced scattering coefficient of RBCs calculated for a high blood concentration. The fifth column represents the number of RBCs per unit volume calculated for a low blood concentration $(0.2 \% \mathrm{v} / \mathrm{v})$. The sixth column represents the reduced scattering coefficient of RBCs calculated for a low blood concentration.

\begin{tabular}{|l|l|l|l|l|l|}
\hline$\varepsilon_{\mathrm{IL}}\left(\frac{1}{\mu \mathrm{m}^{3}}\right)$ & $\begin{array}{l}\mathrm{IL}(5 \% \mathrm{v} / \mathrm{v}) \\
\mu^{\prime}{ }_{\mathrm{s}} \mathrm{mm}^{-1}\end{array}$ & $\begin{array}{l}\varepsilon_{\mathrm{RBC}}^{\mathrm{H}}(6 \%) \\
\left(\frac{1}{\mu \mathrm{m}^{3}}\right)\end{array}$ & $\begin{array}{l}\mathrm{RBC}(6 \%) \\
\mu_{\mathrm{s}}^{\prime \mathrm{H}} \mathrm{mm}^{-1}\end{array}$ & $\begin{array}{l}\varepsilon_{\mathrm{RBC}}^{\mathrm{L}}(0.2 \%) \\
\mu \mathrm{m}^{3}\end{array}$ & $\mathrm{RBC}(0.2 \%)$ \\
\hline $1.00 \mathrm{E}+01$ & $3.62 \mathrm{E}-02$ & $3.00 \mathrm{E}-04$ & $2.00 \mathrm{E}-01$ & $1.00 \mathrm{E}-05$ & $6.97 \mathrm{E}-03$ \\
\hline
\end{tabular}


Table 6-9: Calculation of reduced scattering coefficient for MBs at $1310 \mathrm{~nm}$. The first column of the table represents the Definity ${ }^{\circledR}$ microbubble injection doses. The second column represents the number of MBs per unit volume calculated for a high MB concentration. The third column represents the reduced scattering coefficient of MBs calculated for a high MB concentration. The fourth column represents the number of MBs per unit volume calculated for a low MB concentration. The fifth column represents the reduced scattering coefficient of MBs calculated for a low MB concentration.

\begin{tabular}{|l|l|l|l|l|}
\hline $\begin{array}{c}\mathrm{D}_{\mathrm{I}} \\
\mu \mathrm{L} / \mathrm{kg}\end{array}$ & $\varepsilon_{\mathrm{MB}}^{\mathrm{H}}\left(\frac{1}{\mu \mathrm{m}^{3}}\right)$ & $\begin{array}{l}\mathrm{MB} \\
\mu_{s}^{\prime \mathrm{H}} \mathrm{mm}^{-1}\end{array}$ & $\varepsilon_{\mathrm{MB}}^{\mathrm{L}}\left(\frac{1}{\mu \mathrm{m}^{3}}\right)$ & $\begin{array}{l}\mathrm{MB} \\
\mu_{s}^{\prime \mathrm{L}} \mathrm{mm}^{-1}\end{array}$ \\
\hline 25 & $2.00 \mathrm{E}-07$ & $8.72 \mathrm{E}-05$ & $7.00 \mathrm{E}-09$ & $3.05 \mathrm{E}-06$ \\
\hline 50 & $4.00 \mathrm{E}-07$ & $1.74 \mathrm{E}-04$ & $1.40 \mathrm{E}-08$ & $6.10 \mathrm{E}-06$ \\
\hline 83.3 & $7.00 \mathrm{E}-07$ & $3.05 \mathrm{E}-04$ & $2.40 \mathrm{E}-08$ & $1.04 \mathrm{E}-05$ \\
\hline 166 & $1.40 \mathrm{E}-06$ & $6.10 \mathrm{E}-04$ & $4.80 \mathrm{E}-08$ & $2.09 \mathrm{E}-05$ \\
\hline
\end{tabular}


Table 6-10: Calculation of the total reduced scattering coefficient for each bulk phantom at $1310 \mathrm{~nm}$. The first column of the table represents the Definity ${ }^{\circledR}$ microbubble injection doses. The second column represents the total reduced scattering coefficient of the bulk phantom without MBs for a high blood concentration (6\% v/v). The third column represents the total reduced scattering coefficient of the bulk phantom with MBs for a high blood concentration $(6 \% \mathrm{v} / \mathrm{v})$. The fourth column represents the total reduced scattering coefficient of the bulk phantom without MBs for a low blood concentration $(0.2 \% \mathrm{v} / \mathrm{v})$. The fifth column represents the total reduced scattering coefficient of the bulk phantom with MBs for a low blood concentration $(0.2 \% \mathrm{v} / \mathrm{v})$. The sixth column represents the reduced scattering contrast of the bulk phantom without MBs. The seventh column represents the reduced scattering contrast of the bulk phantom with MBs. The eighth column represents the reduced scattering contrast enhancement of the bulk phantom.

\begin{tabular}{|c|c|c|c|c|c|c|c|}
\hline $\begin{array}{c}\mathrm{D}_{\mathrm{I}} \\
\mu \mathrm{L} / \mathrm{kg}\end{array}$ & $\begin{array}{c}\mu_{\mathrm{s}, \text { tot }}^{\prime \mathrm{H}} \\
\mathrm{mm}^{-1}\end{array}$ & $\begin{array}{l}\mu_{\mathrm{s}, \mathrm{tot}}^{\prime \mathrm{H}, \mathrm{MB}} \\
\mathrm{mm}^{-1}\end{array}$ & $\begin{array}{c}\mu_{\text {s,tot }}^{\prime \mathrm{L}} \\
\mathrm{mm}^{-1}\end{array}$ & $\begin{array}{l}\mu_{\mathrm{s}, \mathrm{tot}}^{\prime \mathrm{L}, \mathrm{MB}} \\
\mathrm{mm}^{-1}\end{array}$ & $\begin{array}{l}C_{\mathrm{s}} \\
=\frac{\mu_{\mathrm{s}, \mathrm{tot}}^{\prime \mathrm{H}}}{\mu_{\mathrm{s}, \mathrm{tot}}^{\mathrm{L}}}\end{array}$ & $\begin{array}{l}C_{\mathrm{s}}^{\mathrm{MB}} \\
=\frac{\mu_{s}^{\prime \mathrm{H}, \mathrm{MB}}}{\mu_{\mathrm{s}}^{\mathrm{L}, \mathrm{MB}}}\end{array}$ & $\frac{C_{s}^{\mathrm{MB}}}{C_{\mathrm{s}}}$ \\
\hline 25 & $2.40 \mathrm{E}-01$ & $2.50 \mathrm{E}-01$ & $5.00 \mathrm{E}-02$ & $5.00 \mathrm{E}-02$ & 4.8 & 5 & 1.04 \\
\hline 50 & $2.40 \mathrm{E}-01$ & $2.60 \mathrm{E}-01$ & $5.00 \mathrm{E}-02$ & $5.00 \mathrm{E}-02$ & 4.8 & 5.2 & 1.08 \\
\hline 83.3 & $2.40 \mathrm{E}-01$ & $2.70 \mathrm{E}-01$ & $5.00 \mathrm{E}-02$ & $5.00 \mathrm{E}-02$ & 4.8 & 5.4 & 1.12 \\
\hline 166 & $2.40 \mathrm{E}-01$ & $3.00 \mathrm{E}-01$ & $5.00 \mathrm{E}-02$ & $5.00 \mathrm{E}-02$ & 4.8 & 6 & 1.25 \\
\hline
\end{tabular}

The Mie calculated reduced scattering contrast enhancement were plotted versus four microbubble injection doses and compared against the experimental results for $6 \% \mathrm{v} / \mathrm{v}$ blood concentration. The red lines represent experimental results and blue lines represent simulation values. 

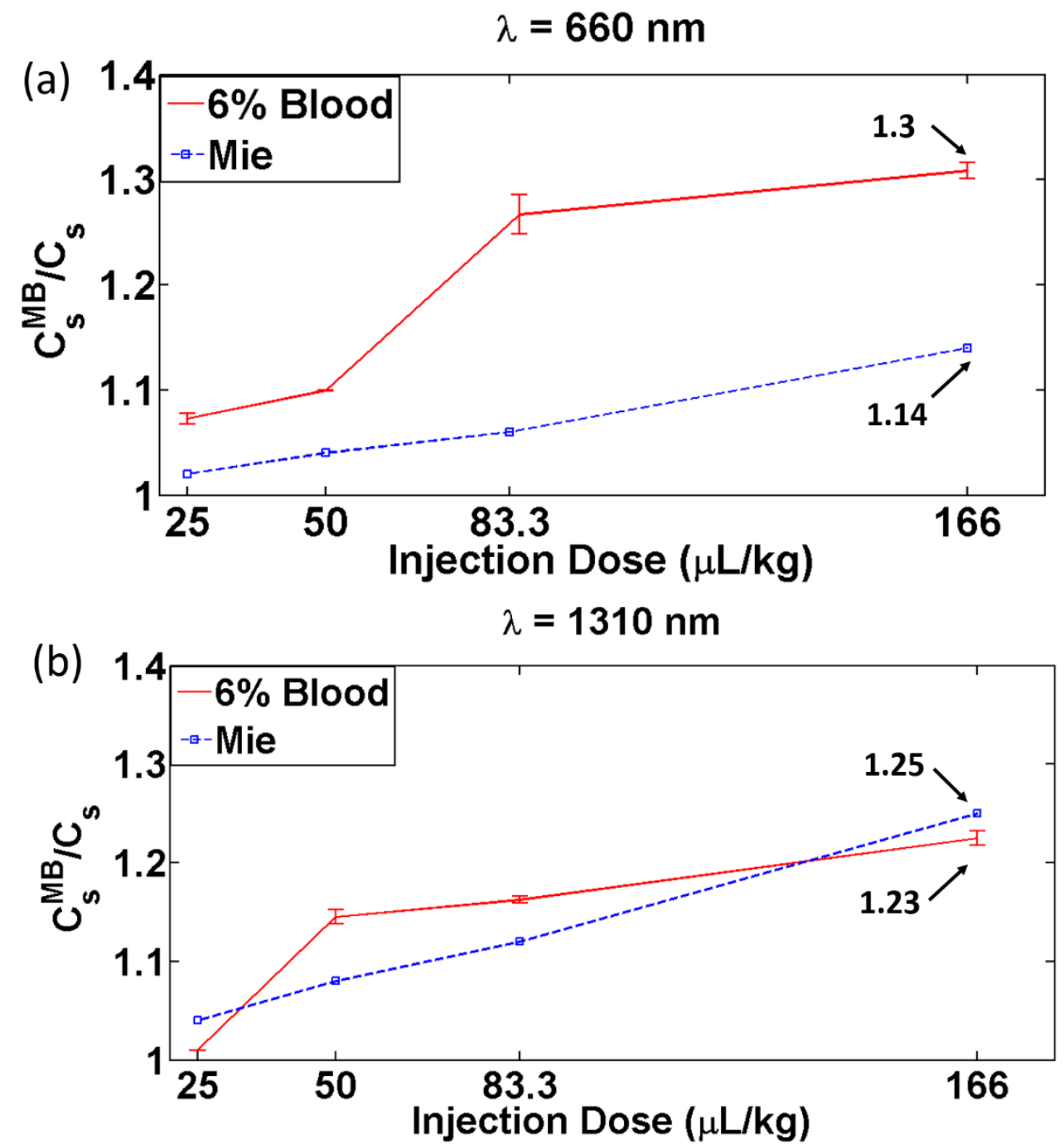

Figure 6-2: The Reduced scattering contrast enhancement vs Definity ${ }^{\circledR}$ microbubble injection doses $(25,50$, 83.3 and $166 \mu \mathrm{L} / \mathrm{kg}$ ) depicted at (a) $660 \mathrm{~nm}$ and (b) $1310 \mathrm{~nm}$. Red lines represent experimental results from spectroscopy and blue squares are simulation results from Mie calculation. Solid lines are used to guide the eye.

The Mie simulated scattering contrast enhancement increases with microbubble injection dose, which was consistent with the experimental results. At $660 \mathrm{~nm}$, the simulated reduced scattering contrast enhancement values were lower compared to experimental 
values. The reason can be a range of the scatterer size distribution in the experiment compared to scatterer with one size diameter in simulation. In addition, the RBC shape was assumed to be spherical when applying Mie theory and the sphere diameter was adjusted to mimic the RBC volume. The discrepancy between theory and measurement might be due to the biconcave disk shape of the RBC that effects the scattering properties of blood in experiment. The simulated reduced scattering contrast enhancement values were close to the experimental results at $1310 \mathrm{~nm}$.

Furthermore, the Mie simulations were performed for concentrations of particles for which the independent scattering approximation is applicable, therefore the scattering coefficient $\mu_{\mathrm{s}}$ increases proportionally to the concentration of the particles. The independent scattering approximation is valid for IL with scatterer concentration less than $4 \%$ volume fraction [105]. However, the IL concentration used in this study were 5\% volume fraction which makes the possibility of deviations from the independent scattering approximation. That might be another source of discrepancy between theory and experiment.

The author plans to improve and to apply the Mie simulation to design the optimum microbubble with a certain size and refractive index (Material) in order to optimize the reduced scattering contrast enhancement.

\subsection{Potential in-vivo study}

The investigation sets the stage for future animal model studies. In future studies of higher microbubble dosage and different abnormal tissue conditions can be investigated via MB-enhanced DOI and MB-enhanced OCT contrast. Both diagnostic and treatment 
monitoring procedures can be studied for in vivo experiments for example, on rodents using dorsal window chamber models of skin cancer implants. Detection of cancerous tumors at different stages can proceed with MB-enhanced DOI and MB-enhanced OCT methods. In addition, an in vivo study of blood flow measurement in cancerous tumors can be investigated in the presence of microbubbles. Another potential application could be experiments using the in vivo dorsal window chamber models for monitoring cancer therapy response. For example, MB-enhanced DOI images of total hemoglobin concentration and reduced scattering coefficient of the cancerous tissue can be produced at different time points within the therapy cycles. MB-enhanced OCT can also be used to differentiate between normal and the cancerous tissue microvasculature with MBs uptake in tumor region that helps to improve the treatment monitoring over time.

It is crucial to note that the contrast enhancement dependents on the microbubble injection dose and the maximum MB dose in this study was below the maximum tolerated dose. In vivo dorsal window chamber studies the contrast of a cancerous tumors can be improved by increasing MBs dosage. That may allow cancer detection at earlier stages with lower blood concentrations.

Finally, it is important to note that there are potential applications such as detection of skin cancer where MB-enhanced optical imaging could have a significant contrast improve in conjunction with other methods. The sensitivity can be enhanced by combining these MBenhanced DOI and MB-enhanced OCT with anatomical imaging methods (such as MRI, Xray, and ultrasound). Perhaps the most natural modality to combine with MB-enhanced DOI and OCT methods is ultrasound. The most straightforward approach is to combine the 
spectroscopic capability of light with the spatial resolution of ultrasound (US) to enhance the detection of cancerous tissue. DOI can be used to measure blood volume and blood oxygenation of tissue of interest. Ultrasound provides relatively high resolution images, but not information related to blood volume and blood oxygenation. Cancer detection can be then improved by the complimentary information from imaging of microvasculature morphology and functionality. Optical coherence tomography is also another possible application to be combined with ultrasound. The translation of this technique to the clinical setting involves; (a) selection of an optimized wavelength for deep tissue detection in the presence of MBs contras agents and (b) a validation study on the animal model with cancerous tissue in order to differentiate ROI with high blood concentrations from surrounding tissue with low blood concentration. 


\section{Appendix A}
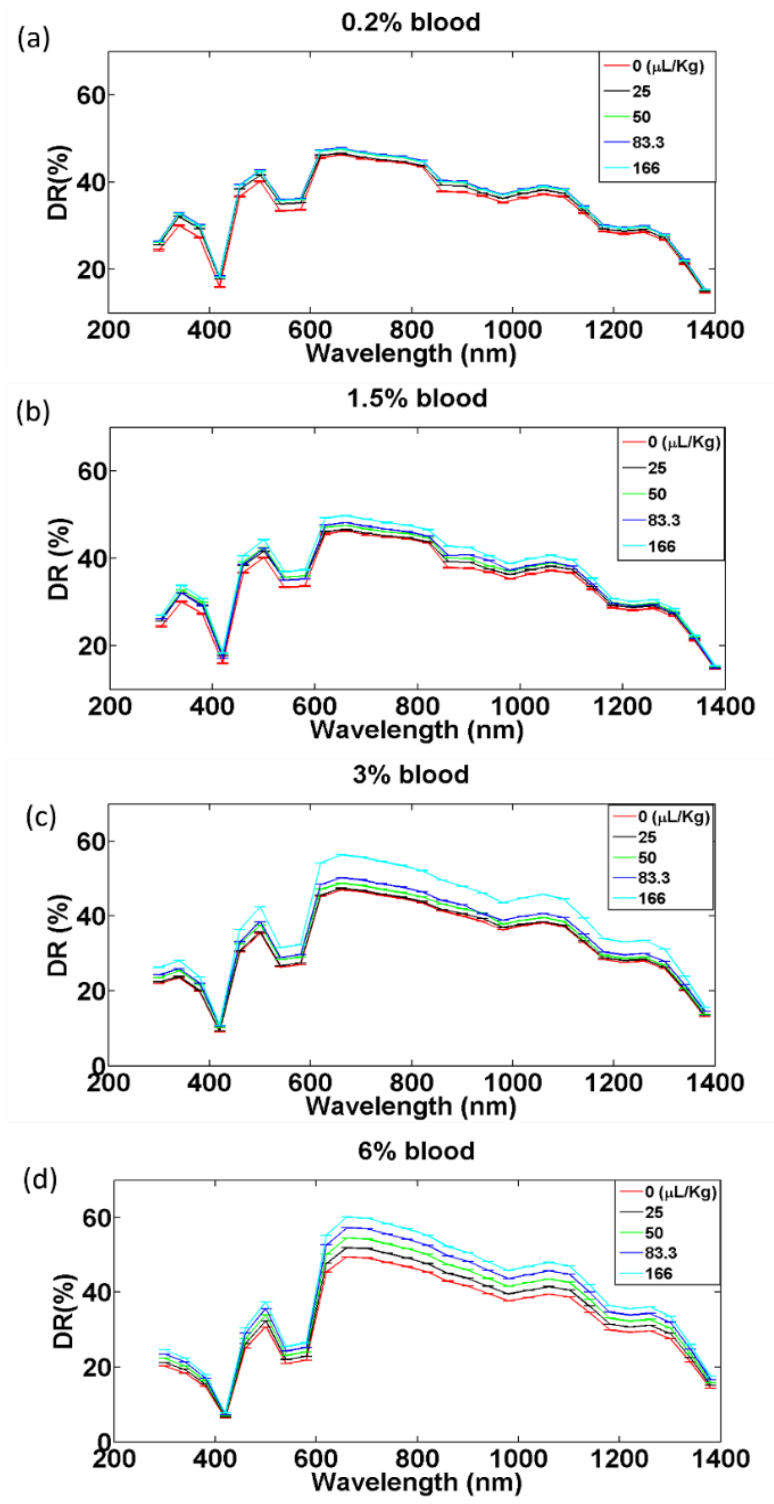

The diffuse reflectance (DR) for the 20 phantom conditions (four blood concentrations at five Definity ${ }^{\circledR}$ microbubble injection doses $(0,25,50,83.3,166 \mu \mathrm{L} / \mathrm{kg}$ )) (a) $0.2 \%$ blood, (b) $1.5 \%$ blood, (c) $3 \%$ blood, (d) $6 \%$ blood. The error bars correspond to the values of standard deviation (SD). 

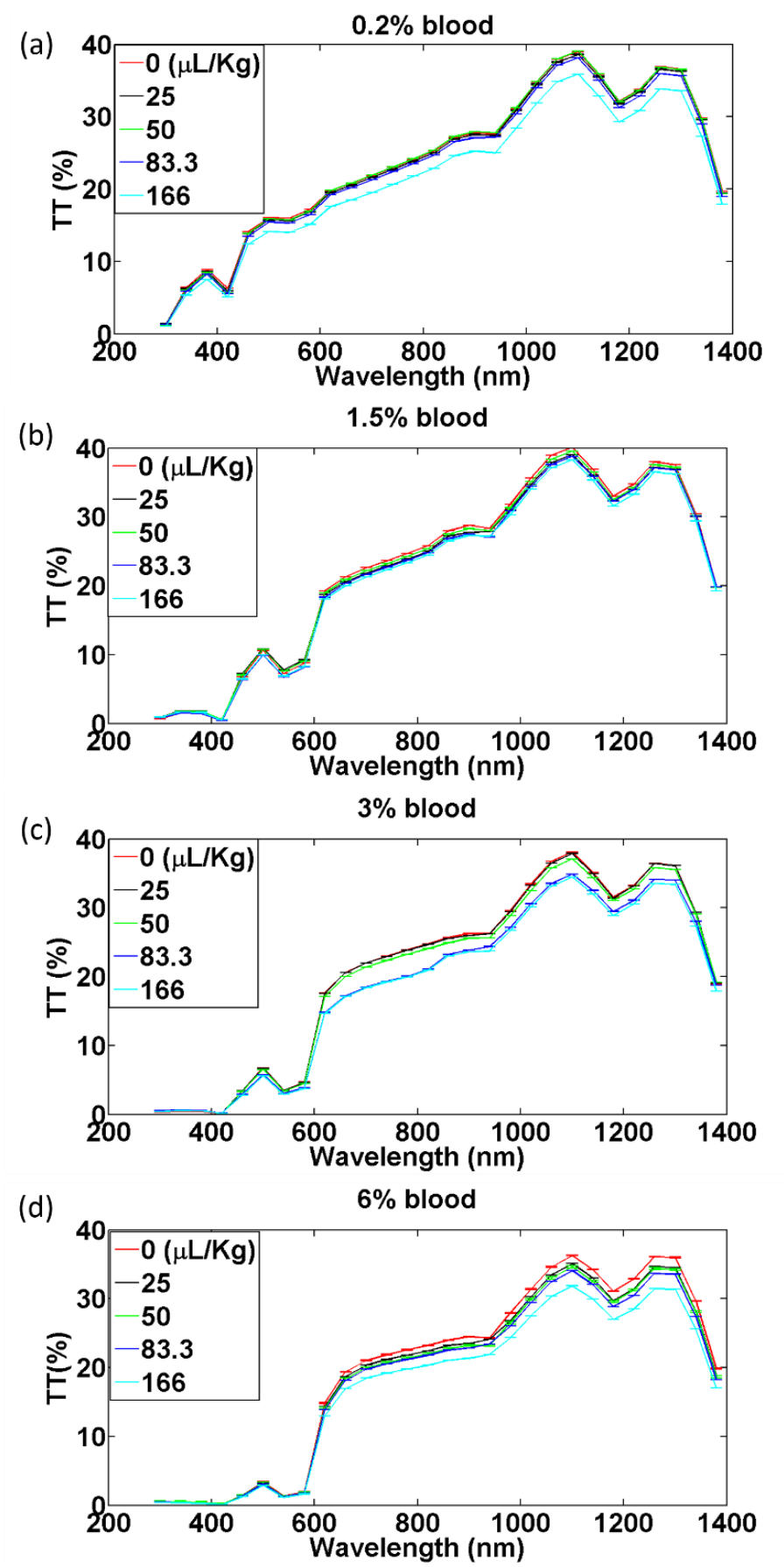

The total transmittance (TT) for the 20 phantom conditions (four blood concentrations at five Definity ${ }^{\circledR}$ microbubble injection doses $(0,25,50,83.3,166 \mu \mathrm{L} / \mathrm{kg}$ )) (a) $0.2 \%$ blood, (b) $1.5 \%$ blood, (c) $3 \%$ blood, (d) $6 \%$ blood. The error bars correspond to the values of standard deviation (SD). 


\section{References}

[1] D. Shepro, "Microvascular research : [biology and pathology]," Dallas, TX: Elsevier Academic Press, 2006, p. 921.

[2] C. A. Cuenod and D. Balvay, "Perfusion and vascular permeability: Basic concepts and measurement in DCE-CT and DCE-MRI,” Diagn. Interv. Imaging, vol. 94, no. 12, pp. 1187-1204, Dec. 2013.

[3] L. E. Clegg and F. Mac Gabhann, "Systems biology of the microvasculature.," Integr. Biol. (Camb)., vol. 7, no. 5, pp. 498-512, May 2015.

[4] B. Al-Husein, M. Abdalla, M. Trepte, D. L. DeRemer, and P. R. Somanath, "Antiangiogenic Therapy for Cancer: An Update," Pharmacother. J. Hum. Pharmacol. Drug Ther., vol. 32, no. 12, pp. 1095-1111, Dec. 2012.

[5] K. A. Miles and R. E. Williams, "Warburg revisited: imaging tumour blood flow and metabolism.," Cancer Imaging, vol. 8, no. 1, pp. 81-6, Mar. 2008.

[6] L. M. Sherwood, E. E. Parris, and J. Folkman, "Tumor Angiogenesis: Therapeutic Implications," N. Engl. J. Med., vol. 285, no. 21, pp. 1182-1186, Nov. 1971.

[7] D. A. Mankoff, L. K. Dunnwald, S. C. Partridge, and J. M. Specht, "Blood flowmetabolism mismatch: good for the tumor, bad for the patient.," Clin. Cancer Res., vol. 15, no. 17, pp. 5294-6, Sep. 2009.

[8] A. R. Kherlopian, T. Song, Q. Duan, M. A. Neimark, M. J. Po, J. K. Gohagan, and A. 
F. Laine, "A review of imaging techniques for systems biology," BMC Syst. Biol., vol. 2, no. 1, p. 74, Aug. 2008.

[9] A. Rege, N. Thakor, and A. Pathak, "Optical Imaging of Microvascular Morphology and Perfusion," Curr. Angiogenesise, vol. 1, no. 3, pp. 243-260, Jul. 2012.

[10] A. Gibson and H. Dehghani, “Diffuse optical imaging," Philos. Trans. R. Soc. A Math. Phys. Eng. Sci., vol. 367, no. 1900, pp. 3055-3072, Aug. 2009.

[11] H. Soliman, A. Gunasekara, M. Rycroft, J. Zubovits, R. Dent, J. Spayne, M. J. Yaffe, and G. J. Czarnota, "Functional imaging using diffuse optical spectroscopy of neoadjuvant chemotherapy response in women with locally advanced breast cancer," Clin. Cancer Res., vol. 16, no. 9, pp. 2605-2614, 2010.

[12] J. M. Schmitt, "Optical coherence tomography (OCT): a review," IEEE J. Sel. Top. Quantum Electron., vol. 5, no. 4, pp. 1205-1215, 1999.

[13] J. K. Barton, J. B. Hoying, and C. J. Sullivan, "Use of Microbubbles as an Optical Coherence Tomography Contrast Agent,” Acad. Radiol., vol. 9, no. 1, pp. S52-S55, Jan. 2002.

[14] M. C. Pierce, D. J. Javier, and R. Richards-Kortum, "Optical contrast agents and imaging systems for detection and diagnosis of cancer," Int. J. Cancer, vol. 123, no. 9, pp. 1979-1990, Nov. 2008.

[15] E. Stride and N. Saffari, "Microbubble ultrasound contrast agents: A review," Proc. Inst. Mech. Eng. Part H J. Eng. Med., vol. 217, no. 6, pp. 429-447, Jun. 2003.

[16] E. G. Schutt, D. H. Klein, R. M. Mattrey, and J. G. Riess, "Injectable microbubbles as contrast agents for diagnostic ultrasound imaging: the key role of 
perfluorochemicals.," Angew. Chem. Int. Ed. Engl., vol. 42, no. 28, pp. 3218-35, Jul. 2003.

[17] A. H. Hielscher, A. Y. Bluestone, G. S. Abdoulaev, A. D. Klose, J. Lasker, M. Stewart, U. Netz, and J. Beuthan, "Near-infrared diffuse optical tomography.," Dis. Markers, vol. 18, no. 5-6, pp. 313-37, 2002.

[18] S. van de Ven, S. Elias, A. Wiethoff, M. van der Voort, A. Leproux, T. Nielsen, B. Brendel, L. Bakker, M. van der Mark, W. Mali, and P. Luijten, "Diffuse optical tomography of the breast: Initial validation in benign cysts," Mol. Imaging Biol., vol. 11, no. 2, pp. 64-70, 2009.

[19] B. J. Tromberg, A. Cerussi, N. Shah, M. Compton, A. Durkin, D. Hsiang, J. Butler, and R. Mehta, "Imaging in breast cancer: diffuse optics in breast cancer: detecting tumors in pre-menopausal women and monitoring neoadjuvant chemotherapy.," Breast Cancer Res., vol. 7, no. 6, pp. 279-85, 2005.

[20] H. Jiang, B. W. Pogue, M. S. Patterson, K. D. Paulsen, and U. L. Osterberg, “Optical image reconstruction using frequency-domain data: simulations and experiments," $J$. Opt. Soc. Am. A, vol. 13, no. 2, p. 253, Feb. 1996.

[21] M. A. O’Leary, D. A. Boas, B. Chance, and A. G. Yodh, "Experimental images of heterogeneous turbid media by frequency-domain diffusing-photon tomography," Opt. Lett., vol. 20, no. 5, p. 426, Mar. 1995.

[22] O. Falou, H. Soliman, A. Sadeghi-Naini, S. Iradji, S. Lemon-Wong, J. Zubovits, J. Spayne, R. Dent, M. Trudeau, J. F. Boileau, F. C. Wright, M. J. Yaffe, and G. J. Czarnota, "Diffuse optical spectroscopy evaluation of treatment response in women 
with locally advanced breast cancer receiving neoadjuvant chemotherapy.," Transl. Oncol., vol. 5, no. 4, pp. 238-46, 2012.

[23] S. Brem, R. Cotran, and J. Folkman, "Tumor angiogenesis: a quantitative method for histologic grading.," J. Natl. Cancer Inst., vol. 48, no. 2, pp. 347-56, Feb. 1972.

[24] N. Weidner, "Intratumor microvessel density as a prognostic factor in cancer.," Am.J. Pathol., vol. 147, no. 1, pp. 9-19, Jul. 1995.

[25] D. R. Busch, R. Choe, M. A. Rosen, W. Guo, T. Durduran, M. D. Feldman, C. Mies, B. J. Czerniecki, J. Tchou, A. Demichele, M. D. Schnall, and A. G. Yodh, “Optical malignancy parameters for monitoring progression of breast cancer neoadjuvant chemotherapy.," Biomed. Opt. Express, vol. 4, no. 1, pp. 105-21, 2013.

[26] R. Choe, "Diffuse optical tomography and spectroscopy of breast cancer and fetal brain," Ph.D dissertation, University of Pennsylvania, Philadelphia, Pennsylvania, 2005.

[27] A. N. Bashkatov, E. A. Genina, V. I. Kochubey, and V. V Tuchin, "Optical properties of human skin, subcutaneous and mucous tissues in the wavelength range from 400 to 2000 nm,” J. Phys. D. Appl. Phys., vol. 38, no. 15, pp. 2543-2555, 2005.

[28] I. V. Meglinski and S. J. Matcher, "Quantitative assessment of skin layers absorption and skin reflectance spectra simulation in the visible and near-infrared spectral regions.," Physiol. Meas., vol. 23, no. 4, pp. 741-753, 2002.

[29] E. Salomatina, B. Jiang, J. Novak, and A. N. Yaroslavsky, "Optical properties of normal and cancerous human skin in the visible and near-infrared spectral range," $J$. Biomed. Opt., vol. 11, no. 6, p. 64026, 2006. 
[30] N. Rajaram, J. S. Reichenberg, M. R. Migden, T. H. Nguyen, and J. W. Tunnell, "Pilot clinical study for quantitative spectral diagnosis of non-melanoma skin cancer," Lasers Surg. Med., vol. 42, no. 10, pp. 716-727, 2010.

[31] S. Strieth, W. Hartschuh, L. Pilz, and N. E. Fusenig, "Carcinoma-like vascular density in atypic keratoacanthoma suggests malignant progression.," Br. J. Cancer, vol. 87, no. 11 , pp. 1301-7, Nov. 2002.

[32] N. B. Teo, B. S. Shoker, C. Jarvis, L. Martin, J. P. Sloane, and C. Holcombe, "Vascular density and phenotype around ductal carcinoma in situ (DCIS) of the breast.," Br. $J$. Cancer, vol. 86, no. 6, pp. 905-11, Mar. 2002.

[33] T. Vo-Dinh, "Biomedical photonics handbook," Boca Raton, FL: CRC Press, 2003, pp. $23-122$.

[34] H. C. van de Hulst, "Light scattering by small particles," Mineola, NY: Dover Publications, 1957, pp. 395-406.

[35] S. A. Prahl, "Light transport in tissue.," Ph.D dissertation, University of texas, Austin, Texas, 1989.

[36] F. Martelli and Society of Photo-optical Instrumentation Engineers., "Light propagation through biological tissue and other diffusive media : theory, solutions, and software,” Bellingham, Washington D.C: SPIE Press, 2010, pp. 13-39.

[37] A. Yaroshevsky, Z. Glasser, E. Granot, and S. Sternklar, "Transition from the ballistic to the diffusive regime in a turbid medium," Opt. Lett., vol. 36, no. 8, p. 1395, Apr. 2011.

[38] S. Prahl, "Optical property measurements using the inverse adding-doubling 
program," Oregon Med. Laser Center, St. Vincent Hosp., vol. 1, pp. 14-16, 1999.

[39] S. A. Prahl, M. J. C. van Gemert, and A. J. Welch, "Determining the optical properties of turbid media by using the adding-doubling method," Appl. Opt., vol. 32, no. 4, p. 559, Feb. 1993.

[40] D. K. Sardar and L. B. Levy, "Optical Properties of Whole Blood," Lasers in Medical Science, vol. 13, no. 2. pp. 106-111, 1998.

[41] H. C. Lowe, J. Narula, J. G. Fujimoto, and I.-K. Jang, "Intracoronary optical diagnostics current status, limitations, and potential.," JACC. Cardiovasc. Interv., vol. 4, no. 12, pp. 1257-70, Dec. 2011.

[42] A. Johansson, K. Kromer, R. Sroka, and H. Stepp, "Clinical optical diagnostics Status and perspectives," Med. Laser Appl., vol. 23, no. 4, pp. 155-174, Nov. 2008.

[43] A. F. Fercher, “Optical coherence tomography," J. Biomed. Opt., vol. 1, no. 2, p. 157, Apr. 1996.

[44] F. Prati, G. Guagliumi, G. S. Mintz, M. Costa, E. Regar, T. Akasaka, P. Barlis, G. J. Tearney, I.-K. Jang, E. Arbustini, H. G. Bezerra, Y. Ozaki, N. Bruining, D. Dudek, M. Radu, A. Erglis, P. Motreff, F. Alfonso, K. Toutouzas, N. Gonzalo, C. Tamburino, T. Adriaenssens, F. Pinto, P. W. J. Serruys, C. Di Mario, and Expert's OCT Review Document, "Expert review document part 2: methodology, terminology and clinical applications of optical coherence tomography for the assessment of interventional procedures," Eur. Heart J., vol. 33, no. 20, pp. 2513-2520, Oct. 2012.

[45] D. Huang, E. A. Swanson, C. P. Lin, J. S. Schuman, W. G. Stinson, W. Chang, M. R. Hee, T. Flotte, K. Gregory, C. A. Puliafito, and J. G. Fujimoto, “Optical coherence 
tomography.," Science, vol. 254, no. 5035, pp. 1178-81, Nov. 1991.

[46] Z. Zhi, "Development and Application of Multifunctional Optical Coherence Tomography,” Ph.D dissertation, University of Washington,Washington D.C., 2014.

[47] E. A. Swanson, D. Huang, C. P. Lin, C. A. Puliafito, M. R. Hee, and J. G. Fujimoto, "High-speed optical coherence domain reflectometry," Opt. Lett., vol. 17, no. 2, p. 151, Jan. 1992.

[48] Y. Wang and R. Wang, "Autocorrelation optical coherence tomography for mapping transverse particle-flow velocity.," Opt. Lett., vol. 35, no. 21, pp. 3538-40, Nov. 2010.

[49] A. Mariampillai, B. A. Standish, E. H. Moriyama, M. Khurana, N. R. Munce, M. K. K. Leung, J. Jiang, A. Cable, B. C. Wilson, I. A. Vitkin, and V. X. D. Yang, "Speckle variance detection of microvasculature using swept-source optical coherence tomography," Opt. Soc. Am., vol. 33, no. 13, pp. 1530-1532, 2008.

[50] M. S. Mahmud, D. W. Cadotte, B. Vuong, C. Sun, T. W. H. Luk, A. Mariampillai, and V.X. D. Yang, "Review of speckle and phase variance optical coherence tomography to visualize microvascular networks.," J. Biomed. Opt., vol. 18, no. 5, p. 50901, May 2013.

[51] A. Maeda, M. K. K. Leung, L. Conroy, Y. Chen, J. Bu, P. E. Lindsay, S. Mintzberg, C. Virtanen, J. Tsao, N. A. Winegarden, Y. Wang, L. Morikawa, I. A. Vitkin, D. A. Jaffray, R. P. Hill, and R. S. DaCosta, "In Vivo Optical Imaging of Tumor and Microvascular Response to Ionizing Radiation,” PLoS One, vol. 7, no. 8, p. e42133, Aug. 2012.

[52] R. Leitgeb, "Current Technologies for High-Speed and Functional Imaging with 
Optical Coherence Tomography," in Advances in Imaging and Electron Physics, Amsterdam, Netherlands: Elsevier, 2011, pp. 170-172.

[53] M. C. Pierce, D. J. Javier, and R. Richards-Kortum, "Optical contrast agents and imaging systems for detection and diagnosis of cancer.," Int. J. Cancer, vol. 123, no. 9, pp. 1979-90, Nov. 2008.

[54] J. T. Alander, I. Kaartinen, A. Laakso, T. Pätilä, T. Spillmann, V. V. Tuchin, M. Venermo, and P. Välisuo, “A Review of Indocyanine Green Fluorescent Imaging in Surgery," Int. J. Biomed. Imaging, vol. 2012, pp. 1-26, 2012.

[55] X. Huang and M. A. El-Sayed, "Gold nanoparticles: Optical properties and implementations in cancer diagnosis and photothermal therapy," J. Adv. Res., vol. 1, no. 1, pp. 13-28, 2010.

[56] H. Cang, T. Sun, Z.-Y. Li, J. Chen, B. J. Wiley, Y. Xia, and X. Li, "Gold nanocages as contrast agents for spectroscopic optical coherence tomography," Opt. Lett., vol. 30, no. 22, p. 3048, 2005.

[57] X. Huang, P. K. Jain, I. H. El-Sayed, and M. a El-Sayed, "Gold nanoparticles: interesting optical properties and recent applications in cancer diagnostics and therapy.," Nanomedicine (Lond)., vol. 2, no. 5, pp. 681-93, Oct. 2007.

[58] E. Boisselier, D. Astruc, C. A. Mirkin, A. P. Alivisatos, R. B. Bhonde, M. Satry, G. Schmid, W. Brandau, C. Li, S. H. Cho, J. W. Tunnell, J. D. Hazle, and S. Krishnan, “Gold nanoparticles in nanomedicine: preparations, imaging, diagnostics, therapies and toxicity," Chem. Soc. Rev., vol. 38, no. 6, p. 1759, May 2009.

[59] C. Loo, A. Lin, L. Hirsch, M.-H. Lee, J. Barton, N. Halas, J. West, and R. Drezek, 
"Nanoshell-Enabled Photonics-Based Imaging and Therapy of Cancer," Technol. Cancer Res. Treat., vol. 3, no. 1, pp. 33-40, Feb. 2004.

[60] Y. Zhao, "Indocyanine Green-Loaded Nanocarriers as Contrast Agents for NIR Fluorescent Optical Imaging,” J. Nanomed. Nanotechnol., vol. 3, no. 8, 2012.

[61] T. S. Leung, N. Aladangady, C. E. Elwell, D. T. Delpy, and K. Costeloe, "A new method for the measurement of cerebral blood volume and total circulating blood volume using near infrared spatially resolved spectroscopy and indocyanine green: application and validation in neonates.," Pediatr. Res., vol. 55, no. 1, pp. 134-41, Jan. 2004.

[62] A. Iriyama, S. Uchida, Y. Yanagi, Y. Tamaki, Y. Inoue, K. Matsuura, K. Kadonosono, and M. Araie, "Effects of indocyanine green on retinal ganglion cells.," Invest. Ophthalmol. Vis. Sci., vol. 45, no. 3, pp. 943-7, Mar. 2004.

[63] A. L. Oldenburg, M. N. Hansen, D. A. Zweifel, A. Wei, and S. A. Boppart, "Plasmonresonant gold nanorods as low backscattering albedo contrast agents for optical coherence tomography," Opt. Express, vol. 14, no. 15, p. 6724, 2006.

[64] V. J. Mohanraj and Y. Chen, "Nanoparticles - A review," Trop. J. Pharm. Res., vol. 5, no. 1, pp. 561-573, Jul. 2007.

[65] W. H. De Jong and P. J. A. Borm, "Drug delivery and nanoparticles:applications and hazards.," Int. J. Nanomedicine, vol. 3, no. 2, pp. 133-49, 2008.

[66] P. A. Dijkmans, L. J. M. Juffermans, R. J. P. Musters, A. van Wamel, F. J. ten Cate, W. van Gilst, C. A. Visser, N. de Jong, and O. Kamp, "Microbubbles and ultrasound: from diagnosis to therapy.," Eur. J. Echocardiogr., vol. 5, no. 4, pp. 245-56, Aug. 
2004.

[67] J. J. Kwan and M. A. Borden, "Lipid monolayer collapse and microbubble stability.," Adv. Colloid Interface Sci., vol. 183-184, pp. 82-99, Nov. 2012.

[68] J. J. Kwan and M. A. Borden, "Microbubble dissolution in a multigas environment.," Langmuir, vol. 26, no. 9, pp. 6542-8, May 2010.

[69] S. Sirsi and M. Borden, "Microbubble Compositions, Properties and Biomedical Applications.," Bubble Sci. Eng. Technol., vol. 1, no. 1-2, pp. 3-17, Nov. 2009.

[70] E. Stride and N. Saffari, "Microbubble ultrasound contrast agents: a review.," Proc. Inst. Mech. Eng. H., vol. 217, no. 6, pp. 429-47, Jan. 2003.

[71] M. Todorova, V. Agache, O. Mortazavi, B. Chen, R. Karshafian, K. Hynynen, S. Man, R. S. Kerbel, and D. E. Goertz, "Antitumor effects of combining metronomic chemotherapy with the antivascular action of ultrasound stimulated microbubbles.," Int. J. Cancer, vol. 132, no. 12, pp. 2956-66, Jun. 2013.

[72] G. J. Czarnota, R. Karshafian, P. N. Burns, S. Wong, A. Al Mahrouki, J. W. Lee, A. Caissie, W. Tran, C. Kim, M. Furukawa, E. Wong, and A. Giles, "Tumor radiation response enhancement by acoustical stimulation of the vasculature.," Proc. Natl. Acad. Sci. U. S. A., vol. 109, no. 30, pp. E2033-41, Jul. 2012.

[73] C. Tarapacki and R. Karshafian, "Enhancing laser therapy using PEGylated gold nanoparticles combined with ultrasound and microbubbles.," Ultrasonics, vol. 57, pp. 36-43, Mar. 2015.

[74] K. Sarkar, A. Katiyar, and P. Jain, "Growth and dissolution of an encapsulated contrast microbubble: effects of encapsulation permeability.," Ultrasound Med. Biol., vol. 35, 
no. 8 , pp. 1385-96, Aug. 2009.

[75] H. Assadi, R. Karshafian, and A. Douplik, "Optical Scattering Properties of Intralipid Phantom in Presence of Encapsulated Microbubbles," Int. J. Photoenergy, vol. 2014, pp. 1-9, 2014.

[76] J. W. Pickering, S. A. Prahl, N. van Wieringen, J. F. Beek, H. J. Sterenborg, and M. J. van Gemert, "Double-integrating-sphere system for measuring the optical properties of tissue.," Appl. Opt., vol. 32, no. 4, pp. 399-410, Feb. 1993.

[77] S. Prahl, "Inverse Adding-Doubling Software," Inverse Adding-Doubling Software, Oregon Medical Laser Center, USA, 1988. [Online]. Available: http://omlc.org/software/iad/index.html. [Accessed: 20-Sep-2017].

[78] M. Nan and Q. He, "Study on the effect of blood content on diffuse reflectance spectra of basal cell carcinoma skin tissue.," ScientificWorldJournal., vol. 2013, p. 192495, 2013.

[79] A. Amelink and H. J. C. M. Sterenborg, "In vivo measurement of the local optical properties of tissue by use of differential path-length spectroscopy," vol. 29, no. 10, pp. 1087-1089, 2004.

[80] J. Tu, J. E. Swalwell, D. Giraud, W. Cui, W. Chen, and T. J. Matula, "Microbubble sizing and shell characterization using flow cytometry.," IEEE Trans. Ultrason. Ferroelectr. Freq. Control, vol. 58, no. 5, pp. 955-63, May 2011.

[81] H. Shekhar, J. J. Rychak, and M. M. Doyley, "Modifying the size distribution of microbubble contrast agents for high-frequency subharmonic imaging.," Med. Phys., vol. 40, no. 8, p. 82903, Aug. 2013. 
[82] H. C. Kim, A. Al-Mahrouki, A. Gorjizadeh, A. Sadeghi-Naini, R. Karshafian, and G. J. Czarnota, "Quantitative ultrasound characterization of tumor cell death: Ultrasoundstimulated microbubbles for radiation enhancement," PLoS One, vol. 9, no. 7, pp. 1820, 2014.

[83] E. C. Unger, T. Porter, W. Culp, R. Labell, T. Matsunaga, and R. Zutshi, "Therapeutic applications of lipid-coated microbubbles," Adv. Drug Deliv. Rev., vol. 56, no. 9, pp. 1291-1314, 2004.

[84] A. Tang, T. K. Kim, J. Heathcote, M. Guindi, H. J. Jang, R. Karshafian, P. N. Burns, and S. R. Wilson, "Does hepatic vein transit time performed with contrast-enhanced ultrasound predict the severity of hepatic fibrosis?," Ultrasound Med. Biol., vol. 37, no. 12, pp. 1963-1969, 2011.

[85] A. Corlu, T. Durduran, R. Choe, M. Schweiger, E. M. C. Hillman, S. R. Arridge, and A. G. Yodh, "Uniqueness and wavelength optimization in continuous-wave multispectral diffuse optical tomography," Opt. Lett., vol. 28, no. 23, p. 2339, 2003.

[86] B. Yu, J. Y. Lo, T. F. Kuech, G. M. Palmer, J. E. Bender, and N. Ramanujam, "Costeffective diffuse reflectance spectroscopy device for quantifying tissue absorption and scattering in vivo," J. Biomed. Opt., vol. 13, no. 6, p. 60505, 2008.

[87] T. Dahiru, "P - value, a true test of statistical significance? A cautionary note.," Ann. Ibadan Postgrad. Med., vol. 6, no. 1, pp. 21-6, Jun. 2008.

[88] A. Mariampillai, M. K. K. Leung, M. Jarvi, B. A. Standish, K. Lee, B. C. Wilson, A. Vitkin, and V. X. D. Yang, "Optimized speckle variance OCT imaging of microvasculature," Opt. Soc. Am., vol. 35, no. 8, pp. 1257-1259, 2010. 
[89] H. J. van Staveren, C. J. Moes, J. van Marie, S. A. Prahl, and M. J. van Gemert, "Light scattering in Intralipid-10\% in the wavelength range of 400-1100 nm.," Appl. Opt., vol. 30, no. 31, pp. 4507-14, Nov. 1991.

[90] O. Yalcin, D. Ortiz, A. T. Williams, P. C. Johnson, and P. Cabrales, "Perfusion pressure and blood flow determine microvascular apparent viscosity," Exp. Physiol., vol. 100, no. 8, pp. 977-987, Aug. 2015.

[91] B. Fagrell, A. Fronek, and M. Intaglietta, "A microscope-television system for studying flow velocity in human skin capillaries," Am J Physiol Hear. Circ Physiol, vol. 233, no. 2, pp. H318-321, Aug. 1977.

[92] D. J. Griffiths, "Introduction to electrodynamics," Fourth., London, UK: Pearson, 1999, p. 423.

[93] D. J. Faber, M. C. G. Aalders, E. G. Mik, B. A. Hooper, M. J. C. van Gemert, and T. G. van Leeuwen, "Oxygen Saturation-Dependent Absorption and Scattering of Blood," Phys. Rev. Lett., vol. 93, no. 2, p. 28102, Jul. 2004.

[94] S. L. Jacques, "Optical properties of biological tissues: a review.," Phys. Med. Biol., vol. 58, no. 11, pp. R37-61, 2013.

[95] N. Weiss, T. G. van Leeuwen, and J. Kalkman, "Simultaneous and localized measurement of diffusion and flow using optical coherence tomography," Opt. Express, vol. 23, no. 3, p. 3448, Feb. 2015.

[96] T. Wriedt, "Mie Theory: A Review," Berlin, Heidelberg: Springer, 2012, pp. 53-71.

[97] S. Prahl, "Mie Scattering Calculator," Mie Scattering Calculator, Oregon Medical Laser Center, USA, 2007. [Online]. Available: 
http://omlc.ogi.edu/calc/mie_calc.html. [Accessed: 26-Jul-2017].

[98] R. Graaff, J. G. Aarnoudse, J. R. Zijp, P. M. A. Sloot, F. F. M. de Mul, J. Greve, and M. H. Koelink, "Reduced light-scattering properties for mixtures of spherical particles: a simple approximation derived from Mie calculations," Appl. Opt., vol. 31, no. 10, p. 1370, Apr. 1992.

[99] H. Ding, J. Q. Lu, K. M. Jacobs, and X.-H. Hu, "Determination of refractive indices of porcine skin tissues and Intralipid at eight wavelengths between 325 and $1557 \mathrm{~nm}$," J. Opt. Soc. Am. A, vol. 22, no. 6, p. 1151, Jun. 2005.

[100] A. Nahmad-rohen and H. Contreras-tello, "On the effective refractive index of blood," Phys. Scr., vol. 91, no. 1, p. 15503, 2014.

[101] A. Roggan, M. Friebel, K. Dörschel, A. Hahn, and G. Müller, “Optical Properties of Circulating Human Blood in the Wavelength Range 400-2500 nm," J. Biomed. Opt., vol. 4, no. 1, p. 36, 1999.

[102] M. a Yurkin, K. a Semyanov, P. a Tarasov, A. V Chernyshev, A. G. Hoekstra, and V. P. Maltsev, "Experimental and theoretical study of light scattering by individual mature red blood cells by use of scanning flow cytometry and a discrete dipole approximation.," Appl. Opt., vol. 44, no. 25, pp. 5249-5256, 2005.

[103] N. Bosschaart, G. J. Edelman, M. C. G. Aalders, T. G. van Leeuwen, and D. J. Faber, “A literature review and novel theoretical approach on the optical properties of whole blood," Lasers Med. Sci., vol. 29, no. 2, pp. 453-479, Mar. 2014.

[104] J. F. Guan and T. J. Matula, "Using light scattering to measure the response of individual ultrasound contrast microbubbles subjected to pulsed ultrasound in vitro," 
J. Acoust. Soc. Am., vol. 116, no. 5, pp. 2832-2842, 2004.

[105] R. Michels, F. Foschum, and A. Kienle, "Optical properties of fat emulsions.," Opt. Express, vol. 16, no. 8, pp. 5907-25, Apr. 2008. 